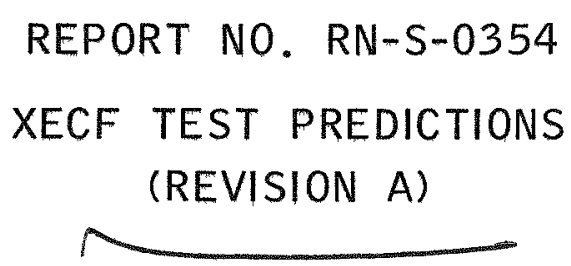

Attached is a complete revision of RN-S-0354, XECF Test Predictions. All textual and illustrative material in the copy you now have should be destroyed. Dividers, however, must be retained. Substitute new pages as follows (title, page through page ix precede introduction divider):

Divider

Introduction

Followed By

Engine Description

Pages 1 through 6

Test Facilities

Pages 7 through 15

Test Predictions

Pages 17 through 37

Instrumentation

Pages 39 through 83

Pages 85 through 113

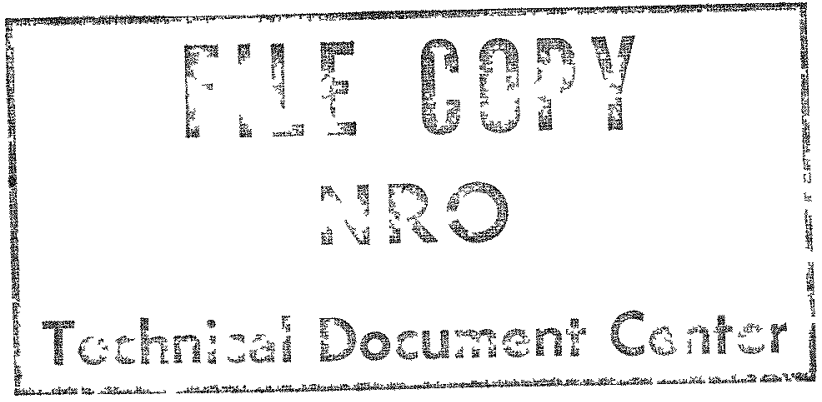




\section{DISCLAIMER}

This report was prepared as an account of work sponsored by an agency of the United States Government. Neither the United States Government nor any agency Thereof, nor any of their employees, makes any warranty, express or implied, or assumes any legal liability or responsibility for the accuracy, completeness, or usefulness of any information, apparatus, product, or process disclosed, or represents that its use would not infringe privately owned rights. Reference herein to any specific commercial product, process, or service by trade name, trademark, manufacturer, or otherwise does not necessarily constitute or imply its endorsement, recommendation, or favoring by the United States Government or any agency thereof. The views and opinions of authors expressed herein do not necessarily state or reflect those of the United States Government or any agency thereof. 


\section{DISCLAIMER}

Portions of this document may be illegible in electronic image products. Images are produced from the best available original document. 
NOTICE

This report was prepared as an account of work sponsored by the United States Government. Neither the United States nor the United States Energy the United States nor the United States nor any of their employees, nor any of their contractors, subcontractors, or their employees, makes any subcontractors, or their employees, makes any lability or responsibility for the accuracy, completeness lability or responsibility for the accuracy, completeness or usefulness of any information, apparatus, product or process disclosed, or represents

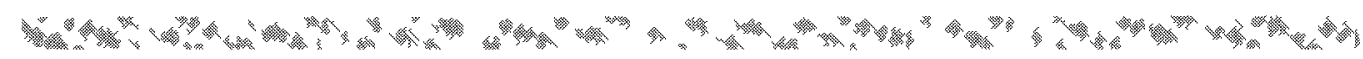

REPORT NO。RN-S=0354

(REVISION A)

XECF TEST PREDICFIONS

NERVA PROGRAM

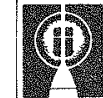

CONTRACT SNP-1

NUCLEAR ROCKET OPERATIONS

DECEMBER 1967

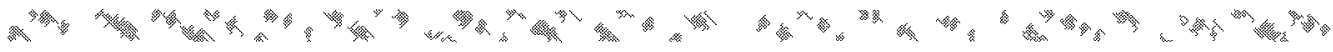

UNCLASSIFIED

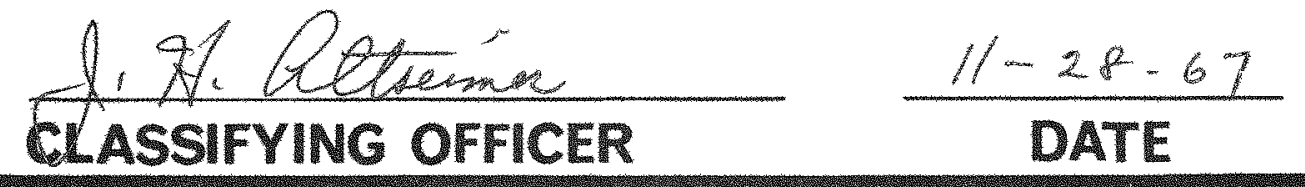

\section{AER OJET-GENERAL CORPORATION}

A SUESIDIARY OF THE GENERALTIRE \& RUBEER COMPANY 


\section{BLANK}


REPORT NO. RN-S-0354

(REVISION A)

\title{
XECF TEST PREDICTIONS
}

\author{
L. K. Hampson \\ E. J. Sebek \\ $R$. R. Stiger \\ R. J. Williams
}

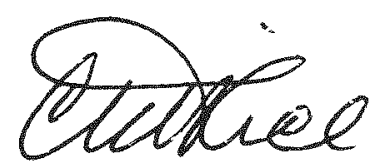

C. M. Rice

Program Manager Nuclear Rocket Operations 


\section{BLANK}




\section{ABSTRACT}

This report describes the expected performance of the XECF test assembly. Predictions are presented and discussed for all tests outlined in RN-S-0314, XECF Test Specification, and in modifications No. 1 and 2 thereof.

The test-prediction analysis indicated that, under all test conditions considered, the test-parameter limits would at no time be exceeded; and no unsafe conditions were disclosed that could result in damage to the test article or facility.

Descriptions of the engine system, the test facility, and the instrumentation system are included so the report can be used as a comprehensive reference document during quick-1ook analyses of test results. 
BLANK 


\section{CONTENTS}

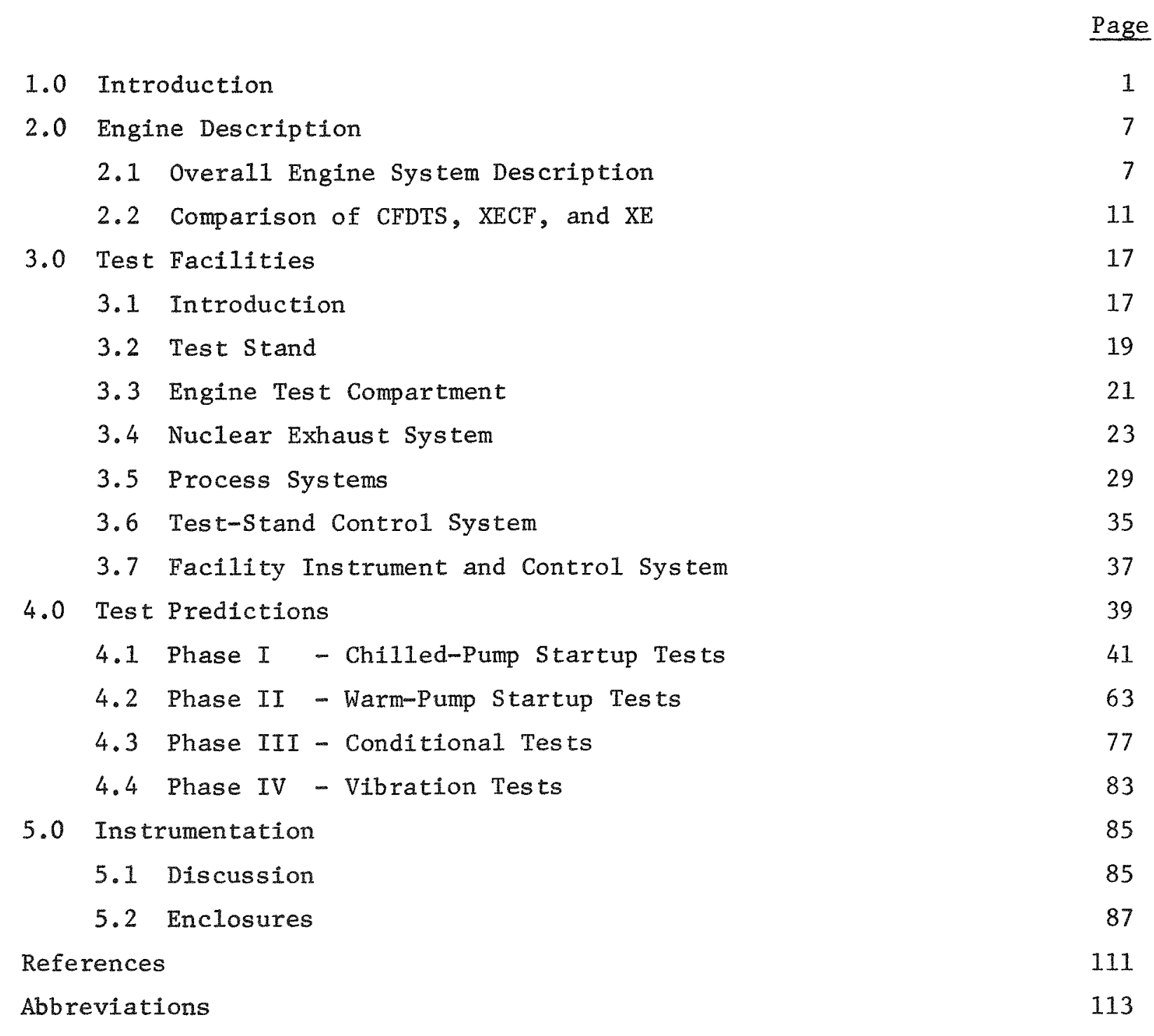




\section{FIGURES}

Number

$\underline{\text { Page }}$

2-1 Piping and Instrumentation Diagram, XECF 8

3-1 ETS-1 Complex 18

3-2 ETS - Configuration-Control Test-Stand Section 20

3-3 ETC Shield Configuration 22

3-4 Nuclear-Exhaust-System Duct Configuration 25

3-5 Engine-Compartment Pressure vs Engine Chamber Pressure 26

3-6 Schematic Composite Flow Diagram of Fluid Process Systems 30

4-1 XECF Test Prediction, Phase I, Run 1, Chilled Pump, $P_{T}=35$ psia 43

4-2 XECF Test Prediction, Phase I, Run 1, Chilled Pump, $P_{T}=35$ psia 44

4-3 XECF Test Prediction, Phase I, Run 1, Chilled Pump, $P_{T}=35$ psia 45

4-4 XECF Test Prediction, Phase I, Run 2, Chilled Pump, $P_{T}=25$ psia 46

4-5 XECF Test Prediction, Phase I, Run 2, Chilled Pump, $P_{T}=25$ psia 47

4-6 XECF Test Prediction, Phase I, Run 2, Chilled Pump, $P_{T}=25$ psia 48

4-7 XECF Test Prediction, Phase I, Run 4, Chilled Pump, $\mathrm{P}_{\mathrm{T}}=35$ psia 51

4-8 XECF Test Prediction, Phase $I$, Run 4, Chilled Pump, $P_{T}=35$ psia 52

4-9 XECF Test Prediction, Phase I, Run 4, Chilled Pump, $P_{T}=35$ psia 53

4-10 XECF Test Prediction, Phase I, Run 5, Chilled Pump, $\mathrm{P}_{\mathrm{T}}=60$ psia 56

4-11 XECF Test Prediction, Phase I, Run 5, Chilled Pump, $P_{T}=60$ psia 57

4-12 XECF Test Prediction, Phase I, Run 5, Chilled Pump, $\mathrm{P}_{\mathrm{T}}=60$ psia 58

4-13 XECF Test Prediction, Phase I, Run 6, Chilled Pump, $\mathrm{P}_{\mathrm{T}}=60$ psia 59

4-14 XECF Test Prediction, Phase I, Run 6, Chilled Pump, $P_{T}=60$ psia 60

4-15 XECF Test Prediction, Phase I, Run 6, Chilled Pump, $P_{T}=60$ psia 61

4-16 XECF Test Prediction, Phase II, Run 1, Dry Pump, $P_{T}=35$ psia 64

4-17 XECF Test Prediction, Phase II, Run 1, Dry Pump, $\mathrm{P}_{\mathrm{T}}=35$ psia 65

4-18 XECF Test Prediction, Phase II, Run 1, Dry Pump, $P_{T}=35$ psia 66

4-19 XECF Test Prediction, Phase II, Run 2, Dry Pump, $\mathrm{P}_{\mathrm{T}}=35$ psia 69

4-20 XECF Test Prediction, Phase II, Run 2, Dry Pump, $\mathrm{P}_{\mathrm{T}}=35$ psia 70

4-21 XECF Test Prediction, Phase II, Run 2, Dry Pump, $P_{T}=35$ psia 71

4-22 XECF Test Prediction, Phase II, Run 3, Dry Pump, $\mathrm{P}_{\mathrm{T}}=60$ psia 73

4-23 XECF Test Prediction, Phase II, Run 3, Dry Pump, $\mathrm{P}_{\mathrm{T}}=60$ psia 74 


\section{FIGURES}

$\underline{\text { Page }}$

4-24 XECF Test Prediction, Phase II, Run 3, Dry Pump, $\mathrm{P}_{\mathrm{T}}=60$ psia 75

4-25 XECF Test Prediction, Phase III, Run 2, Dry Pump, $\mathrm{P}_{\mathrm{T}}=35$ psia 79

4-26 XECF Test Prediction, Phase III, Run 2, Dry Pump, $\mathrm{P}_{\mathrm{T}}=35$ psia 80

4-27 XECF Test Prediction, Phase III, Run 2, Dry Pump, $P_{T}=35$ psia 81

5-1 Propellant Feed Line 90

5-2 Pump Discharge Line 1

5-3 Nozzle Assembly; Hot-Bleed Port and Bolt Coolant Line 92

5-4 Turbine Inlet Line and Diluent Line 93

5-5 Pressure Vessel 94

5-6 Turbopump Assembly 95

5-7 Turbine Exhaust Lines 96

5-8 Simplified Facility Schematic 97

5-9 V5001-LH Run Tank 98

5-10 V5002-High Pressure Storage Tank 99

5-11 V3801-LH 2 Storage Tank 100

5-12 Gaseous Helium Cool-down Line 101

5-13 Gaseous Hydrogen Cool-down Line 102

5-14 Liquid Hydrogen Fill Line 103

5-15 Liquid Hydrogen Cool-down Line 104

TABLES

Number

Page

1-1 XECF Test-Plan Summary 2

2-1 Comparison of CFDTS, XECF, and XE Systems 12

3-1 Facility Valve, Filter, and Flowmeter Locations 31

5-1 Instrumentation Transducer List 105

5-2 Facility Transducer List 108 


\section{$1.0 \quad$ INTRODUCTION}

The XECF engine will be the first engine system to be tested in the ETS-1 facility which permits a much closer approach to testing of a flighttype nuclear-powered system than previously possible because: (1) the engine is located immediately below, and close-coupled to, the liquid-hydrogen supply tank; and (2) the engine will be fired downward in a simulated high-altitude environment.

The objectives of the XECF test series can be divided into two main categories: (1) verification that the test facilities are satisfactory and ready for proceeding to XE testing; and (2) evaluation of operating procedures that have not been demonstrated during previous tests. The first category includes checkout of the instrumentation system, control system, handing equipment, and familiarization of test personnel with the equipment. The second category includes engine startup and simulated malfunction tests.

A complete listing of the XECF program objectives is presented in Section I.B of Report RN-S-0314, XECF Test Specification, November 1966. The operational specifications to accomplish these objectives, as set forth in Section II.D. of RN-S-0314, have undergone several modifications, and additional modifications are currently being considered. The test predictions contained herein are based: (1) on the specific test requirements contained in NRO Modification No, 2, approved by the Test Specification and Procedures Review Board 5 July 1967, Meeting No. 3; and (2) on Change 5 to the XECF test specification, approved by the Test Review Board 18 October 1967. Subsequent modifications to the test specification that would affect the results of these analyses will be covered by separately published supplements to this report. The operational specifications used for this report are summarized in Table 1-1. A blank column labeled "Updating Remarks" is provided in Table 1-1 so recipients of this report may incorporate changes made in the testing procedures after the report is issued. 


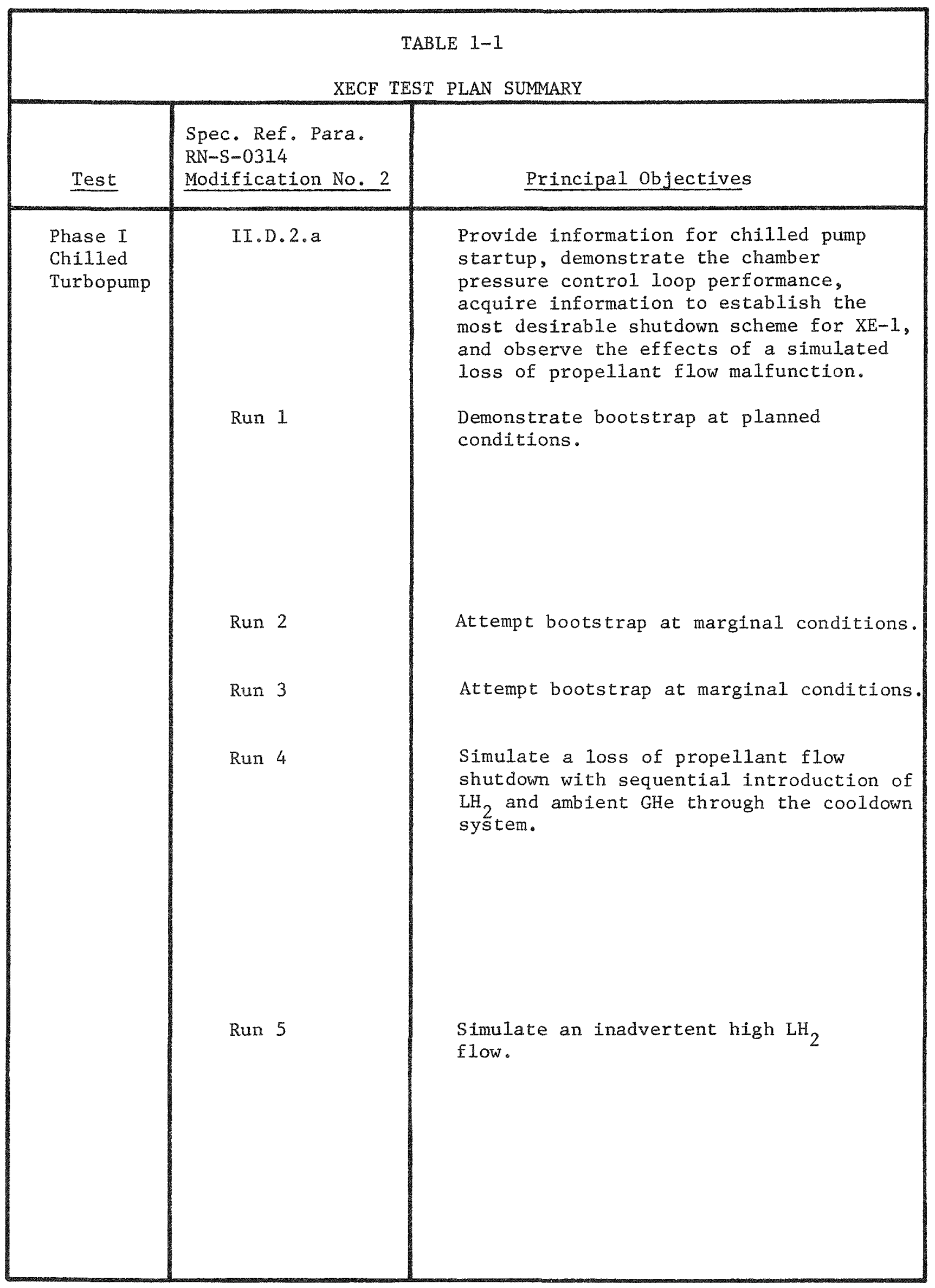


The initial run tank pressure will be set at 35 psia. The pump will be prechilled and the reactor core will be at ambient temperature. The test will be initiated by opening PDSV and the pressure control loop will be closed when the nozzle tube outlet temperature reaches a preplanned value.

Same as Run 1 except the tank pressure will be reduced to 25 psia.

Same as Run 1 except the tank pressure will be set at 27 psia.

The run tank line, pump and cooldown supply line will be prechilled, and the cooldown supply line pressure regulated to 50 psia. The test will be initiated by opening PDSV. TPCV will be stepped to $80^{\circ}$ when the nozzle tube outlet temperature reaches a preplanned value. When pump discharge pressure reaches 50 psia the CSV will be opened. When the pump discharge pressure reaches 100 psia the TPCV will be stepped closed to simulate loss of flow.

The run tank pressure will be set at 60 psia and $\mathrm{V}-5002$ tank pressure at 100 psia. The pump and emergency cooldown line will be chilled. $\mathrm{LH}_{2}$ flow will be initiated by opening PDSV. When the reflector inlet temperature reaches $200^{\circ} \mathrm{R}, \mathrm{PCV}-472$ will be stepped open to $30^{\circ}$ and PDSV closed. After 3 sec, PCV -472 will be closed and PDSV reopened. V-5002 tank pressure will be increased to 400 psia. When $\mathrm{T}_{\mathrm{c}}$ reaches $400^{\circ} \mathrm{R}$ PCV-472 will be stepped open to $30^{\circ}$ and PDSV closed. After $3 \mathrm{sec}, \mathrm{PCV}-472$ will be closed. TPCV remains closed during the test. 


\begin{tabular}{|c|c|c|}
\hline & $\begin{array}{r}\text { TABLE } \\
\text { XECF TEST }\end{array}$ & $\begin{array}{l}-1 \text { (Cont.) } \\
\text { LAN SUMMARY }\end{array}$ \\
\hline \multirow[t]{2}{*}{ Test } & $\begin{array}{l}\text { Spec. Ref. Para. } \\
\text { RN-S-0314 } \\
\text { Modification No. } 2 \\
\end{array}$ & Principal Objectives \\
\hline & Run 6 & $\begin{array}{l}\text { Simulate an inadvertent high } \mathrm{LH}_{2} \\
\text { flow. }\end{array}$ \\
\hline \multirow[t]{3}{*}{$\begin{array}{l}\text { Phase II } \\
\text { Warm } \\
\text { Turbopump }\end{array}$} & Run 1 & $\begin{array}{l}\text { Provide information for develop- } \\
\text { ing optimum warm pump startup } \\
\text { procedures. Verify computer pre- } \\
\text { dictions and operation of the } \\
\text { chamber pressure control loop, } \\
\text { and observe the effects of a } \\
\text { simulated loss of propellant } \\
\text { flow malfunction. } \\
\text { Demonstrate bootstrap at planned } \\
\text { conditions. }\end{array}$ \\
\hline & Run 2 & $\begin{array}{l}\text { Simulate a loss of propellant } \\
\text { flow shutdown with sequential } \\
\text { introduction of } \mathrm{LH}_{2} \text { and } \mathrm{GH}_{2} \\
\text { through the cooldown system. }\end{array}$ \\
\hline & Run 3 & $\begin{array}{l}\text { Demonstrate the controlling } \\
\text { action of the chamber pressure } \\
\text { control loop. }\end{array}$ \\
\hline \multirow[t]{3}{*}{$\begin{array}{l}\text { Phase III } \\
\text { Conditional } \\
\text { Tests }\end{array}$} & II.D.2.C & $\begin{array}{l}\text { To provide additional tests if } \\
\text { further operator training is } \\
\text { required. }\end{array}$ \\
\hline & Run 1 & $\begin{array}{l}\text { Attempt a warm turbopump boot- } \\
\text { strap at marginal conditions. }\end{array}$ \\
\hline & Run 2 & $\begin{array}{l}\text { Demonstrate fixed TPCV startup } \\
\text { with a warm pump. }\end{array}$ \\
\hline $\begin{array}{l}\text { Phase IV } \\
\text { Vibration } \\
\text { Tests }\end{array}$ & II.D.2.d & $\begin{array}{l}\text { To determine the resonances, nodal } \\
\text { deflections and amplification factors } \\
\text { of the test stand, and what response } \\
\text { the XE- } 1 \text { will have to its vibration } \\
\text { environment. }\end{array}$ \\
\hline
\end{tabular}


Similar to Run 5 except the initial V-5002 tank pressure will be 400 psia. When the reflector inlet temperature reaches $200^{\circ} \mathrm{R}$, PCV -472 will be stepped open to $30^{\circ}$ and PDSV closed. After $10 \mathrm{sec}$ the run will be terminated by closing PCV -472 .

Similar to Run 1 of Phase I except the pump will not be chilled; the test will be initiated by opening PSV and the pressure control loop will be closed when the nozzle tube outlet temperature reaches a preplanned value.

Similar to Run 4 of Phase 1, except the pump will not be chilled, the test will be initiated by opening PSV and ambient $\mathrm{GH}_{2}$ will be used in place of GHe after the emergency shutdown.

Similar to Run 1 of Phase II, except the run tank pressure will be set at $60 \mathrm{psia}$, and a chamber pressure of 35 psia demanded.

Similar to Run 1 of Phase II, except the tank pressure will be 25 psia, and pressure control loop closing will be based on results of Phase II, Runs 1 and 2.

Similar to Run 1 of Phase II, except the pressure control loop will be open and the IPCV will be stepped to a fixed position.

The engine will be excited by a sinusoidal force with the excitation points located at the nozzle-pressure vessel interface. The frequency range from 5 to 1500 cycles per second will be investigated. 
The engine system will be operating under transient conditions throughout all testing. Transient analyses of the system have been made for each test phase. Phase I covers initial engine startup with the turbopump prechilled to liquid-hydrogen temperature and provides for simulation of a lossof-propellant-flow malfunction. Phase II covers initial engine startup with a warm turbopump and operation of the chamber-pressure control 1oop and provides for simulation of a loss-of-propellant-flow malfunction. Phase III covers tests designated to be performed if additional runs are required for operator training. Phase IV provides for determination of engine and teststand resonance frequencies.

This report is expected to be used as a working document for analysis of test results and therefore contains a description of the engine and major facility systems, predictions for each test, and detailed descriptions of pertinent engine transducer locations. 
There was no Page 7 in original document. 
There was no Page 8 in original document. 
3. Reactor Assemb1y
a. Reflector
b. Shield
c. Core

4. Thrust-Structure Assembly

a. Test-Stand Adapter

b. Upper Thrust Structure

c. External Shield

d. Lower Thrust Structure 
BLANK 


\subsection{COMPARISON OF CFDTS, XECF, AND XE}

The CFDTS, XECF, and XE systems are similar to each other. The differences that could have a minor influence on the operational characteristics of the systems are detalled in Table 2-1.

Additional design information for XECF (including component flow and heat-transfer coefficients used in the computer model for performing pretest predictions) may be found in Report RN-S-0289, XE-Engine Systems Analysis Design Data Book. 
1. PROPELLANT FEED SYSTEM

a. Pump Inlet Line

(1) Flowmeter

(2) Cooldown Lines

(3) Propellant Shutof

b. Turbopump Assemb 1y

\section{Flow}

(2) Turbine Inlet Nozzle

\section{c. Pump Discharge Line}

(1) Length

(2) Pump Discharge Shutoff Valve

(3) Pump Discharge Vent Valve
One 8-inch and one 4-inch turbine type flowmeter

Cooldown port blanked off

Butterfly type valve, pneumatically actuated

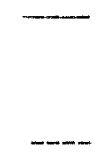

Six-inch butterfly type valve

Two-inch butterfly valve
One 8-inch turbine type

Five-inch cooldown lines feed to pump inlet line

Poppet type valve, spring actuated

to close, pneumatically actuated

to open

The shaft to bearing retaining

1abyrinth annular flow area is

reduced from that of CFDrS (708800-79, S/N 10)

The turbine inlet nozzle flow

area is about $4 \%$ larger than that.

of CFDTS

Approximately 50 inches longer than CFDT'S

Five-inch butterfly type valve

Five-inch butterfly type valve
Same as XECF

Same as XECF

Same as XECF

Same as XECF

Same as XECF

Same as XECE

Same as XECF

Same as XECF 
ITEM

(4) Vent Line

d. Turbine Inlet Line

(1) Length

(2) Jacketed Section

(3) Component Sequence

e. Diluent Line

\section{CFDTS}

Two-inch diameter

XECF

Five-inch diameter

$\underline{\mathrm{XE}}$

Same as XECF

Approximately 50 inches longer than CFDTS

Jacketed at elbow only at hot-bleed port or about one half as long as

CFDTS

to pressure vessel forward

flange area

Venturi Meter, Overspeed Trip Valve, Turbine Power Contro1

Valve

Two-Inch Line, 67 inches long

Flow measuring orifices

Two-inch, ON/OFF butterfly

type valve

f. Turbine Exhaust System
Venturi Meter, Turbine Power Control

Valve, Turbine Blocking Valve

Three-inch line, 107.5 inches long with 2 -inch reducer at dome

\section{Venturi flow meter}

Flow restrictions orifice,

2.167 in., dia

Twin lines and nozzles dischargin into the facility exhaust duct in the vicinity of the engine nozzle
Twin exhaust lines, manifolding

in upper thrust structure and exhausting to a separate ejector
Same as XECF

Same as XECF

Same as XECF

Similar to XECF

no two inch reducer

Same as XECF

Same as XECF,

1.937 in., dia

Same as XECF 
2. THRUST CHAMBER ASSEMBLY

a. Pressure Vesse1

(1) Closure (Dome)

(2) Cylinder

(3) Nozzle Flange

(4) Nozzle Tubes
(a) Design
$\mathrm{S} / \mathrm{N} 23$ (b) Hot Side Effective
Throat Area
58.30 in. $^{2}$
(c) Minimum Coolant
6.12 in. $^{2}$

Lugs welded on closure flange for attachment to lower thrust structure

Support brackets for turbine inlet line

No instrumentation brackets

Instrumentation brackets

No turbine exhaust line support bracket lugs Flow Area
Closure flange diameter enlarged to allow for attachment to the lower thrust structure

Line mounting brackets removed

Two instrumentation brackets bolted

to forward flange

Removed CFDTS instrumentation brackets and added XECF brackets

Added turbine exhaust line support lugs

Same hardware as CFDTS

58.2463

6.4 in. $^{2}$
$\mathrm{S} / \mathrm{N} 30$

Same as XECF

Same as XECF

Same as $\mathrm{XECF}$

Same as XECE

Same as XECF 
(5) Hot Bleed Port

3. REACTOR ASSEMBLY
a. Design
b. Core
c. Reflector

4. THRUST STRUCTURE ASSEMBLY

a. Test Stand Adapter

b. Upper Thrust Structure

(1) Length

(2) External Shield

None

(3) Lower Thrust Structure
a. Material
Aluminum

Unfueled
Refurbished A-1 Reactor (Mostly instrumentation deletions)

Stationary Drums

No Drum Actuators

Inner reflector with AI Barrel

Added test stand adapter as

transition section from test

stand to upper thrust structure

Approximately 50 inches 1onger than CFDTS

Installed between upper and lower thrust structures

Titanium
Same as XECF

A-5 Type

Fueled, $6 \%$ increase

in core $\Delta P$

Movab le Drums

Live Drum Actuators

Thicker inner reflecto

and $A 1$ barrel deleted

Same as XECF

Same as XECF

Same as XECF

Titanium with thinner structural sections 


\section{BLANK}




\subsection{TEST FACILITIES}

A brief description of the ETS-1 test facility is presented herein; a more complete description is presented in Report NTO-R-0086, ETS-1 Facility Data Book.

\subsection{INTRODUCTION}

The Engine Test Stand No. 1 (ETS-1) complex provides facilities required for the cold-flow testing of the NERVA XE engine (XECF). An aerial photograph of the ETS-1 complex is shown in Figure 3-1. In addition to the test stand, the complex includes the engine test compartment (ETC), nuclear exhaust system (NES), the process systems, instrumentation and control systems, and an electric-power generation and distribution system. Also, ETS-1 provides the safety systems and emergency equipment and radiation shielding for the protection of personnel, facility components, and test hardware.

To support the test operations at ETS-1, a complete engine maintenance, assembly, and disassembly (E-MAD) facility has been constructed. The facility will be used for assembly and checkout of the engine prior to testing and for postoperative examination of the engine after testing. 


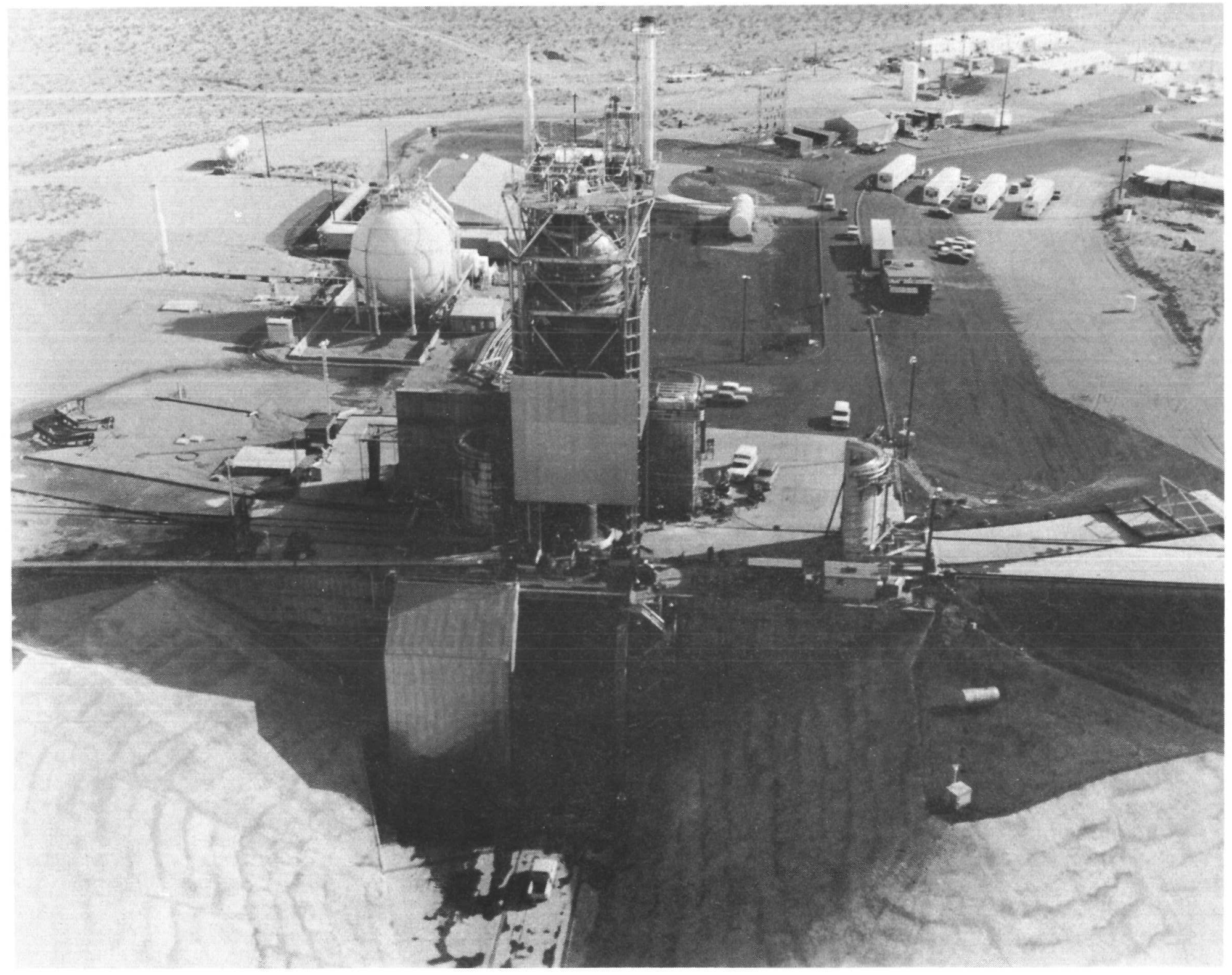

Figure 3-1 - ETS-1 Complex 


\subsection{TEST STAND}

The test stand (Figure 3-2) supports the test engine, the 77,000gallon $\mathrm{LH}_{2}$ run tank (V-5001), and the miscellaneous piping systems required for engine operation. The structure is made of aluminum and is formed by four main vertical columns that are connected by a network of cross braces and trusses. The engine load is transmitted to the main support structure through four thrust columns and the thrust support ring.

At the test stand, the test hardware is mated with the facility to provide an integrated test system. The fluid transfer systems connect to the test stand to provide engine coolant, postoperational cooldown fluids, pneumatic actuation supply fluids, inlet gas purge, water for cooling facility components and shielding, and steam for the NES. 


\subsection{ENGINE TEST COMPARTMENT}

The engine test compartment (ETC) has four basic functions: (1) to provide a safe, oxygen-free operating environment for the engine during the test; (2) to permit reduction in ambient atmospheric pressure around the engine in order to partially simulate space environmental conditions; (3) to reduce the damaging effects of radiation on the test-system components located outside the compartment; and (4) to allow greater personnel access to the facility areas after engine shutdown.

A sketch of the engine test compartment is shown in Figure 3-3. The walls consist of four radiation shields: two movable side shields, $S-1$ and $\mathrm{S}-2$, (one at each side of the test stand); a top shield, $\mathrm{S}-5$; and a bottom shield, S-4. A donut-shaped intermediate shield (S-6), half of which is attached to each side shield, mates with the external engine shield located at the upper end of the lower thrust structure when the two side shields are engaged in the test position. In this position, the shields reduce the external radiation levels during and immediately after the test run. Seals are used between the two side shields, between the side and bottom shield, and between the side and top shield to preclude entry of air into the compartment.

Neutron detectors, used to provide the primary nuclear input signal to the engine control and safety systems, are contained in three instrumentation packets located in the $\mathrm{S}-2$ shield. 


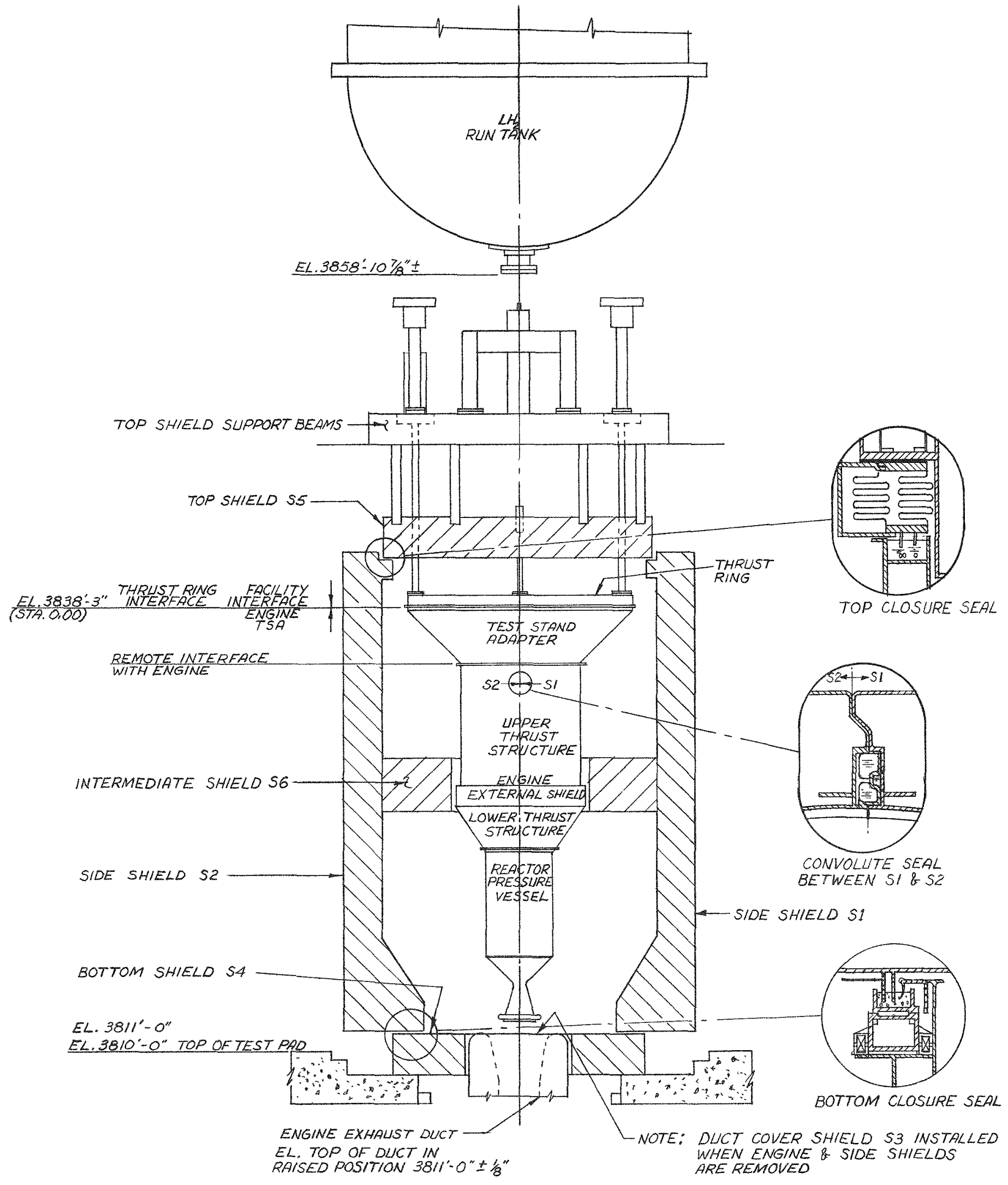

Figure 3-3 - ETC Shield Configuration 


\subsection{NUCLEAR EXHAUST SYSTEM}

The nuclear exhaust system (NES) contains two major subsystems: the duct assembly and the steam-generator system. The duct assembly directs the hydrogen exhaust gases expelled from the engine away from the test stand so they may be burned safely and assists in reducing the pressure in the ETC during engine operation. The steam-generator system provides a continuous flow of steam to the duct during engine operation. The steam flow ejected through the duct reduces the ETC pressure during engine startup and, should sudden termination of hydrogen flow to the engine occur, prevents the back flow of air into the system.

\subsubsection{Duct Assembly}

\subsubsection{Design}

The duct assembly is located in a concrete vault directly below the engine test position (see Figure 3-2). The exhaust end of the duct vault is open to permit installation and removal of the duct. At the conclusion of testing, an aluminum-covered concrete door can be moved across this vault opening to shield personnel from residual radiation.

The duct consists of the primary, elbow, and secondary sections. It is fabricated from type-347 stainless steel. Two types of double-wall construction are used to provide longitudinal channels for the flow of cooling water between the inner and outer walls. The primary and secondary sections are constructed of sheet and angle sections welded together to provide rectangular channels. The elbow section is constructed of round tubes that are welded together. In addition, the elbow section is provided with an additional watex jacket to prevent entrance of air into the duct if the tubular wall construction in the elbow should fail. 
The duct configuration is shown in Figure 3-4. The primary section is designed as a second-throat supersonic diffuser, the first throat being that of the test-engine nozzle. To minimize the heat flux on the elbow, the supersonic exhaust stream that enters the duct is "shocked down" to a subsonic stream in the second-throat portion of the duct. The secondary section is a cylindrical duct that carries the exhaust gases away from the test stand. The steam ejector consists of a series of two-dimensional sonic nozzles attached to an uncooled torus at the inlet of the secondary section. The nozzles discharge the steam downstream along the inner surface of the duct. In Figure 3-4, an ejector nozzle is shown in the enlarged sketch.

\subsubsection{Performance}

The extent to which the duct is expected to develop and maintain the desired environmental conditions in the engine test compartment is indicated by the relationship between the engine-compartment pressure and the engine-nozzle-chamber pressure illustrated in Figure 3-5. The minimum engine-compartment pressure due to secondary ejection alone is about 7.5 psia. As the engine chamber pressure increases to approximately 140 psia, the expansion process in the primary section is sufficient to provide an enginecompartment pressure of approximately 1 psia.

\subsubsection{Steam-Generator System}

The steam-generator system consists of three subunits or modules connected to a common steam-collection and-discharge plenum. Each module consists of a steam generator with control, safety, and sequence equipment that renders it capable of operating independently of the other modules or as an integrated unit of the steam-generator system.

The steam-generator system has been designed to produce a normal output of superheated steam in accordance with the following specification: 
NOTES:

1. DIMENSIONS ARE IN INCHES.

2. DIAMETER ARE INTERNAL.

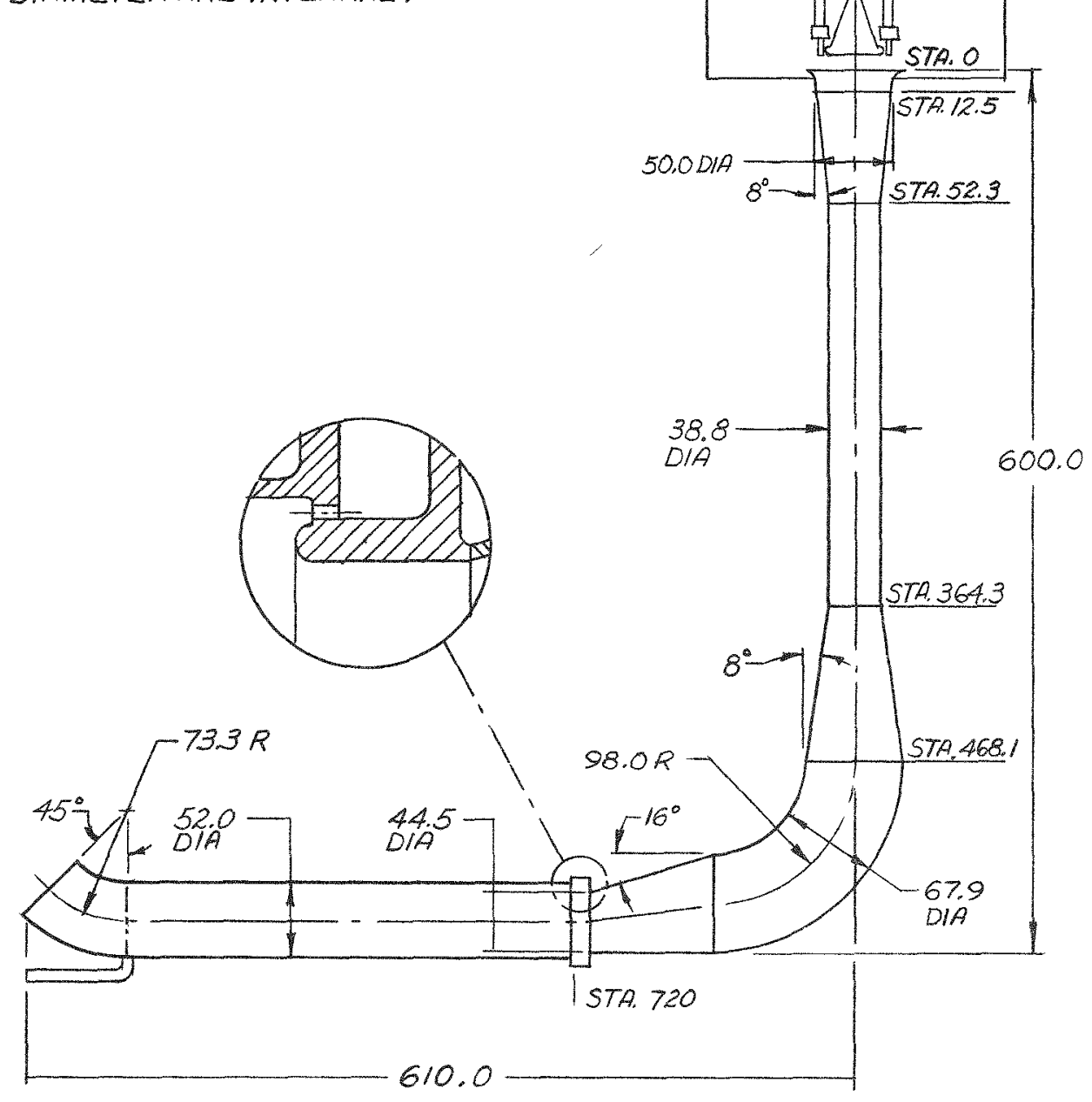

Figure 3-4 - Nuclear-Exhaust-System Duct Configuration 
NOTES: 1. TURBINE EXHAUST FLOW AT DESIGN VALUE

2. EJECTOR STEAM SUPPLY; 111 psia, $1380^{\circ} \mathrm{R}$, 139 LB/SEC

3. AMBIENT PRESSURE, 12.8 psia

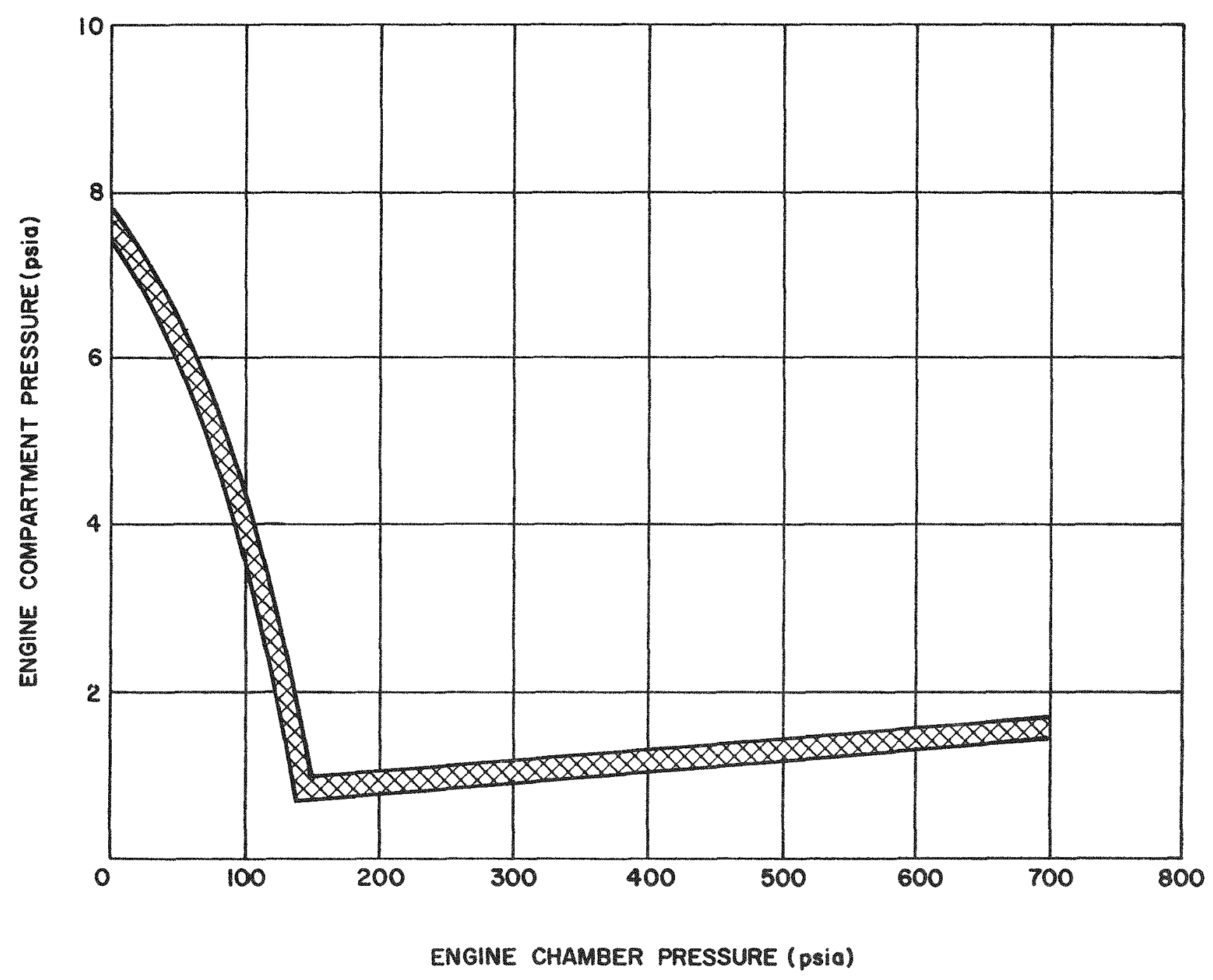

Figure 3-5 - Engine-Compartment Pressure vs Engine Chamber Pressure 


$\begin{array}{ll}\text { Steam Temperature } & 1300 \pm 100^{\circ} \mathrm{F} \\ \text { Steam Pressure (Minimum) } & 130 \mathrm{psia} \\ \text { Weight Flow (Minimum) } & 120 \mathrm{lb} / \mathrm{sec}\end{array}$

Each steam generator is designed to produce steam at a rate in excess of $65 \mathrm{lb} / \mathrm{sec}$; thus, the required normal output for the system (120 1b/sec) can be met by two modules, with the third kept on standby. 


\section{BLANK}




\subsection{PROCESS SYSTEMS}

The fluid process systems provide the storage vessels and transfer piping for the various fluids required for engine testing. The primary fluids are gaseous helium, gaseous nitrogen, gaseous hydrogen, liquid hydrogen, liquid nitrogen, and water. A simplified composite flow diagram of these process systems (less the water system) is shown in Figure 3-6. Table 3-1 provides the locations (the flow-diagram coordinates and transfer-1ine identification number) of the remotely operated valves, globe valves, pressurereducing valves, check valves, pressure-control valves, filters, and flowmeters shown in Figure 3-6.

\subsubsection{High-Pressure Gaseous Systems}

\subsubsection{Gaseous-Nitrogen System}

The gaseous-nitrogen system provides nitrogen for: (1) the actuation of remotely operated facility valves to purge the engine, exhaust duct, and facility and (2) pressurization of liquid-nitrogen, liquid-oxygen, and propane storage vessels. The gaseous nitrogen system consists primarily of three high-pressure vessels (V-3201, V-3202, and V-3203) and associated transfer piping. In addition, a separate $\mathrm{GN}_{2}$ system, using four 3,500 psia storage vessels, was added to the facility to supply nitrogen for inerting of the duct vault and pipe chase.

\subsubsection{Gaseous-Helium System}

The gaseous-helium system provides helium for actuation of remotely operated engine valves and for purging of the engine and facility. Also, gaseous helium is being considered as an inert propellant for an alternative cooldown system. The gaseous-helium system consists mainly of the three high-pressure vessels (V-3204, V-3205, and V-3206) and transfer piping. 


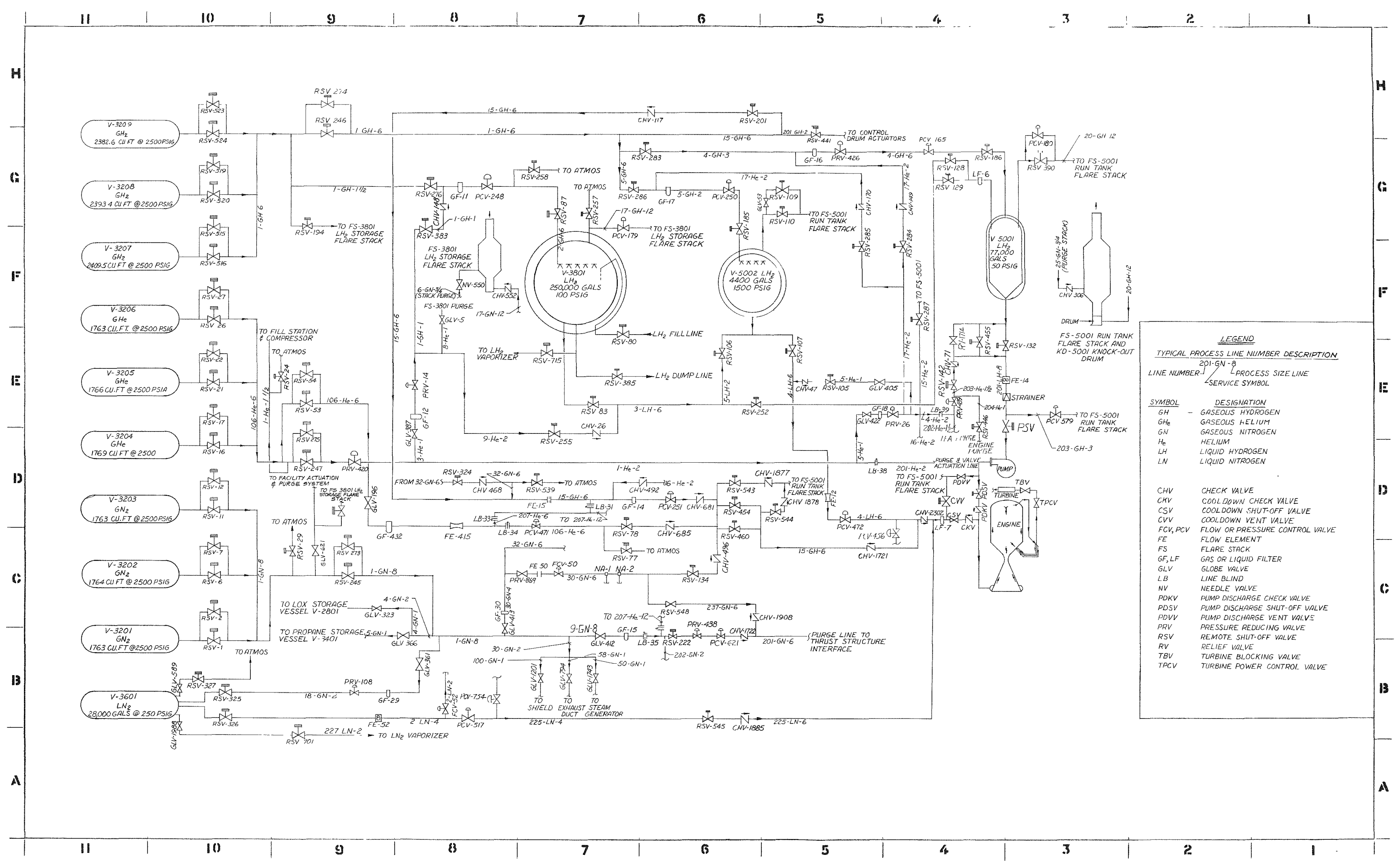

Figure 3-6 - Schematic Composite Flow Diagram of Fluid Process Systems 
TABLE 3-1

FACILITY VALVE, FILTER, AND FLOWMETER LOCATIONS

\begin{tabular}{l} 
Component \\
Identification \\
Number \\
CHV-26 \\
CHV-47 \\
CHV-71 \\
CHV-117 \\
CHV-148 \\
CHV-149 \\
CHV-306 \\
CHV-468 \\
CHV-492 \\
CHV-496 \\
CHV-552 \\
CHV-681 \\
CHV-1721 \\
CHV-1722 \\
CHV-1877 \\
CHV-1878 \\
CHV-1885 \\
CHV-1908 \\
FE-12 \\
FE-14 \\
FE-15 \\
FE-50 \\
FE-52 \\
FE-415 \\
GF-11 \\
GF-12 \\
GF-14 \\
GF-15 \\
GF-16 \\
\hline
\end{tabular}

\begin{tabular}{l}
\multicolumn{1}{c}{ Component } \\
Line \\
No. \\
$9-\mathrm{He}-2$ \\
$5-\mathrm{He}-1$ \\
$203-\mathrm{He}-1-1 / 2$ \\
$15-\mathrm{GH}-6$ \\
$1-\mathrm{GH}-1$ \\
$17-\mathrm{He}-2$ \\
$25-\mathrm{GN}-12$ \\
$32-\mathrm{GN}-6$ \\
$6-\mathrm{He}-2$ \\
$30-\mathrm{GN}-6$ \\
$17-\mathrm{GN}-12$ \\
$15-\mathrm{GH}-6$ \\
$15-\mathrm{GH}-6$ \\
$9-\mathrm{GN}-8$ \\
$-\mathrm{-}$ \\
- \\
$225-\mathrm{LN}-4$ \\
$237-\mathrm{GN}-6$ \\
$4-\mathrm{LH}-6$ \\
$201-\mathrm{LH}-8$ \\
$15-\mathrm{GH}-6$ \\
$30-\mathrm{GN}-6$ \\
$2-\mathrm{LN}-4$ \\
$106-\mathrm{He}-6$ \\
$1-\mathrm{GH}-1-1 / 2$ \\
$3-\mathrm{He}-1$ \\
$15-\mathrm{GH}-6$ \\
$9-\mathrm{GN}-8$ \\
$4-\mathrm{GH}-9$ \\
\end{tabular}

Component

Identification

Number

\section{GF-17}

GF -18

GF-29

$\mathrm{GF}-30$

$G F-432$

GLV-5

GLV -53

GLV-196

GLV-323

GLV-361

GLV -366

GLV-387

GLV-405

GLV-412

GLV -413

GLV -422

GLV-589

GLV-621

GLV-794

GLV-1201

GLV-1743

GLV-1988

FCV -50

FCV-52

LF -6

LF-7

$\mathrm{NV}-550$

\begin{tabular}{lc}
\multicolumn{2}{c}{ Component Location } \\
\hline Line & *Schematic \\
No. & Coordinates \\
\hline
\end{tabular}

5-GH-2

5-He-1

18-GN-1

$30-G N-4$

106-He-6

8-He-1

$-$

106-He-6

4-GN-1

18-GN-1

5-GN-1

3-He-1

5- $\mathrm{He}-1$

9-GN-8

30-GN-4

5-He-1

$-$

30-

100-GN-1

$50-\mathrm{GN}-1$

227-LN-2

30-GN-6

2-LN-2

3-LH-6

4-LH-6

$6-\mathrm{GN}-3 / 4$
G6

E5

B9

C8

D9

F8

F8

D5

C9

B8

C8

E8

E5

B7

C8

E5

B10

C9

B7

B7

B7

A10

C7

B8

G4

D4

F8

* See Figure 3-6 
TABLE 3-1 (cont.)

\begin{tabular}{|c|c|c|c|c|c|}
\hline \multirow{3}{*}{$\begin{array}{l}\text { Component } \\
\text { Identification } \\
\text { Number } \\
\end{array}$} & \multicolumn{2}{|c|}{ Component Location } & \multirow{3}{*}{$\begin{array}{l}\text { Component } \\
\text { Identification } \\
\text { Number } \\
\end{array}$} & \multicolumn{2}{|c|}{ Component Location } \\
\hline & Line & *Schematic & & Line & *Schematic \\
\hline & No. & Coordinates & & No. & Coordinates \\
\hline PCV-165 & $4-\mathrm{GH}-6$ & G4 & RSV -21 & 104-He-4 & E10 \\
\hline PCV-179 & $17-\mathrm{GH}-12$ & G7 & RSV -22 & $104-\mathrm{He}-4$ & E10 \\
\hline PCV -180 & $20-\mathrm{GH}-12$ & G3 & RSV -24 & $1-\mathrm{He}-1-1 / 2$ & E9 \\
\hline PCV-248 & $1-G H-1-1 / 2$ & G8 & $R S V-26$ & $115-\mathrm{GH}-4$ & F10 \\
\hline PCV-250 & $5-\mathrm{GH}-2$ & G6 & RSV -27 & $115-\mathrm{GH}-4$ & F10 \\
\hline PCV-251 & $15-\mathrm{GH}-6$ & D6 & RSV-29 & $1-G N-8$ & C9 \\
\hline$P C V-456$ & $4-\mathrm{LH}-6$ & B4 & RSV -53 & $106-\mathrm{He}-6$ & E9 \\
\hline PCV -471 & $106-\mathrm{He}-6$ & D7 & RSV -54 & $106-\mathrm{He}-6$ & E9 \\
\hline PCV -472 & $4-\mathrm{LH}-6$ & D5 & RSV -77 & $1-\mathrm{He}-1$ & $\mathrm{C7}$ \\
\hline PCV -517 & $225-L N-4$ & B8 & RSV -78 & 106-He-6 & D7 \\
\hline PCV- 579 & $203-\mathrm{GH}-3$ & E3 & RSV -80 & $1-\mathrm{LH}-2$ & F7 \\
\hline PCV -621 & $9-G N-8$ & B6 & RSV -83 & $3-\mathrm{LH}-6$ & E7 \\
\hline PCV -754 & - & B8 & RSV -87 & $2-\mathrm{GH}-6$ & G7 \\
\hline & & & RSV-105 & $5-\mathrm{He}-1$ & E5 \\
\hline PRV-14 & $3-\mathrm{He}-1$ & E9 & RSV-106 & $5-\mathrm{LH}-2$ & F6 \\
\hline PRV-26 & $17-\mathrm{He}-2$ & E5 & RSV -107 & $4-\mathrm{LH}-6$ & E5 \\
\hline PRV-108 & $18-G N-2$ & B9 & RSV-109 & $19-\mathrm{GH}-2$ & G5 \\
\hline$P R V-411$ & $9-G N-8$ & B6 & RSV -110 & $19-\mathrm{GH}-4$ & G5 \\
\hline PRV -420 & $1-\mathrm{He}-2$ & D9 & RSV-128 & $3-\mathrm{LH}-6$ & G4 \\
\hline PRV -426 & $4-\mathrm{GH}-6$ & G5 & RSV-129 & $3-\mathrm{LH}-6$ & G4 \\
\hline PRV -438 & $9-G N-8$ & $\mathrm{C} 6$ & RSV -132 & 201-LH-8 & E3 \\
\hline PRV -439 & $4-\mathrm{He}-2$ & E4 & RSV-134 & $30-\mathrm{GN}-6$ & $\mathrm{C} 6$ \\
\hline PRV-869 & $30-G N-6$ & C7 & RSV-142 & $203-\mathrm{He}-1-1 / 2$ & E4 \\
\hline & & & RSV -185 & $5-\mathrm{GH}-2$ & G6 \\
\hline RSV-1 & $103-G N-4$ & B10 & RSV-186 & $4-\mathrm{GH}-6$ & G4 \\
\hline RSV-2 & $103-G N-4$ & B10 & RSV-194 & -- & G9 \\
\hline RSV-6 & $109-G N-4$ & $\mathrm{C} 10$ & RSV-201 & $15-\mathrm{GH}-6$ & H6 \\
\hline RSV -7 & $109-G N-4$ & C10 & RSV-222 & $9-G N-8$ & $\mathrm{C} 6$ \\
\hline RSV-11 & $106-G N-4$ & D10 & RSV-245 & $1-G N-8$ & C9 \\
\hline RSV -12 & $106-G N-4$ & D10 & RSV-246 & $1-\mathrm{GH}-6$ & G9 \\
\hline RSV-16 & $112-G N-4$ & D10 & RSV-247 & $1-\mathrm{He}-2$ & D9 \\
\hline RSV -17 & $112-G N-4$ & D10 & RSV -252 & $3-\mathrm{LH}-6$ & E6 \\
\hline
\end{tabular}

* See Figure 3-6 
TABLE 3-1 (cont.)

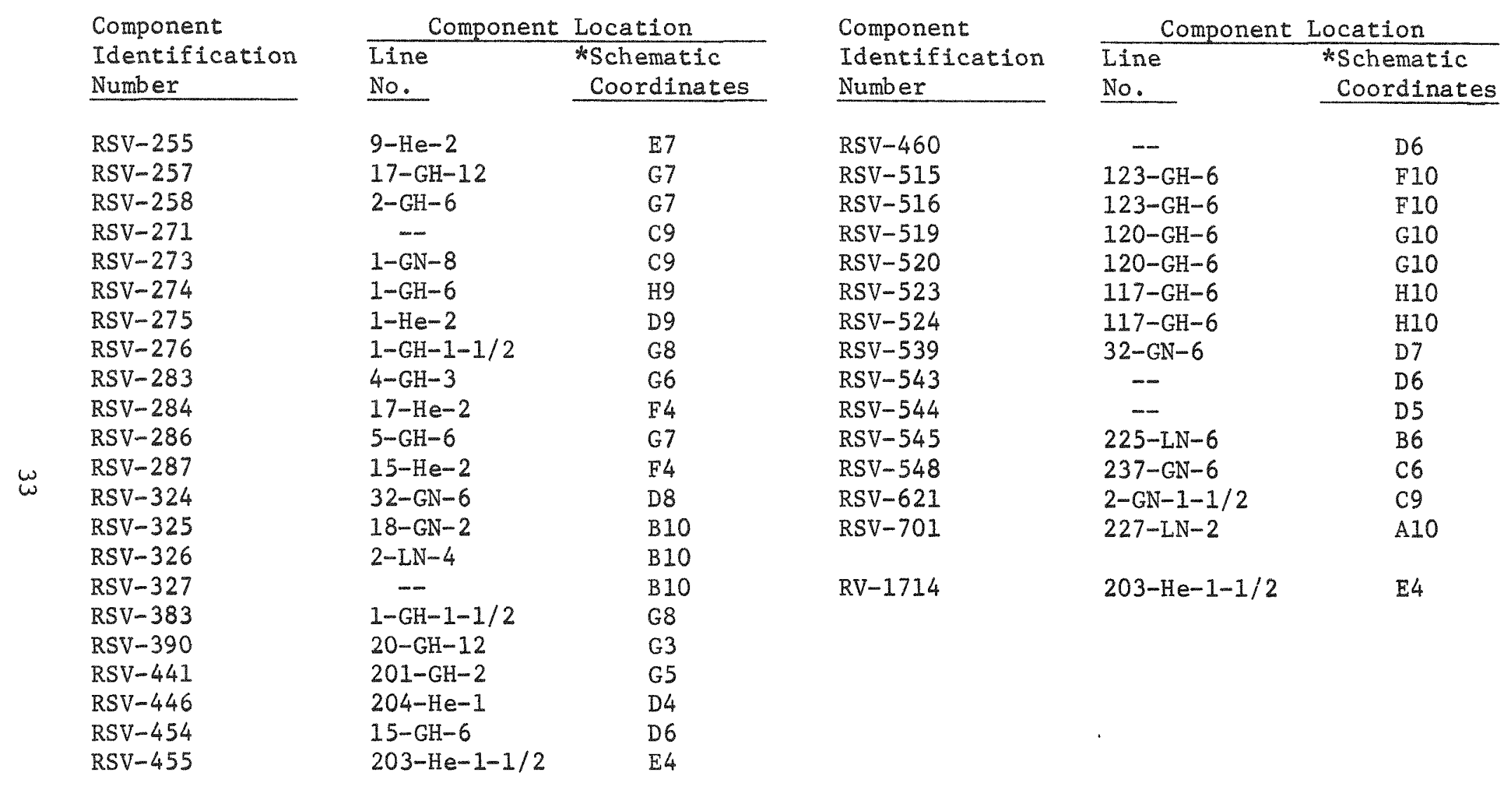




\subsubsection{Gaseous-Hydrogen Systems}

The gaseous-hydrogen system provides hydrogen for the pressurization of three liquid-hydrogen Dewars: the main storage Dewar, $\mathrm{V}-3801$ (to facilitate the transfer of liquid hydrogen to the propellant run tank, V-5001, and the high-pressure 1iquid-hydrogen Dewar, V-5002); the propellant run tank, V-5001 (to provide the desired engine tank pressure); and the high-pressure 1iquid-hydrogen Dewar, V-5002 (for emergency engine cooldown). In addition, the system supplies hydrogen for actuation of the reactor control drums and the turbine-power control valve. The primary components are three high-pressure vessels (V-3207, V-3208, and V-3209) and transfer piping.

\subsubsection{Low-Pressure Liquid-Hydrogen System}

The low-pressure liquid-hydrogen system provides hydrogen to the run tank, V-5001, and the high-pressure Dewar, V-5002. The system also supplies liquid hydrogen for conversion to gaseous hydrogen. The system consists primarily of the main storage Dewar, $V-3801$, and transfer piping.

\subsubsection{High-Pressure Liquid-Hydrogen System}

The high-pressure liquid-hydrogen system provides the delivery capability for engine cooldown (primarily during emergency shutdown) and consists mainly of the high-pressure storage Dewar, V-5002, and transfer piping.

\subsubsection{Propellant Feed System}

The propellant feed system consists primarily of the liquidhydrogen run tank, $\mathrm{V}-5001$, and transfer piping. 


\subsection{TEST-STAND CONTROL SYSTEM}

The main function of the test-stand control system (TSCS) is to provide the overall control and monitoring requirements of ETS-1 and to integrate the engine-oriented facility and engine control and monitoring system. Specifically, the TSCS provides:

(1) Operating control for the engine control system, including the operator consoles.

(2) Operation of the engine-oriented facility controls system.

(3) Test-stand nuclear instrumentation for nuclear-power monitoring.

(4) Conditioned signals to the data-acquisition system for recording of test data.

(5) Integration of the systems that directly control and monitor the engine and test stand into an overall control system.

(6) Capability for integrated system verification through simulation of the engine and TSCS controlled facility parameters.

(7) Operator training by means of simulation of engine and facility parameters.

(8) Sufficient information and control to permit safe performance of al1 TSCS functions during testing.

(9) The engine safety system (ESS) that includes scram, emergency shutdown, and other emergency actions during testing. 


\section{BLANK}




\subsection{FACILITY INSTRUMENTATION AND CONTROL SYSTEM}

The facility instrumentation and control system consists of the facilities control system (FCS), data-acquisition system (DAS), facility safety system, power system, and communications and television.

The FCS provides equipment to control and indicate conditions and to buffer signals for the test-stand support equipment and the fluid process subsystems. This system also conditions and buffers facility signals to be recorded by the DAS. The DAS accepts conditioned signals from the facility and TSCS signal conditioners and provides analog and digital recordings.

Power to operate ETS-1 comes from three primary sources: Nevada Power and Light Company, three caterpillar diesels, and batteries. During nontesting periods, power is supplied by the Nevada Power and Light Company. During test periods, the essential-bus loads will be supplied by three 150-kw diesel units. Instrument-bus loads will be supplied by two 500-kw diesels. Utility loads will be supplied by the Nevada Power and Light Company. A switching system is provided to: (1) switch the essential loads to the Nevada Power and Light Company should the diesels fail or (2) switch the utility load to the diesel units should power be interrupted from the Nevada Power and Light Company supply. In addition to the backup provided within the normal power distribution system, 28-vdc power is provided by batteries as backup to the dc rectifiers that operate off the essential-load bus and supply power for critical pilot valves, relays, instrumentation, and control circuits. 


\section{BLANK}




\subsection{TEST PREDICTIONS}

The predicted behavior of the XECF system during each test planned for the XECF test program is discussed in the following subsections. Report RN-S-0314, XECF Test Specification, NRO Modification No. 2, approved by the Test Specification and Procedures Review Board 5 July 1967, Meeting No. 3 and Change No. 5 to the XECF test specification approved by the Test Review Board 18 October 1967 were considered the primary authority for establishing the test conditions and operational sequence.

The test-prediction analysis indicated that, under all test conditions considered, the test-parameter limits 1isted in Table II.D.1 of Report RN-S-0314 would never be exceeded; and no unsafe conditions were disclosed that could result in damage to the test article or facility.

The predicted engine characteristics were obtained by using transient engine simulation program 16179, with the printout time interval generally set for 1 sec. The 16179 program is a modification of the 12013 program, the logic and equations of which are presented in Report RN-S-0114 Transient Engine Simulation Program Aug. 1964 (U)

The ability of the computer program to predict engine start-transient characteristics was tested by performing posttest computer runs for CFDTS tests conducted at XECF back-pressure conditions. In general, the computed parameters agree well with test data; however, discrepancies were noted for some parameters, particularly at reduced run-tank pressures. The probable influence of these discrepancies at XECF test conditions is more fully evaluated in discussions applicable to each particular test.

Program 16179 is made so that, at the time of test initiation (time zero), the PDSV or PSV steps open and system pressures and flow rates are instantaneously established. Therefore, as may be seen in the plots of predicted engine characteristics (Figures $4-1$ through 4-21), the system 
pressures and flow rates are fully developed at the start of each test. Several modifications have been made to this program to improve its ability to predict engine parameters during chilldown and initial system startup. These modifications include simulation of the turbopump suction and discharge lines, pump-bearing coolant flow, nozzle-bolt coolant flow, flow choking in the nozzle coolant tubes, and compressible flow through the core inlet orifices. The results of recent turbopump tests at the Lewis Laboratory were combined with AGC turbopump data to provide a best estimate of pump efficiency. The combined turbopump data were based on the Lewis Laboratory data at $1500 \mathrm{rpm}$, and on AGC data for pump speeds above 8000 rpm with a smooth merging of data at intermediate speeds between these values.

In addition to the above changes, the following parameters that influence the engine start characteristics were assumed at fixed values in performing test predictions (they are specified as a range of values or as approximations):

1. The initial temperature of all unchilled parts was taken as $540^{\circ} \mathrm{R}$.

2. The engine-test-compartment pressure was assumed to be constant at 7.5 psia.

3. The temperature of Iiquid hydrogen in the run tank and of all metal parts chilled with liquid hydrogen was assumed to be $38^{\circ} \mathrm{R}$. 


\subsection{PHASE I - CHILLED-PUMP STARTUP}

Phase I tests will provide information for developing optimum chilled-pump startup procedures for XE-1. They will provide a comparison with CFDTS tests, verify the computer models for prediction of XE-1 startup, and confirm the performance of the chamber-pressure control 100p. A further purpose of this phase of testing will be to acquire information on line warmup, valve sequencing, and shutdown fluid control to establish the most desirable shutdown scheme for XE-1 within the range of XECF operation. A loss-ofpropellant-flow malfunction will be simulated, and the effects on performance of both facility and engine systems will be obtained. Test data to evaluate the consequence of an inadvertant high $\mathrm{LH}_{2}$ flow malfunction from pressure, power, and reactivity standpoints will be acquired.

\subsubsection{Run 1}

The run-tank line and the pump will be chilled until $\mathrm{LH}_{2}$ conditions exist at the pump discharge. Initial run-tank pressure will be set at 35 psia. Prior to initiation of flow, the reactor temperature (as indicated by reactor-core temperature measurements) will be 500 to $560^{\circ} \mathrm{R}$. The enginetest-compartment pressure wil1 be 7.5 psia. The test will be inftiated by opening the PDSV with the TPCV closed and the pressure-control loop opened. The temperature of the nozzle-tube outlet fluid will decrease to $200^{\circ} \mathrm{R}$ approximately $12 \mathrm{sec}$ after initial opening of the PDSV, at which time the pressurecontrol loop will be closed and a chamber pressure of 60 psia will be demanded. Closing of the pressure-control loop will initiate opening of the TPCV and allow $\mathrm{GH}_{2}$ to flow to the turbine from the dome and hot-bleed port. The turbopump will accelerate from $0 \mathrm{rpm}$ at $15 \mathrm{sec}$ to about $750 \mathrm{rpm}$ at $21 \mathrm{sec}$, after which it will accelerate more rapidly to a maximum speed of $8440 \mathrm{rpm}$ at approximately $30 \mathrm{sec}$. Under XECF test conditions, the TPCV will require approximately $14 \mathrm{sec}$ to open from 0 to $80^{\circ}$ and will therefore reach the $80^{\circ}$ open position at $26 \mathrm{sec}$. The system plenum pressures approximately follow the increase in pump speed, with the pump discharge pressure reaching a maximum pressure of 172 psia at 30 sec. Flow rates also increase with pump speed but 
decrease at a slower rate after the maximum pump speed is attained because of reduction in engine flow impedance as the engine is chilled by the liquid hydrogen. Predicted plots of major engine parameters as a function of test time are presented in Figures 4-1, 4-2, and 4-3.

The conditions for this test are similar to the conditions during CFDTS Test No. 1.2-02-NNS-015, and the predicted engine behavior agrees closely with the test results. During CFDTS Test -015 , a maximum pump speed of $8210 \mathrm{rpm}$ was attained $29.5 \mathrm{sec}$ after test initiation.

\section{1 .2 Run 2}

Run 2 is to be a repeat of Run 1 except that the initial runtank pressure will be set at 25 psia. These initial conditions are nearly identical to those of CFDTS Test No. 1.2-02-NNS-026, which was conducted with a run-tank pressure of 24.3 psia, a back pressure of approximately 7.5 psia, and with the turbopump chilled to $\mathrm{LH}_{2}$ temperature. Attempts to duplicate the results of CFDTS Test No. -026 with the computer model have been of 1 imited success because of the lack of turbopump data at very low pump speeds and low net positive suction head. Examination of the test data indicates that twophase flow probably persists in the pump throughout most of the test. Insufficient data are available at these conditions to provide the computer model with the ability to compute pump head rise and work for two-phase flow. Several other turbopump parameters (negligible at higher system pressures) may also become significant at these low-pressure conditions. These parameters include turbine efficiency when the pressure ratio across the turbine is very low and the effects of the pump-bearing coolant flow being injected into the turbine upstream of the second-stage turbine nozzles.

Predicted plots of major engine parameters as functions of test time for Run 2 are presented in Figures 4-4, 4-5, and 4-6. The computer model indicates that the nozzle-tube outlet temperature will reach $200^{\circ} \mathrm{R}$ 


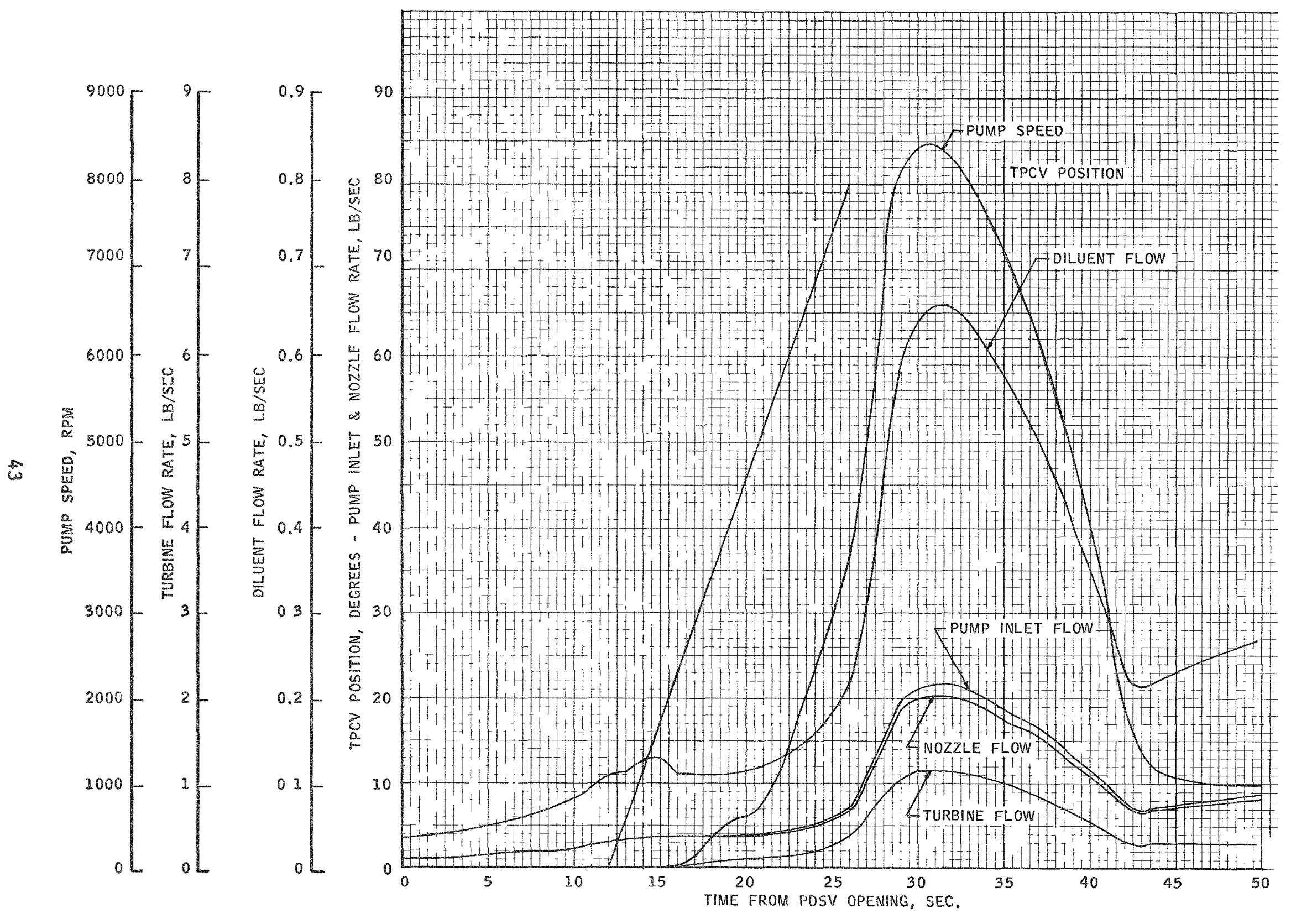

Figure 4-1 - XECF Test Prediction, Phase I, Run 1, Chilled Pump, $P_{T}=35$ psia 


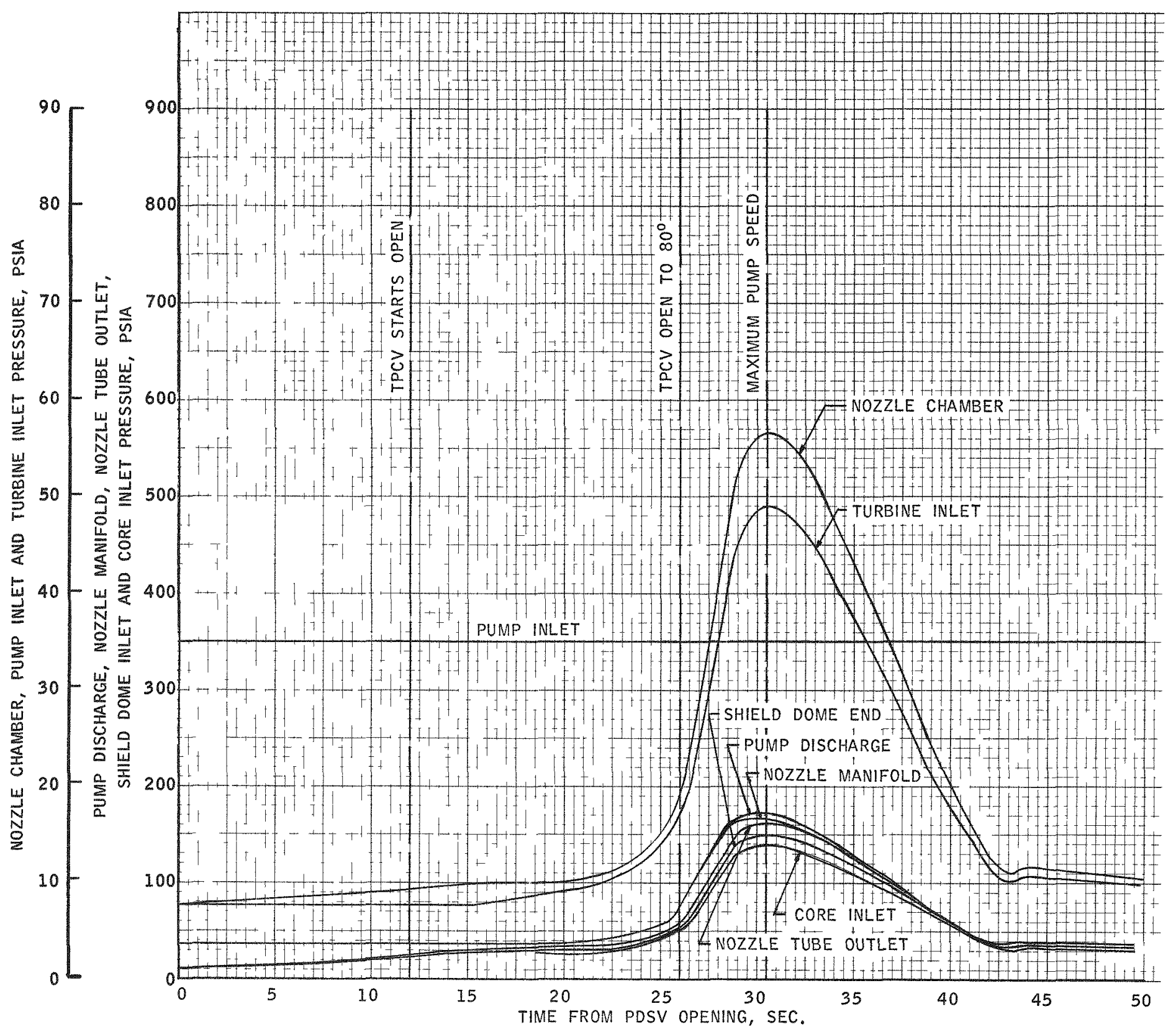

Figure 4-2 - XECF Test Prediction, Phase I, Run 1, Chilled Pump, $P_{T}=35$ psia 


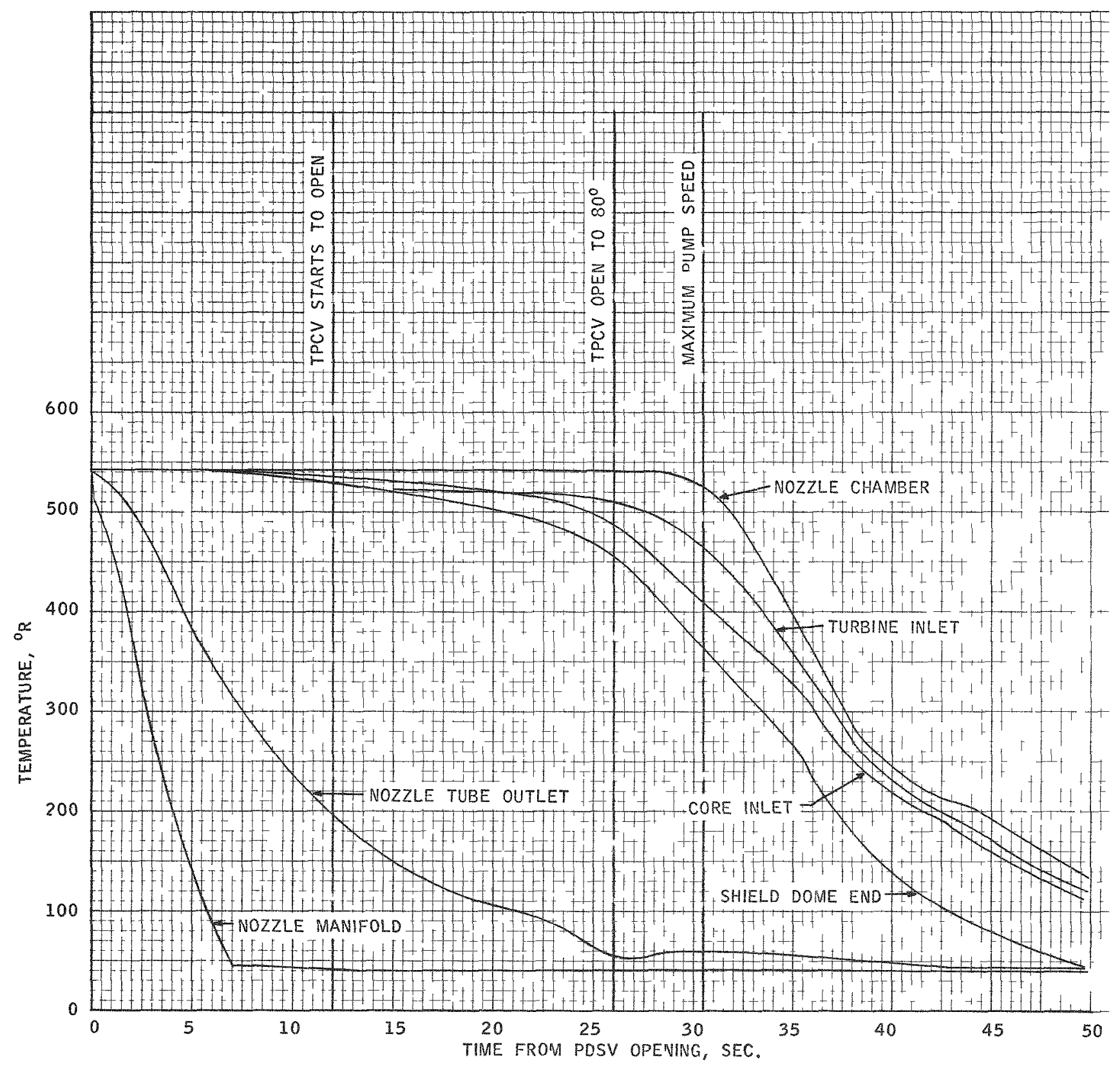

Figure 4-3 - XECF Test Prediction, Phase I, Run 1, Chilled Pump, $P_{\mathrm{T}}=35$ psia 


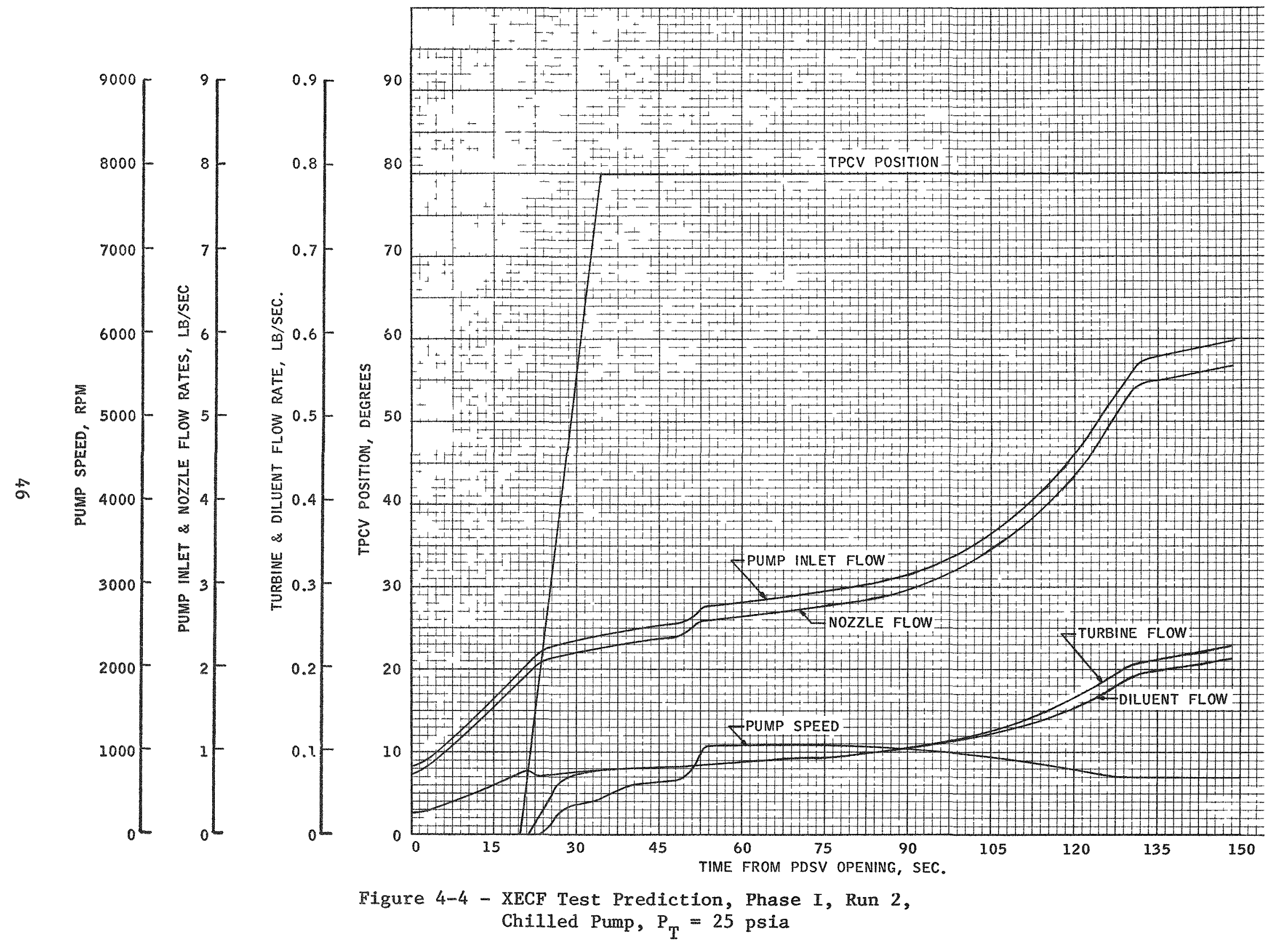




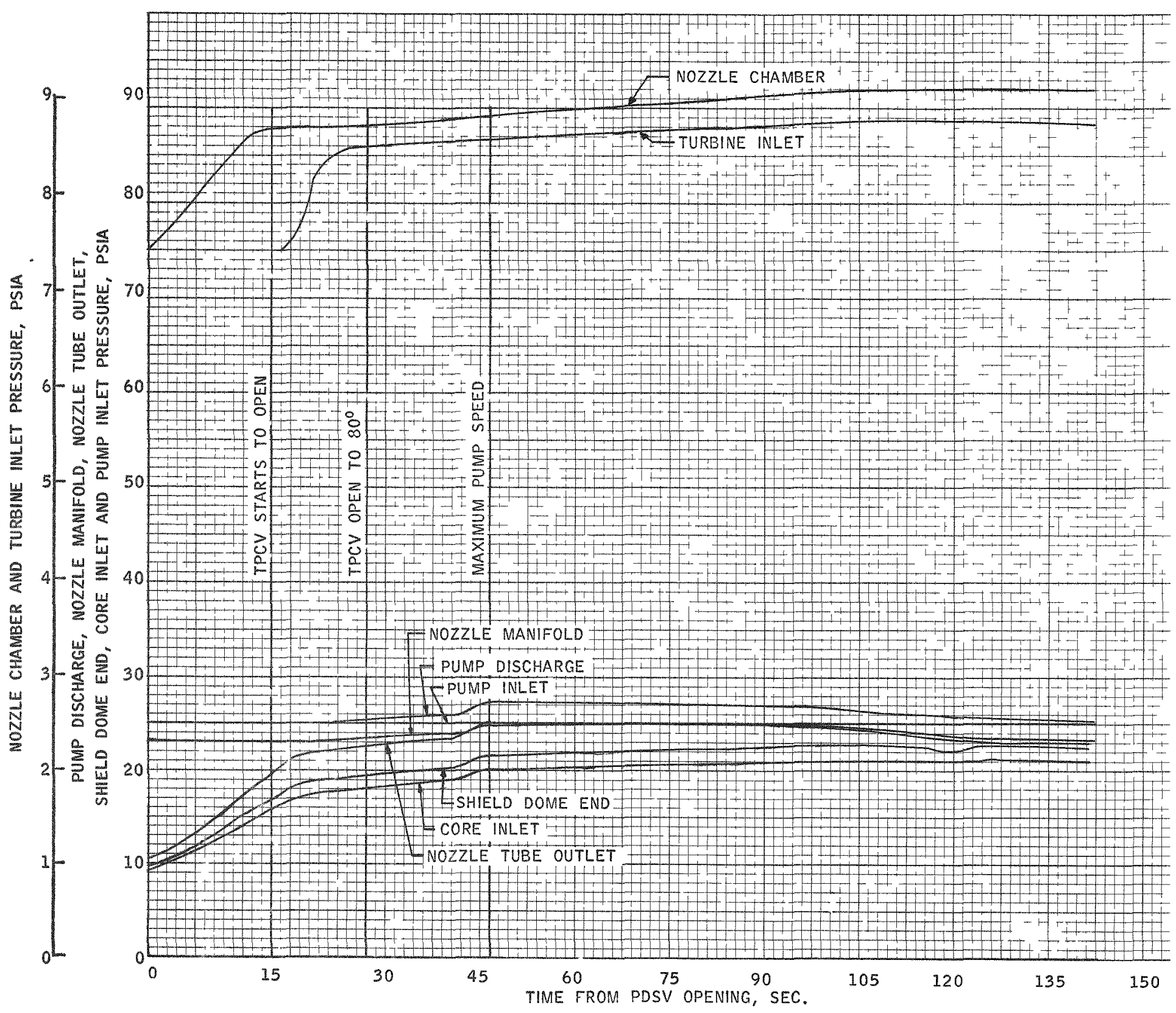

Figure 4-5 - XECF Test Prediction, Phase I, Run 2, Chilled Pump, $P_{T}=25$ psia 


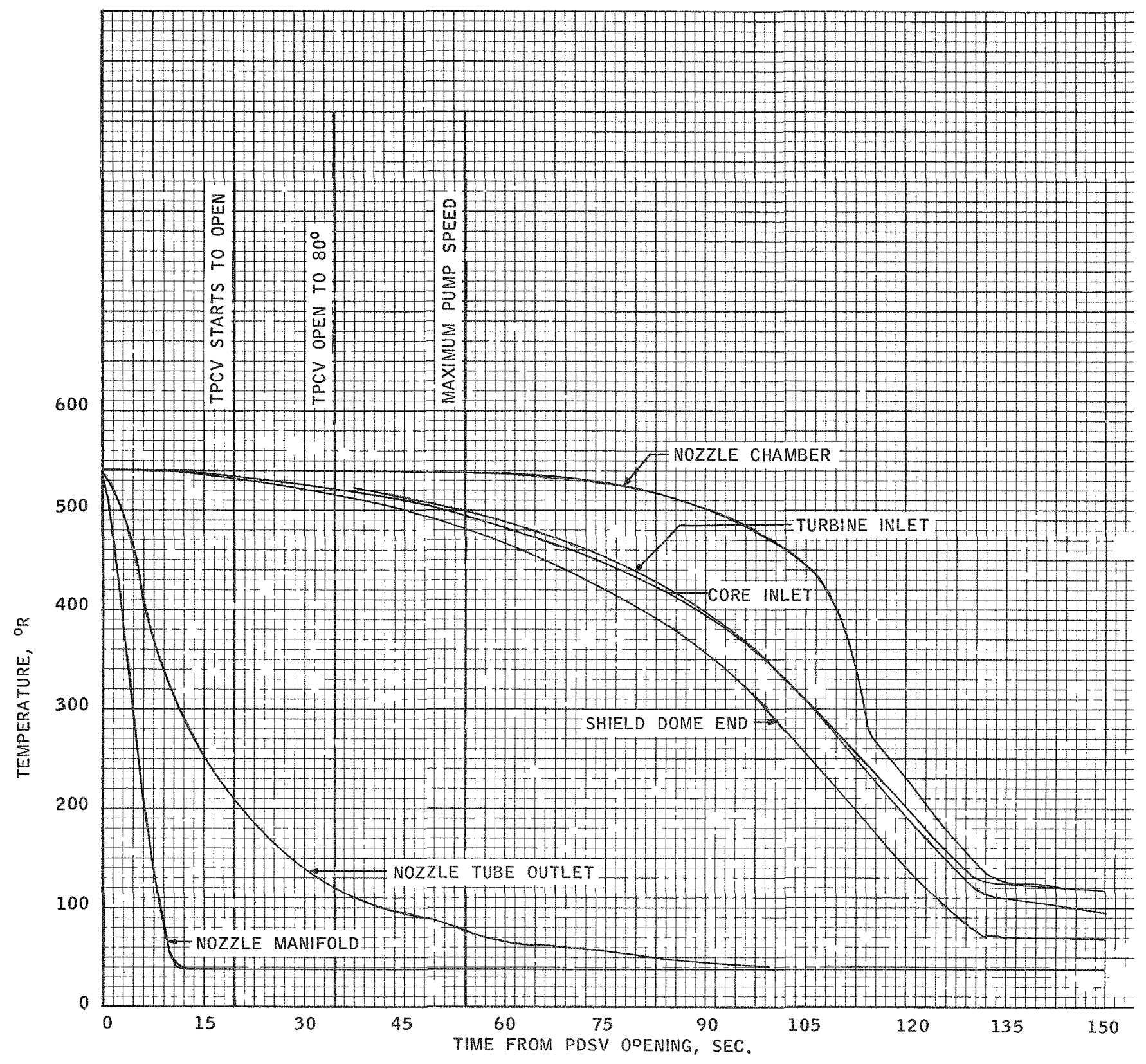

Figure 4-6 - XECF Test Prediction, Phase I, Run 2, Chilled Pump, $P_{T}=25$ psia 
approximately $20 \mathrm{sec}$ after initial opening of the PDSV, at which time closing of the pressure-control 10op will initiate opening of the TPCV and allow $\mathrm{GH}_{2}$ to flow to the turbine. The computer model shows an increase in pump speed to a maximum value of about $1075 \mathrm{rpm} 54 \mathrm{sec}$ after test initiation, after which speed decays very gradually. By contrast, the data from CFDTS Test No. -026 indicated that the pump speed increased slowly to $1500 \mathrm{rpm}$ at $115 \mathrm{sec}$ after test initiation, after which a rapid, minor bootstrap occurred to about 2800 rpm at $130 \mathrm{sec}$, with subsequent speed decay.

\section{1 .3 Run 3}

Run 3 is to be a repeat of Run 1 except that the initial run-tank pressure will be set at 27 psia.

The discussion of problems associated with pretest predictions for Run 2 is equally applicable to this run. Previous test experience has shown that the ability of the engine system to bootstrap is very sensitive to run-tank pressures in the range of 25 to $30 \mathrm{psia}$. The purpose of this run is to provide additional information on the sensitivity to bootstrap. Since a tank pressure of 27 psia lies between that of CFDTS Test No. -026 (24.3 psia) and that of CFDTS Test No. -024 (29.5 psia), maximum pump speed is expected to be between 2850 and $7400 \mathrm{rpm}$ and to occur at some time between 62 and $130 \mathrm{sec}$ after opening of the PDSV. The computer-model engine-chilldown analysis indicated that the temperature of the nozzle-tube outlet fluid will reach $200^{\circ} \mathrm{R}$ approximately $18 \mathrm{sec}$ after initial opening of the PDSV.

\section{1 .4 Run 4}

The run-tank line, the pump, and the cooldown supply line

will be chilled to $\mathrm{LH}_{2}$ temperatures. Initial tank pressure will be set at 35 psia and the ETC pressure will be 7.5 psia at test start. 
V-5002 pressure will be set at 100 psia, and the cooldown line between PCV-472 and CSV maintained below 50 psia. The test will be initiated by opening the PDSV. When the nozzle-tube outlet temperature reaches $200^{\circ} \mathrm{R}$ approximately $12 \mathrm{sec}$ after opening of PDSV, the TPCV will be stepped to a fixed position of $80^{\circ}$. The pump discharge pressure will reach 50 psia approximately $22 \mathrm{sec}$ after initiation of the test, at which time the CSV will be opened. Pump discharge pressure will continue to increase and will reach a value of about 100 psia $25 \mathrm{sec}$ after initiation of the test, at which time the TPCV will be stepped closed to simulate loss of flow.

The TPCV will close in approximately $0.25 \mathrm{sec}$, stopping the flow of $\mathrm{GH}_{2}$ to the turbine. The turbopump will decelerate and the pump discharge pressure will decay rapidly, reaching 50 psia approximately $0.75 \mathrm{sec}$ after the TPCV starts to close. The flow-failure detection system will detect the rapid decay of pump discharge pressure and initiate an emergency shutdown, opening PCV-472 to initiate flow of facility $\mathrm{LH}_{2}$ from $\mathrm{V}-5002$ to the engine system. PCV-472 will be controlled to a demanded nozzle inlet-pressure of 50 psia.

The 50 psia supply pressure of emergency-cooldown $\mathrm{LH}_{2}$ will sustain about $6 \mathrm{lb} / \mathrm{sec}$ of $\mathrm{LH}_{2}$ flow through the engine during this phase of the test, which will further cool engine components. About $41 \mathrm{sec}$ after initiation of the test, ambient $\mathrm{GH}$ flow to the engine system will be established at a nozzle torus inlet-pressure of 100 psia. Predicted plots of engine parameters for this test are shown in Figures $4-7,4-8$ and $4-9$.

No prediction was made of the system characteristics during the ambient facility $\mathrm{GH}_{\mathrm{e}}$ flow phase of the test. Review of the results of a facility test (to determine the cooldown line warmup characteristics during expulsion of $\mathrm{LH}_{2}$ and warmup of the cooldown line with gaseous helium through PCV-471) showed that during the first $10 \mathrm{sec}$ of gaseous helium flow, $\mathrm{LH}_{2}$ contained between $\mathrm{PCV}-472$ and the $\mathrm{LH}_{2} /$ gas cooldown line interface downstream of CHV-1721 boiled off into the $\mathrm{GH}_{e}$ flow resulting in erratic behavior of the 

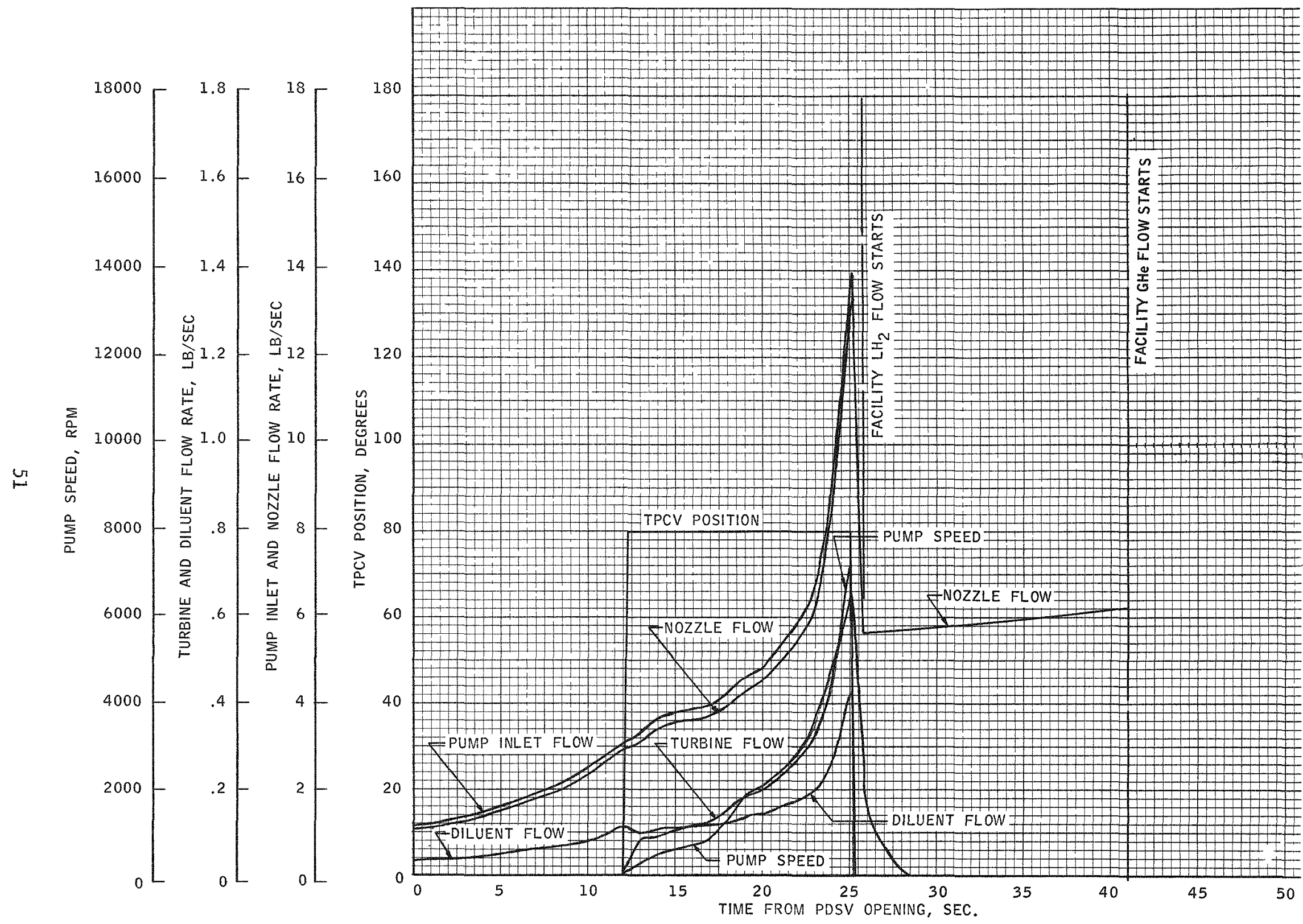

Figure 4-7- XECF Test Prediction, Phase I, Run 4, Chilled Pump, $P_{T}=35$ psia 


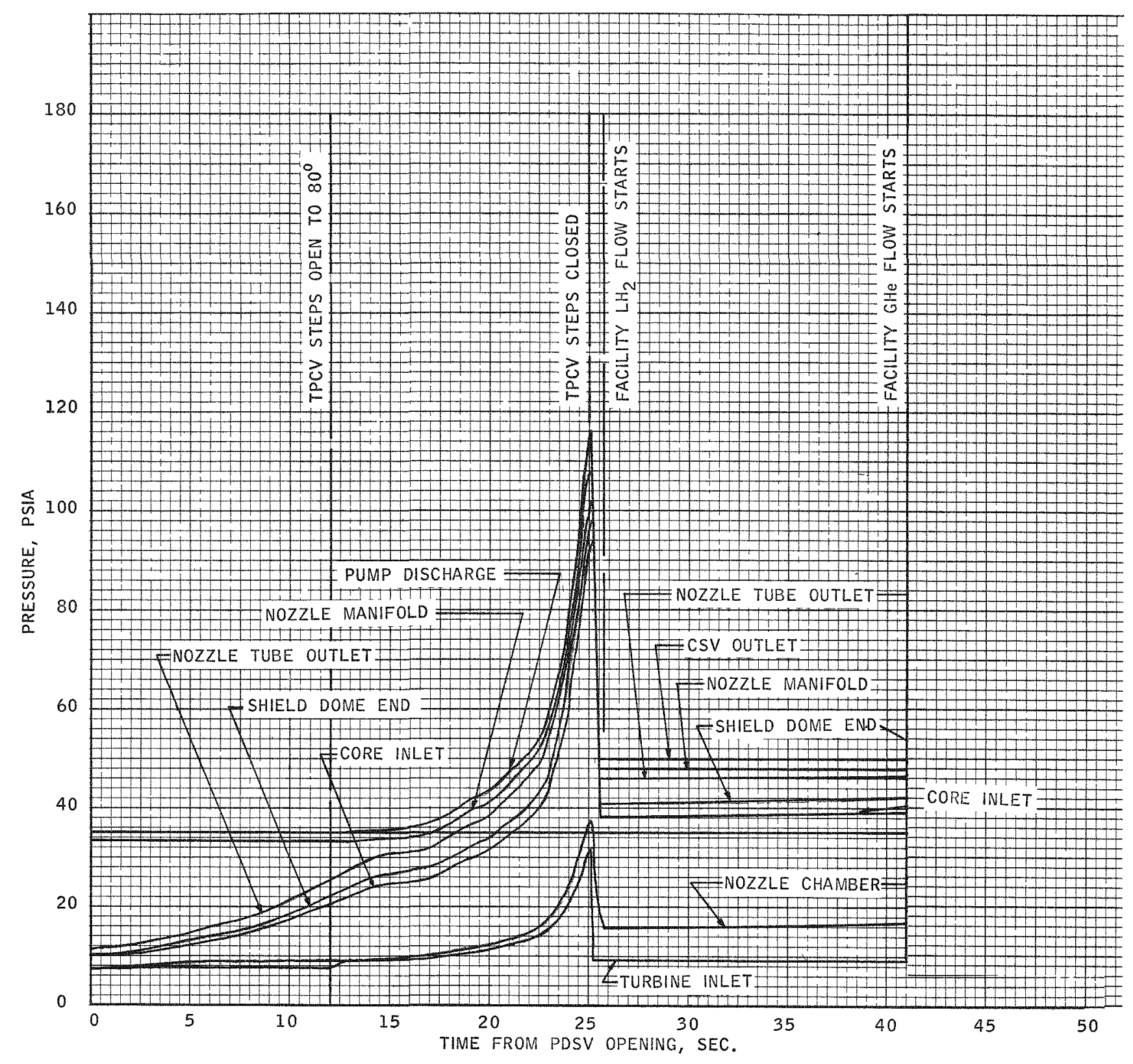

Figure 4-8 - XECF Test Prediction, Phase I, Run 4, Chilled Pump, $P_{T}=35$ psia 


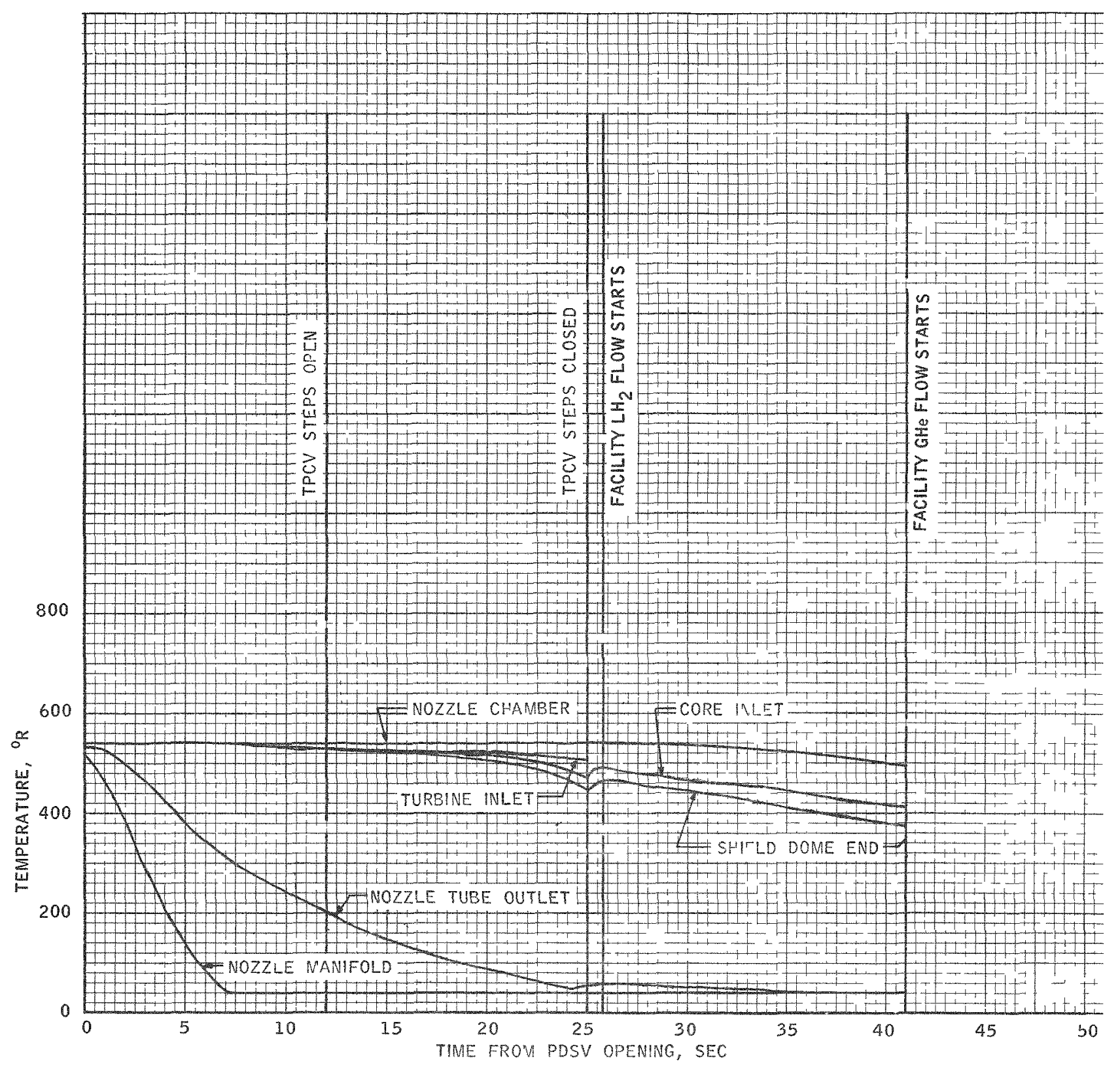

Figure 4-9 - XECF Test Prediction, Phase I, Run 4, Cinlled Pump, $P_{T}=35$ psia 
cooldown line fluid temperature. The analytical model at present has no capability for computing this boil-off characteristic, and there is not sufficient test data at the specified test conditions to provide a meaningful estimate of the gaseous hellum temperature transient. Examination of test data indicates that the cooldown line fluid temperature will be below $250^{\circ} \mathrm{R}$ until boil-off of the trapped $\mathrm{LH}_{2}$ is completed, and that this will require at least $10 \mathrm{sec}$. At completion of $\mathrm{LH}_{2}$ boil-off, the cooldown line temperature will increase rapidly to about $450^{\circ} \mathrm{R}$, with subsequent warming of the engine system components. A discussion of cooldown line warmup characteristics is presented in Section 3.3.3.4 of NTO-R-0110 ETS-1 Test Summary Report, FEP Test Series (U) 26 June 1967.

During the time of flow from the emergency cooldown system, the 16179 computer model is operated in the open-loop mode, which assumes no flow through the diluent line. In actual practice, a small amount of flow will pass through the diluent line and will rejoin the main flow in the nozzle chamber via the hot-gas bleed port.

\section{1 .5 Run 5}

The run-tank line, the pump and the cooldown supply line will be chilled to $\mathrm{LH}_{2}$ temperature. Initial run-tank pressure will be 60 psia and the ETC pressure will be about 7.5 psia. V-5002 tank pressure will be set at 100 psia. The IPCV will remain closed throughout the test. Propellant flow to the engine system will be started by opening PDSV. When the reflector inlet fluid temperature reaches $200^{\circ} \mathrm{R}$ approximately $7 \mathrm{sec}$ after PDSV opens, PCV-472 will be stepped open to the mechanical limit established for the XE tests (nominal 30\%) and PDSV closed. PCV-472 will be held open for $3 \mathrm{sec}$ and then closed. During the time that PCV-472 is open, the 100 psia pressure in $\mathrm{V}-5002$ tank will produce an increase in nozzle flow to about $10 \mathrm{lb} / \mathrm{sec}$ and a more rapid cooldown of the engine components. Immediately after closing of PCV-472, the V-5002 pressure will be increased to 400 psia, and PDSV will be reopened to further chill the engine system. The nozzle chamber fluid 
temperature will decrease to $400^{\circ} \mathrm{R}$ at approximately $37 \mathrm{sec}$, at which time PCV-472 will again be stepped open for $3 \mathrm{sec}$. Due to the 400 psia pressure in V-5002 and the low impedance of the chilled engine system, LH 2 flow will increase rapidly during this $3 \mathrm{sec}$ period. Nozzle flow will be about 35 Ib/ sec immediately after opening of PCV-472 and will increase to about $421 \mathrm{~b} / \mathrm{sec}$ at the time PCV -472 is again closed. At the increased flow rate, engine components will chill quickly with the nozzle chamber fluid temperature decreasing to about $125^{\circ} \mathrm{R}$ at the time of PCV-472 closing. Predicted plots of major engine parameters as a function of test time are presented in Figures $4-10$, 4-11 and 4-12. Since TPCV is closed throughout this test, the turbine and pump parameters are not significant and have been omitted from the figures.

\section{1 .6 Run 6}

The run-tank line, the pump, and the cooldown supply line will be chilled to $\mathrm{LH}_{2}$ temperatures. Initial run-tank pressure will be 60 psia and ETC pressure will be about 7.5 psia. V-5002 tank pressure will be set at 400 psia. The TPCV will remain closed throughout the test. Propellant flow to the engine system will be started by opening PDSV. When the reflector inlet fluid temperature reaches $200^{\circ} \mathrm{R}$ approximately $7 \mathrm{sec}$ after PDSV opens, PCV -472 will be stepped open to the mechanical limits established for the XE test (nomina1 30\%) and PDSV closed. PCV-472 will be held open for $10 \mathrm{sec}$ and the test then terminated by closing PCV-472. Predicted plots of major engine parameters as a function of test time are presented in Figures 4-13, 4-14 and 4-15. Since the TPCV is closed throughout the test, the turbine and pump parameters are not significant and have been omitted from the figures. The computer model indicates that the nozzle flow rate will be about $291 \mathrm{~b} / \mathrm{sec}$ upon opening of PCV-472 and the flow will increase to about $41 \mathrm{lb} / \mathrm{sec}$ at the time $\mathrm{PCV}-472$ is again closed due to reduction in engine flow impedance as the engine is chilled by the liquid hydrogen. The nozzle chamber fluid temperature will decrease to about $145^{\circ} \mathrm{R}$ at the time the test is terminated. 


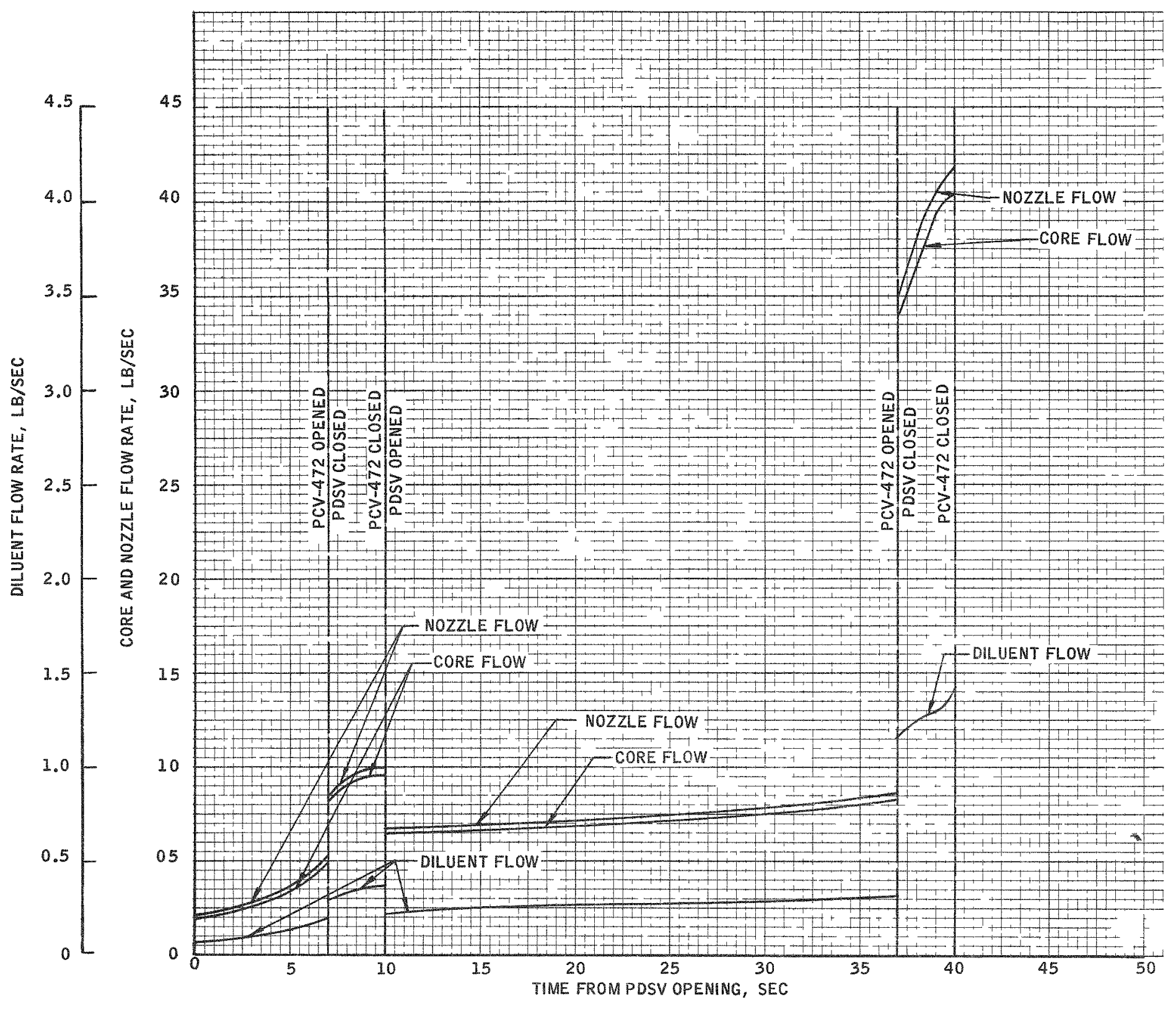

Figure 4-10 - XeCF Test Prediction, Phase I, Run 5, Chilled Pump, $\mathrm{P}_{\mathrm{T}}=60$ psia 


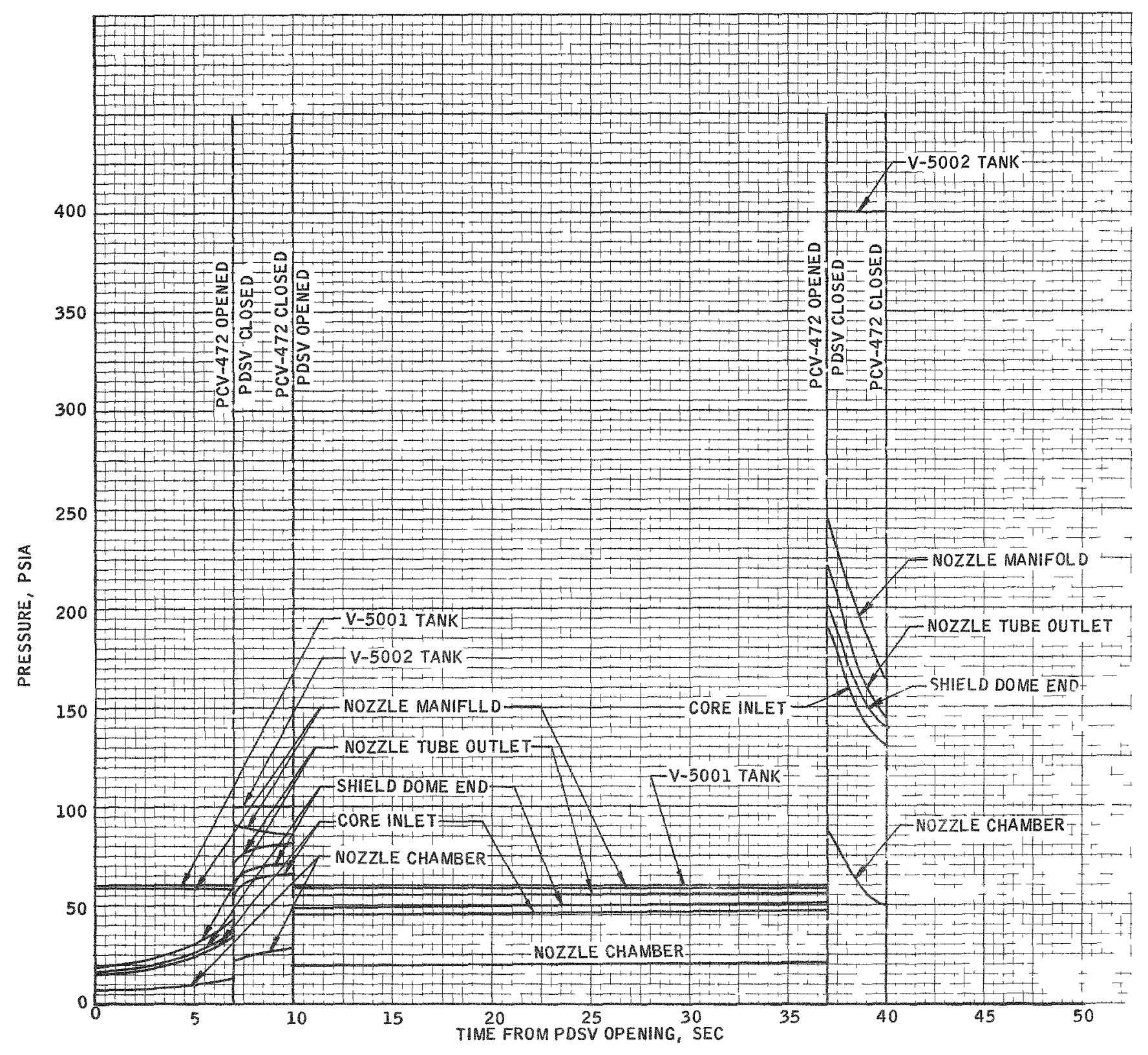

Figure 4-11-XECF Test Prediction, Phase I, Run 5, Chilled Pump, $P_{T}=60$ psia 


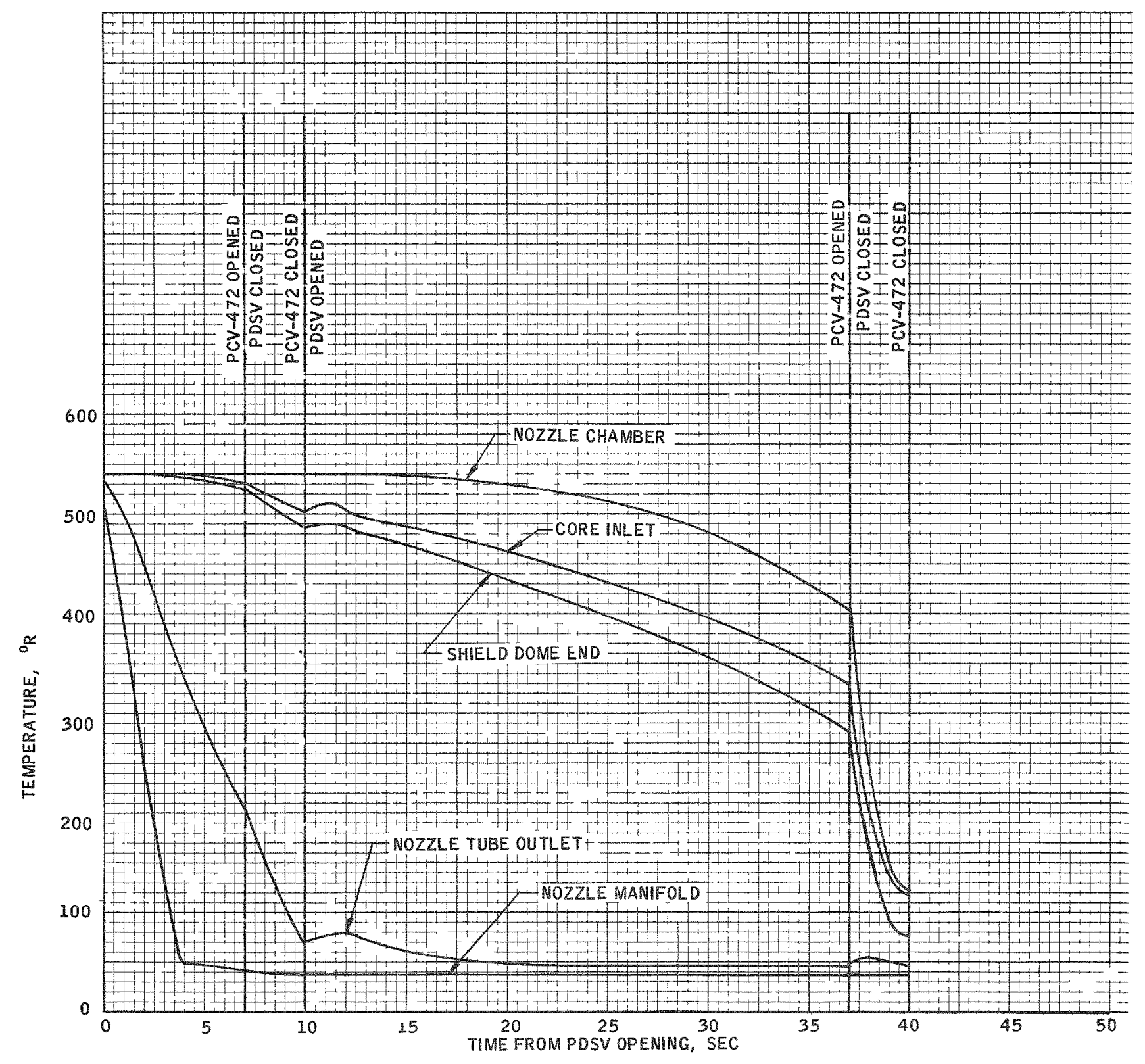

Figure 4-12 - XECF Test Prediction, Phase I, Run 5, Chilled Pump, $P_{T}=60$ psia 


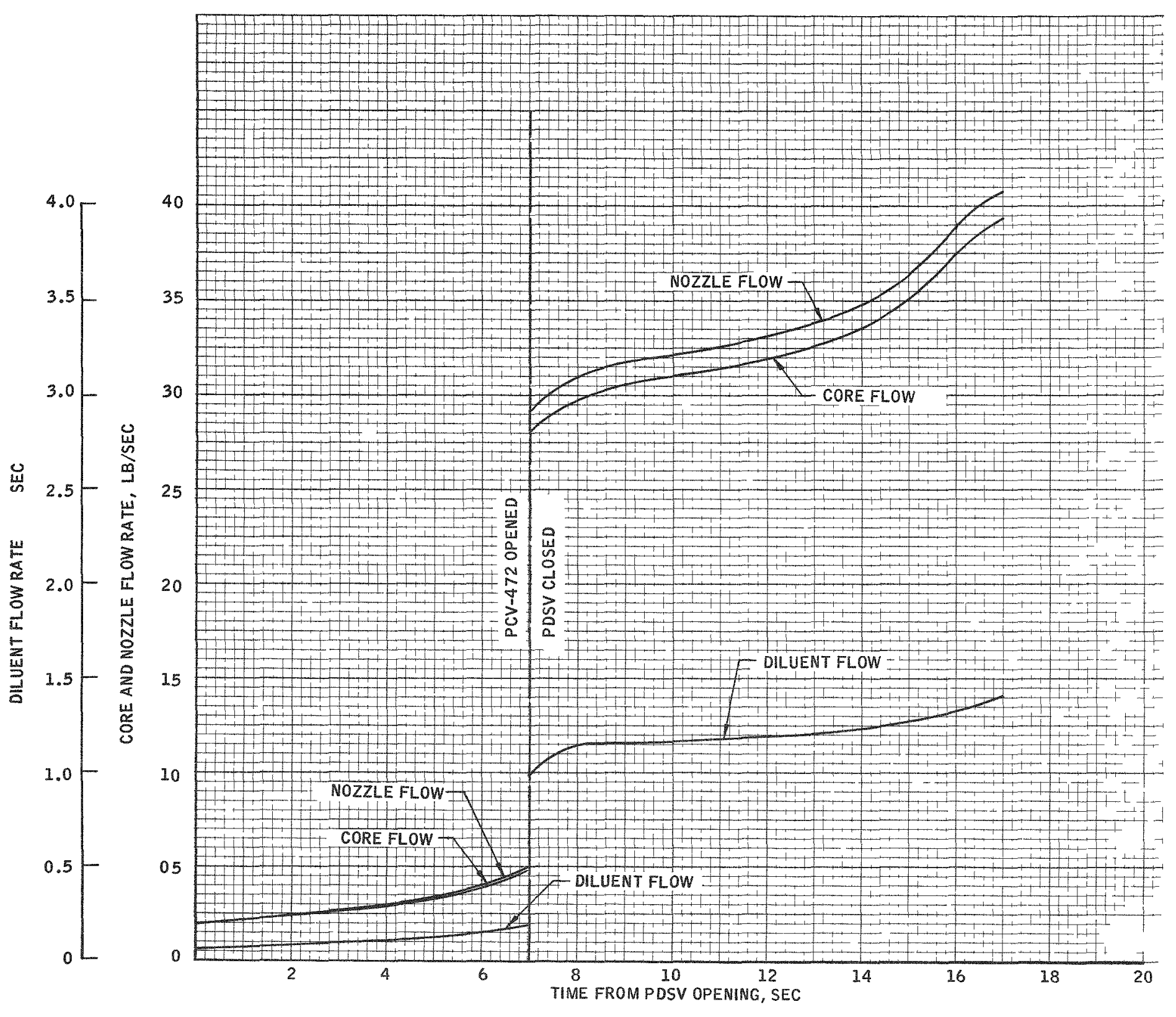

Figure 4-13 - XECF Test Prediction, Phase I, Run 6, Chilled Pump, $P_{T}=60$ ps:a 


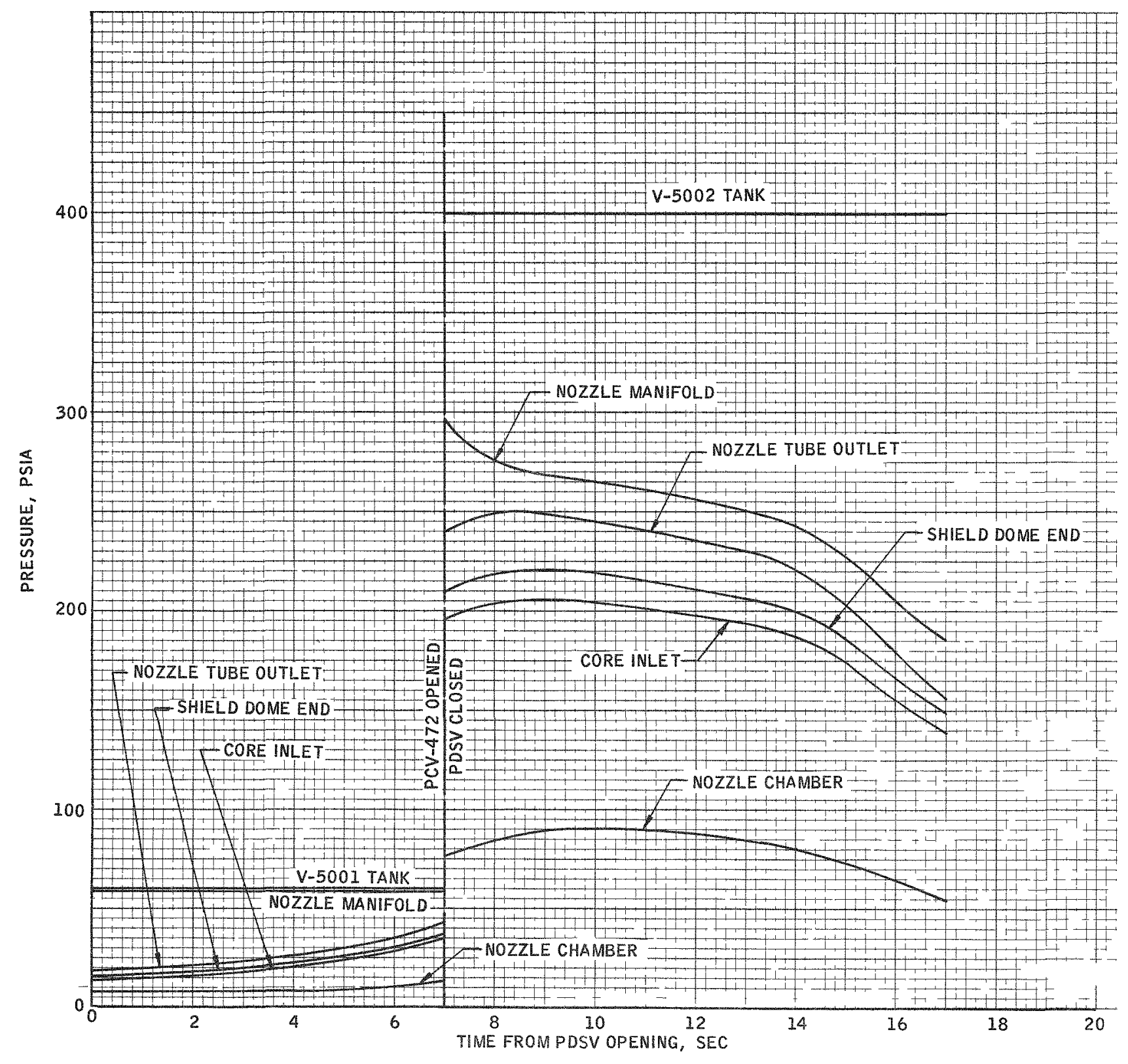

Figure 4-14 - XECF Test Prediction, Phase I, Run 6, Chilled Pump, $P_{T}=60$ psia 


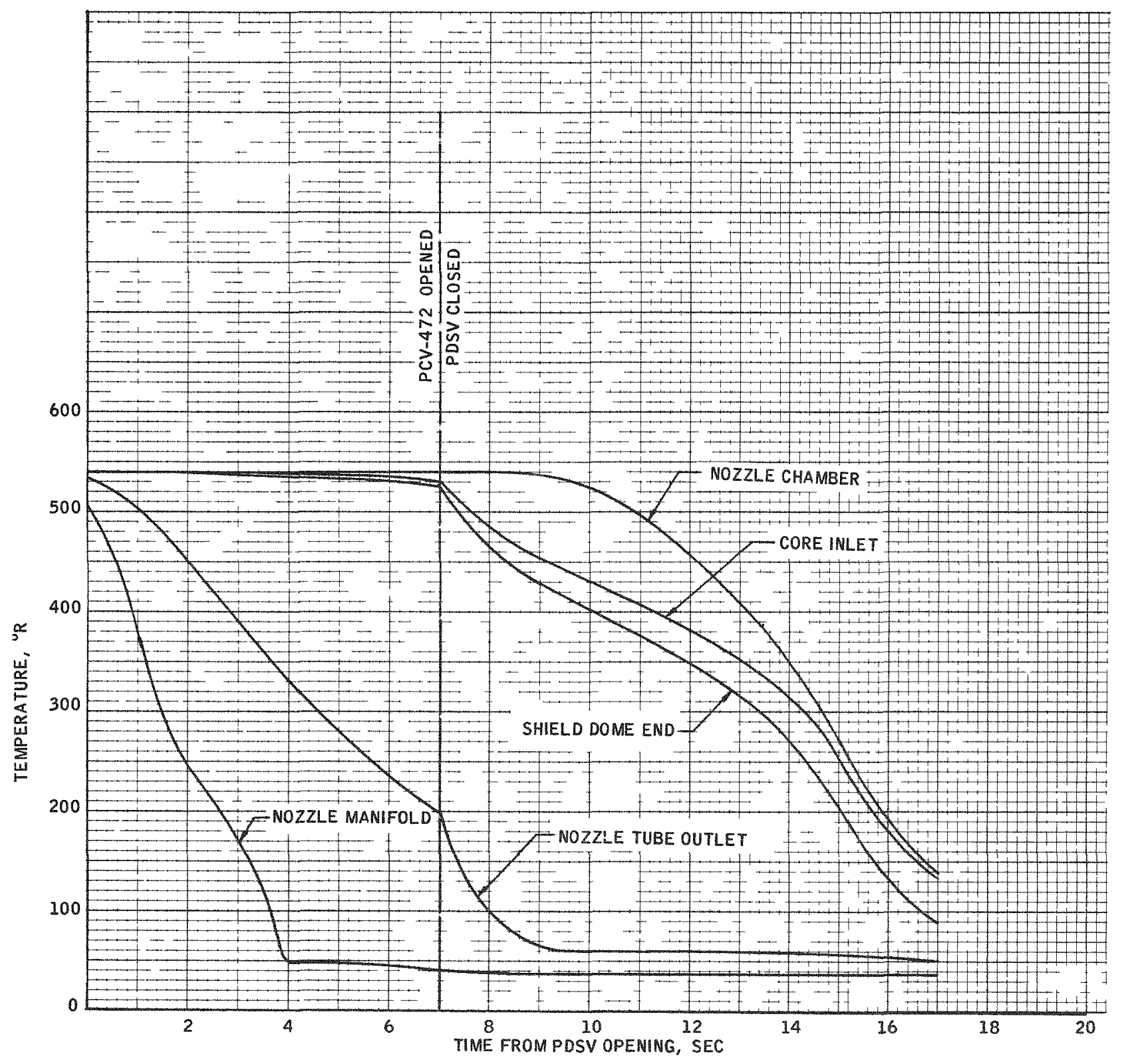

Figure 4-15 - XECF Test Prediction, Phase I, Run 6, Chilled Pump, $\mathrm{P}_{\mathrm{T}}=60$ psia 
BLANK 


\subsection{PHASE II - WARM-PUMP STARTUP TESTS}

Phase II tests will provide information for developing optimum warmpump startup procedures for $\mathrm{XE}-1$. They will verify the computer models for prediction of initial portions of $\mathrm{XE}-1$ startup and operation of the chamberpressure control 10op. A loss-of-flow malfunction will be simulated, providing data on facility and engine systems performance.

\section{2 .1 Run 1}

The run-tank line will be chilled until $\mathrm{LH}_{2}$ conditions exist at the PSV. Initial tank pressure will be set at 35 psia. Before flow is initiated, the reactor temperature (as indicated by reactor-core temperature measurements) will be 500 to $560^{\circ} \mathrm{R}$ and the engine-test-compartment pressure will be 7.5 psia. The test will be initiated by opening the PSV and will be terminated when any test-parameter limit is reached or when the chamber temperature reaches $200^{\circ} \mathrm{R}$. The temperature of the nozzle-tube outlet fluid will decrease to $200^{\circ} \mathrm{R}$ approximately $23 \mathrm{sec}$ after initial opening of the PSV, at which time the pressure-control loop will be closed and a chamber pressure of 60 psia will be demanded. Closing of the pressure-control 10op will initiate opening of the TPCV and allow $\mathrm{GH}_{2}$ to flow to the turbine. Predicted plots of major engine parameters as functions of test time are presented in Figures 4-16, 4-17, and 4-18. Figure 4-16 shows that the maximum predicted pump speed of $7780 \mathrm{rpm}$ is achieved $67 \mathrm{sec}$ after initiation of the test. The peak bootstrap conditions agree well with the results obtained from CFDTS Test No. 1.2-02-NNS-019, which was conducted under similar conditions. The test data indicated that a maximum pump speed of $7850 \mathrm{rpm}$ occurred $64.3 \mathrm{sec}$ after test initiation. The only pronounced difference between the performance predicted for Run 1 of XECF Phase II, and CFDTS Test No. -019 is that the computer mode1 predicts a very slow increase in pump speed between the time of TPCV opening and $62 \mathrm{sec}$, followed by an abrupt bootstrap to the peak values. Examination of data from CFDTS Test No. -019 showed a greater pump acceleration before the 


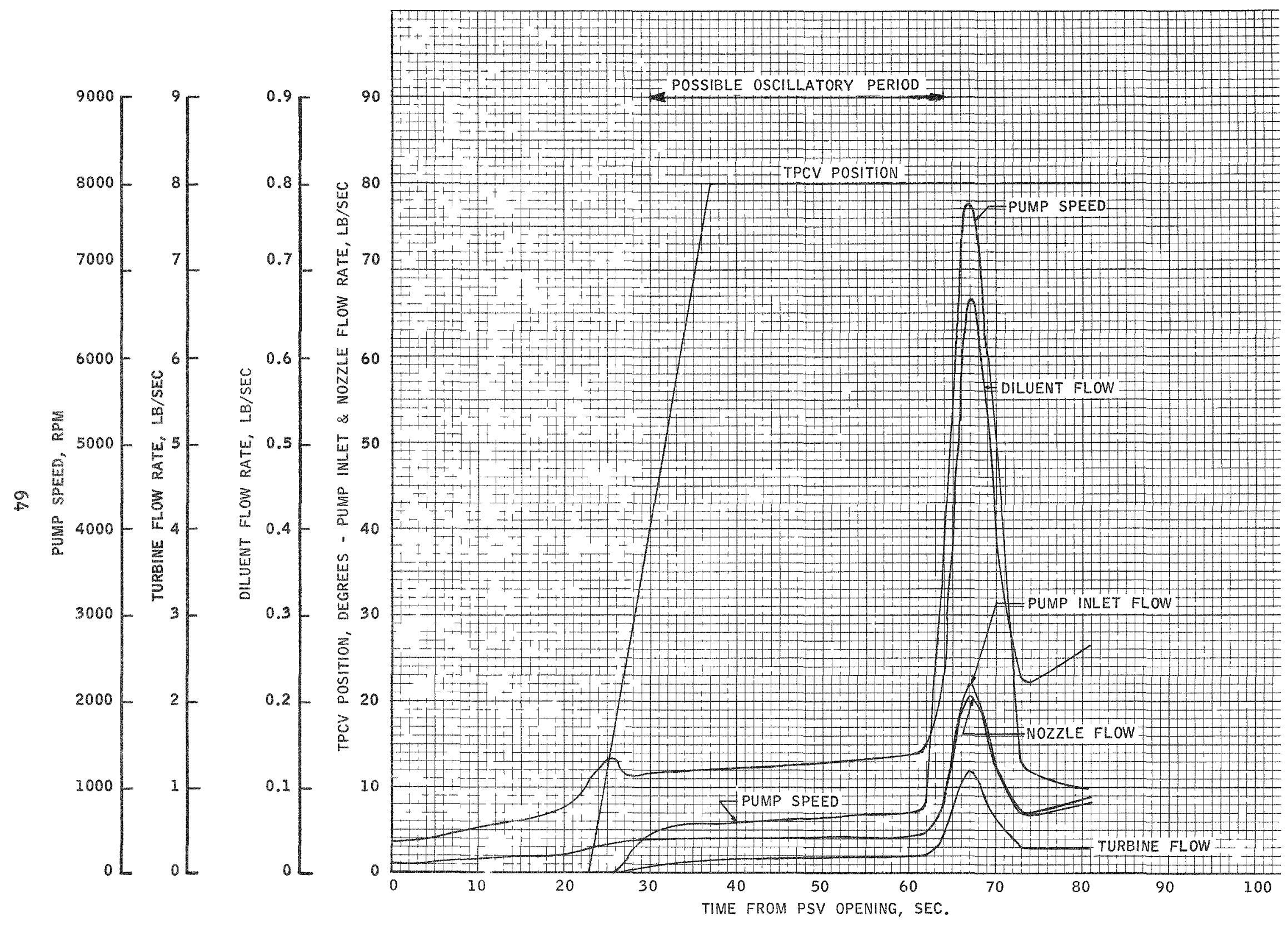

Figure 4-16 - XECF Test Prediction, Phase II, Run 1, Dry Pump, $P_{T}=35$ psia 


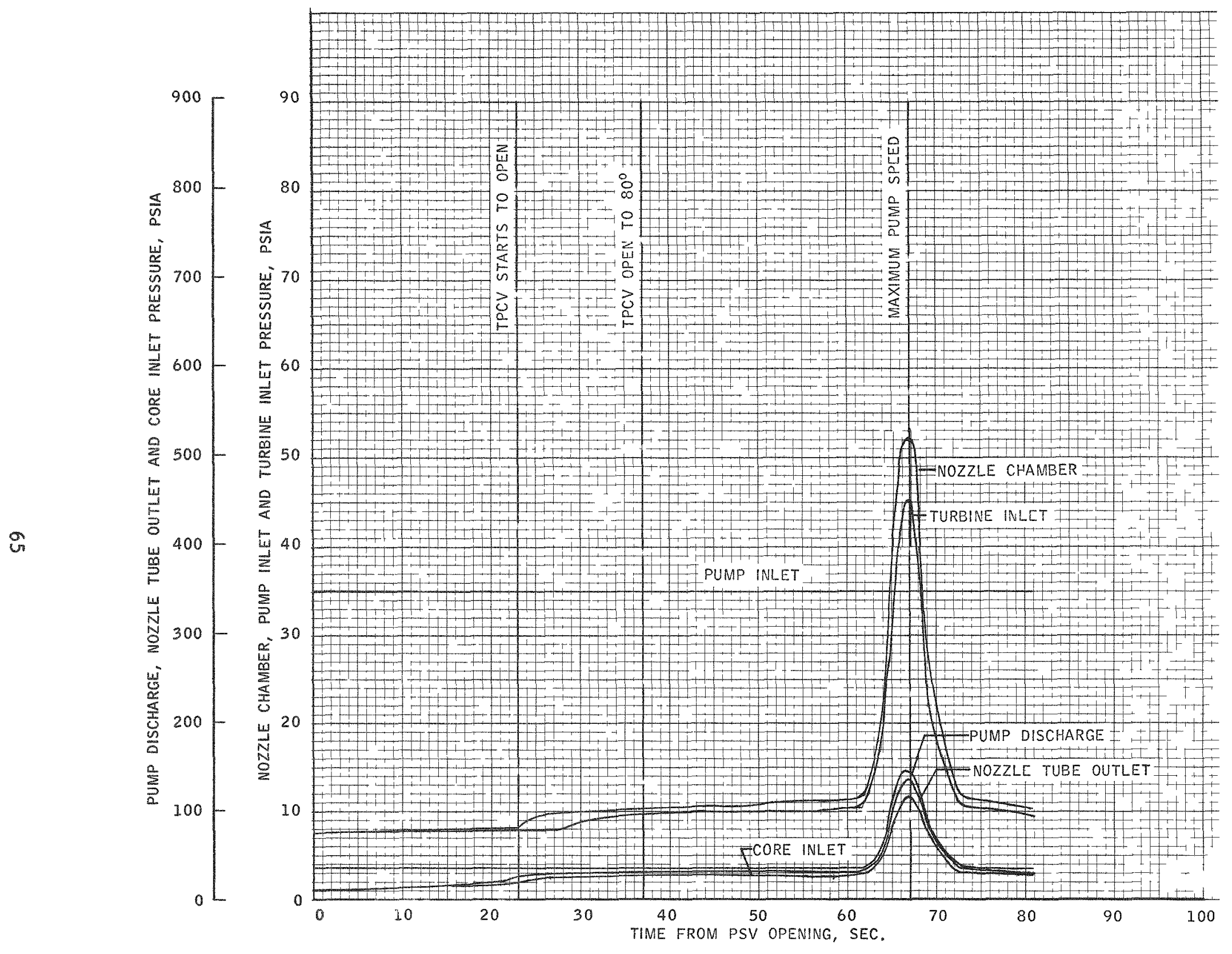

Figure 4-17 - XECF Test Prediction, Phase II, Run 1, Dry Pump, $\mathrm{P}_{\mathrm{T}}=35$ psia 


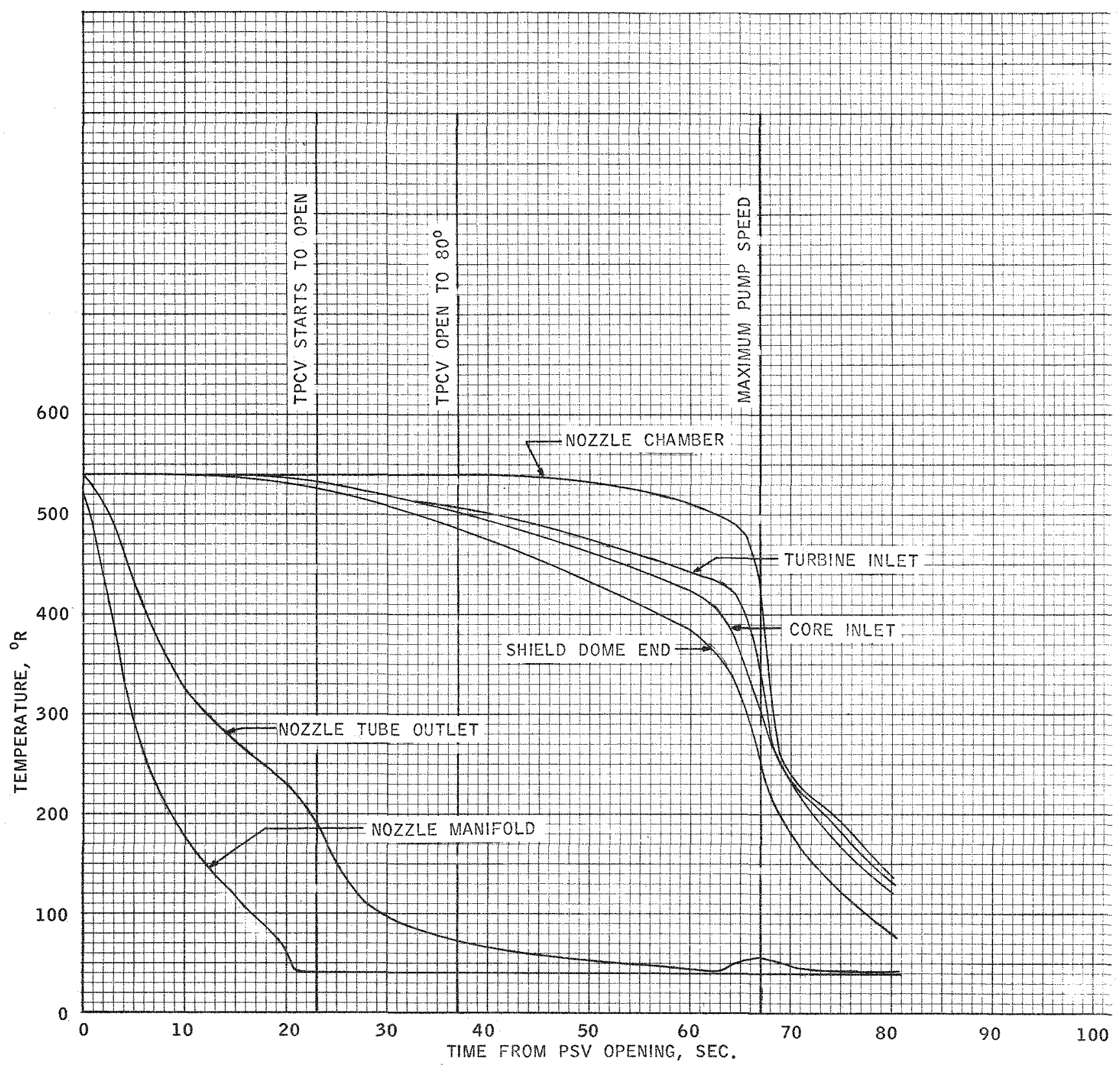

Figure 4-18 - XECF Test Prediction, Phase II, Run 1, Dry Pump, $P_{T}=35$ psia 
start of bootstrap, with low-frequency increasing-amplitude oscillations in pump speed and system pressures between the time the TPCV opened and the time at which the pump speed exceeded $4000 \mathrm{rpm}$. The oscillation in pump speed reached a maximum peak-to-peak amplitude of $2000 \mathrm{rpm}$. These oscillations (apparently due to two-phase flow in the turbopump) are not predictable with the present computer model.

The delay in opening of the TPCV until the nozzle-tube outlet-fluid temperature reaches $200^{\circ} \mathrm{R}$ is intended to eliminate this type of oscillation by providing sufficient cooling of the TPA to obtain pure liquid flow; however, the extent of cooling required is not precisely known, and some oscillations may occur. If pump speed oscillates, a lower nozzle-tube outletfluid temperature may be used during the next test as the point for opening the TPCV. Through this procedure, this test phase will be used to establish the point at which the TPCV can be opened and a smooth-pump-speed engine start can be obtained.

\section{2 .2 Run 2}

A warm-pump test will be performed to establish the interactions between the normal $\mathrm{LH}_{2}$ propellant line and high-pressure $\mathrm{LH}_{2}$ from the cooldown line during emergency shutdown and to establish the nozzle-tube outlet-fluid temperature at which the TPCV can be opened without incurring pump-speed and system-flow oscillations. For this test the run-tank propellant line and the cooldown supply line will be chilled to $\mathrm{LH}_{2}$ temperatures. The initial tank pressure will be set at 35 psia, and the ETC pressure will be 7.5 psia at test start. The TPCV will be in position control.

V-5002 pressure will be set at 100 psia and the cooldown line between PCV-472 and CSV maintained below 50 psia.

The test will be initiated by opening the PSV. When the nozzle-tube outlet remperature reaches $100^{\circ} \mathrm{R}$ approximately $29 \mathrm{sec}$ after opening of the PSV, the TPCV will be stepped to a fixed position of $80^{\circ}$. The pump 
discharge pressure will reach 50 psia approximately $63 \mathrm{sec}$ after initiation of the test at which time CSV will be opened. Pump discharge pressure will continue to increase until a value of about 100 psia is reached 65.1 sec after initiation of the test, at which time TPCV will be stepped closed to simulate loss of flow. The TPCV will close in approximately $0.25 \mathrm{sec}$ stopping the flow of $\mathrm{GH}_{2}$ to the turbine. The turbopump will decelerate and the pump discharge pressure will decay rapidly, reaching 50 psia approximately $0.7 \mathrm{sec}$ after TPCV starts to close.

The flow fallure detection system will detect the rapid decay of pump discharge pressure and initiate an emergency shutdown opening PCV-472 to initiate flow of facility $\mathrm{LH}_{2}$ from $\mathrm{V}-5002$ to the engine system. PCV-472 will be controlled to a demanded nozzle inlet pressure of 50 psia. The 50 psia supply pressure of emergency-cooldown $\mathrm{LH}_{2}$ will sustain about $6.6 \mathrm{lb} / \mathrm{sec}$ of $\mathrm{LH}_{2}$ flow through the engine at the start of this phase of the test, which will further cool the engine components and cause the flow to increase to about $10 \mathrm{lb} / \mathrm{sec}$ after $15 \mathrm{sec}$. About $81 \mathrm{sec}$ after initiation of the test, ambient $\mathrm{GH}_{2}$ flow to the engine system will be established at a nozzle torus inlet pressure of 100 psia. Predicted plots of engine parameters for this test are shown in Figures 4-19, 4-20 and 4-21. No prediction was made of the system characteristics during the ambient facility $\mathrm{GH}_{2}$ flow phase of the test for reasons explained in Section 4.1.4, Run 4 of this report.

\section{$4.2 .3 \operatorname{Run} 3$}

This test will be performed at minimum demanded chamber pressure to observe the controlling action of the TPCV. The run-tank line will be chilled to the PSV. Initial tank pressure will be set at 60 psia. Prior to initiation of flow, the reactor temperature (as indicated by reactor core temperature measurements) will be 500 to $560^{\circ} \mathrm{R}$ and the engine-testcompartment pressure will be 7.5 psia. The test will be initiated by opening the PSV. The nozzle-tube outlet-fluid temperature will reach $200^{\circ} \mathrm{R}$ approximately $12 \mathrm{sec}$ after opening of the PSV, at which time the pressure-control 


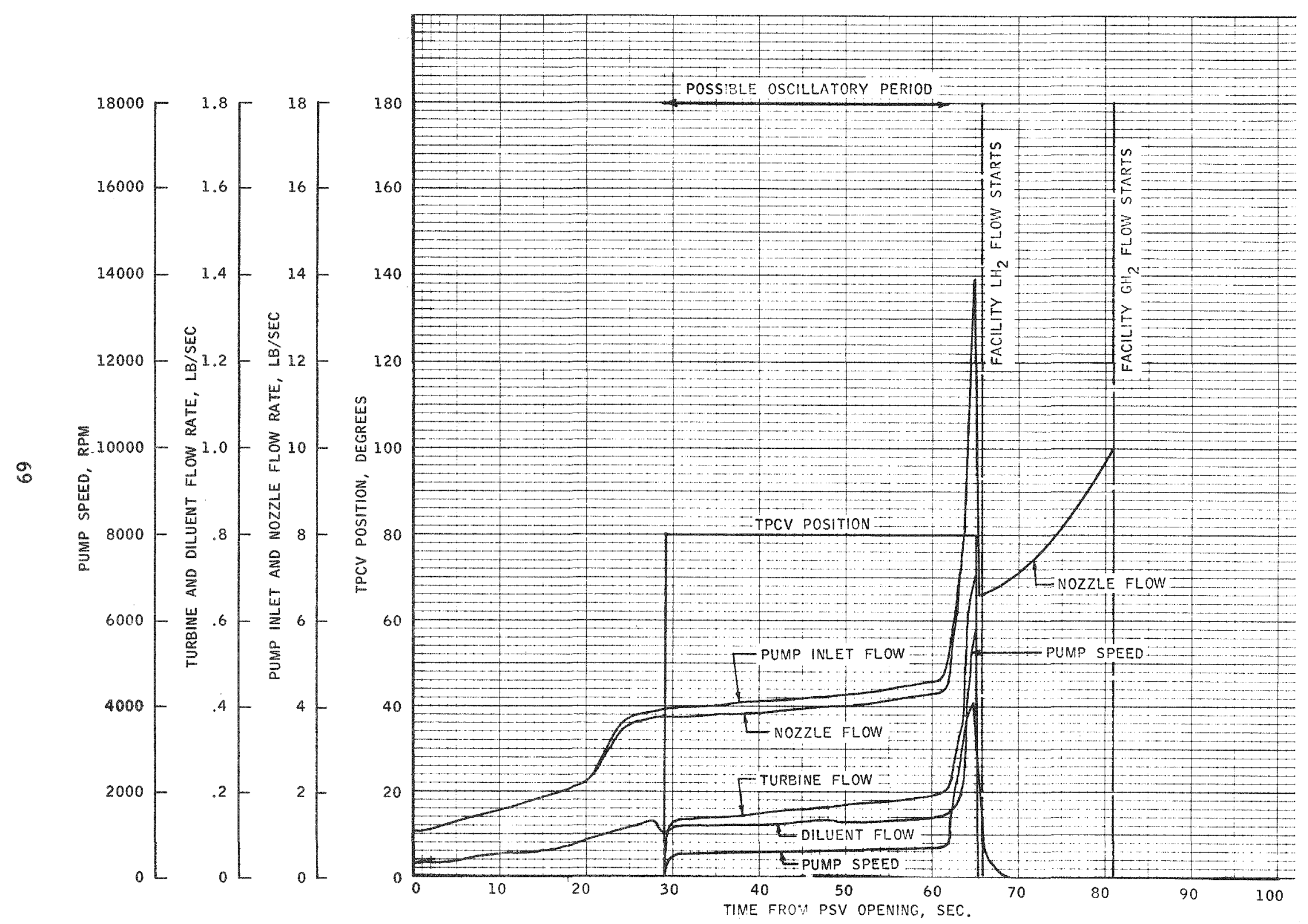

Figure 4-19-XECF Test Prediction, Phase II, Run 2, Dry Pump, $P_{T}=35$ psia 


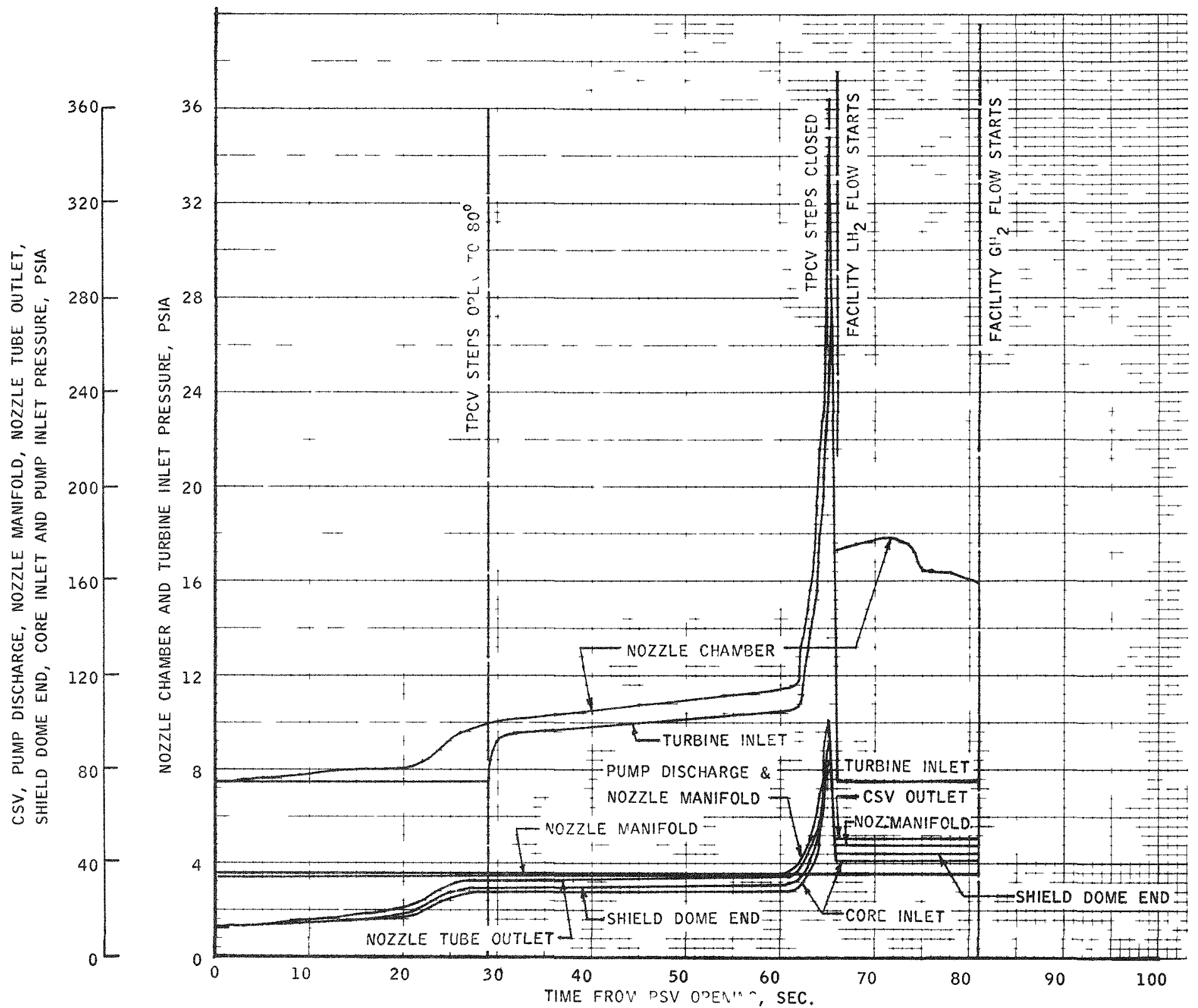

Figure 4-20-XECF Test Prediction, Phase II, Run 2, Dry Pump, $P_{T}=35$ psia 


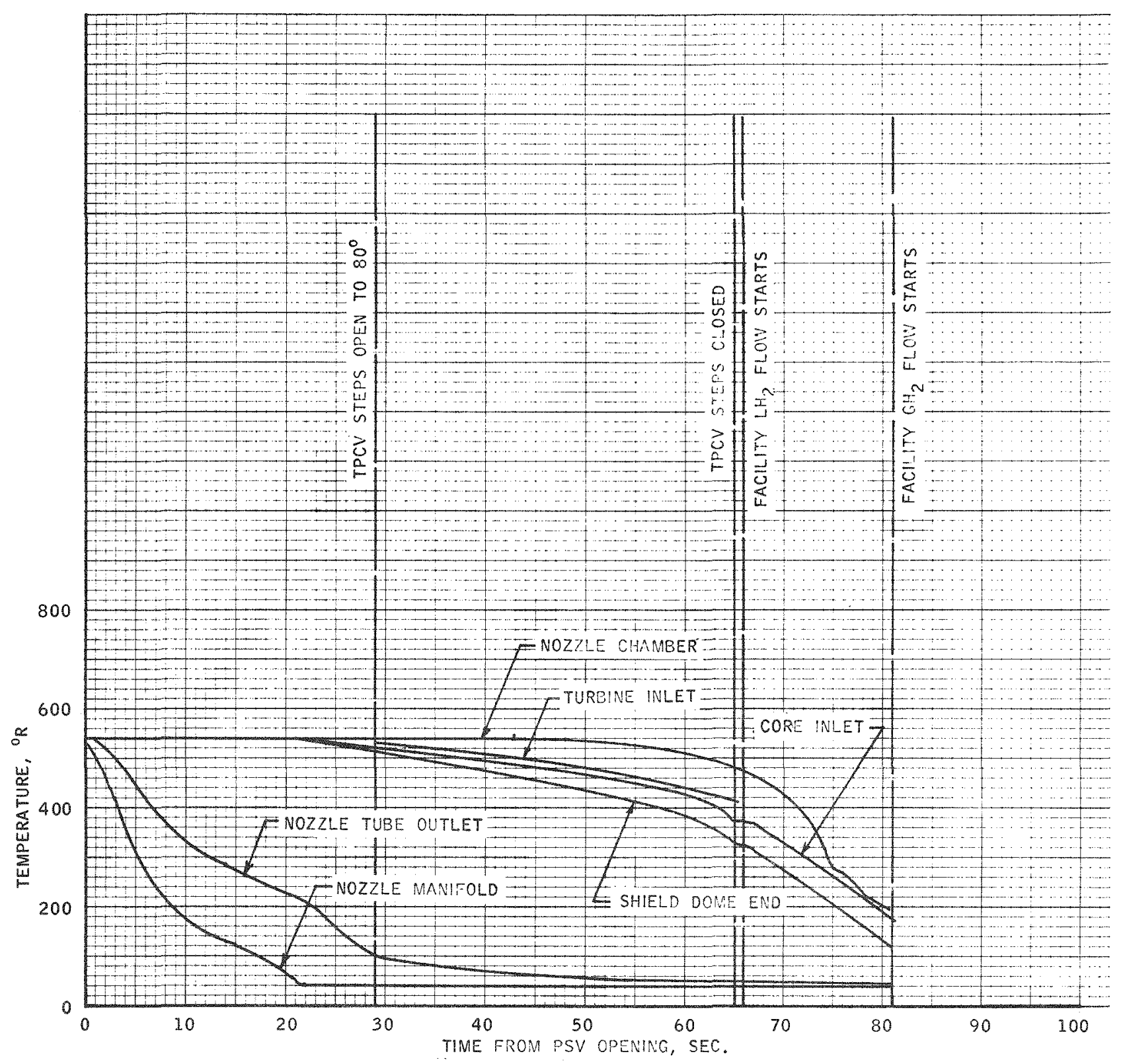

Figure 4-21 - XECF Test Prediction, Phase II, Run 2, Dry Pump, $P_{T}=35$ psia 
loop will be closed and a chamber pressure of 35 psia will be demanded. Because of the low demand pressure, the TPCV opens slowly, and flow of $\mathrm{GH}_{2}$ to the turbine is insignificant until $19 \mathrm{sec}$. Plots of engine parameters predicted by the computer model for this test are shown in Figures 4-22, 4-23, and 4-24. As stated previously, the computer model is not capable of accounting for two-phase flow performance of the turbopump. The model must treat the pump flow as though it were all gas or all liquid. For the test conditions specified for this test, the computer treats the pump flow as gas for the first $29 \mathrm{sec}$. Under these conditions, it is assumed that no work is done by the pump; therefore, the pump accelerates rapidly to a speed of $6275 \mathrm{rpm}$ at $29 \mathrm{sec}$. After $29 \mathrm{sec}$, the computer model treats the pump flow as all liquid. This treatment results in a sudden peak in system pressures and flow at 30 sec because the inertia accumulated by the pump is now converted into pump work, with a corresponding pump deceleration. Examination of data from CFDTS Test No. 1.2-02-NNS-030, which was a warm-pump startup at 69.4-psia tank pressure, indicates that the peak in pump speed, system pressures, and flow predicted at about $30 \mathrm{sec}$ probably will not occur during an actual test. Instead, a twophase flow condition may occur in the pump during the time period from 19 to $30 \mathrm{sec}$, which can result in oscillations in pump speed, system pressures, and flows. After about $31 \mathrm{sec}$, the pump flow should become fully liquid and the remainder of the computer-model test prediction should be a reasonable representation of the system characteristics. 


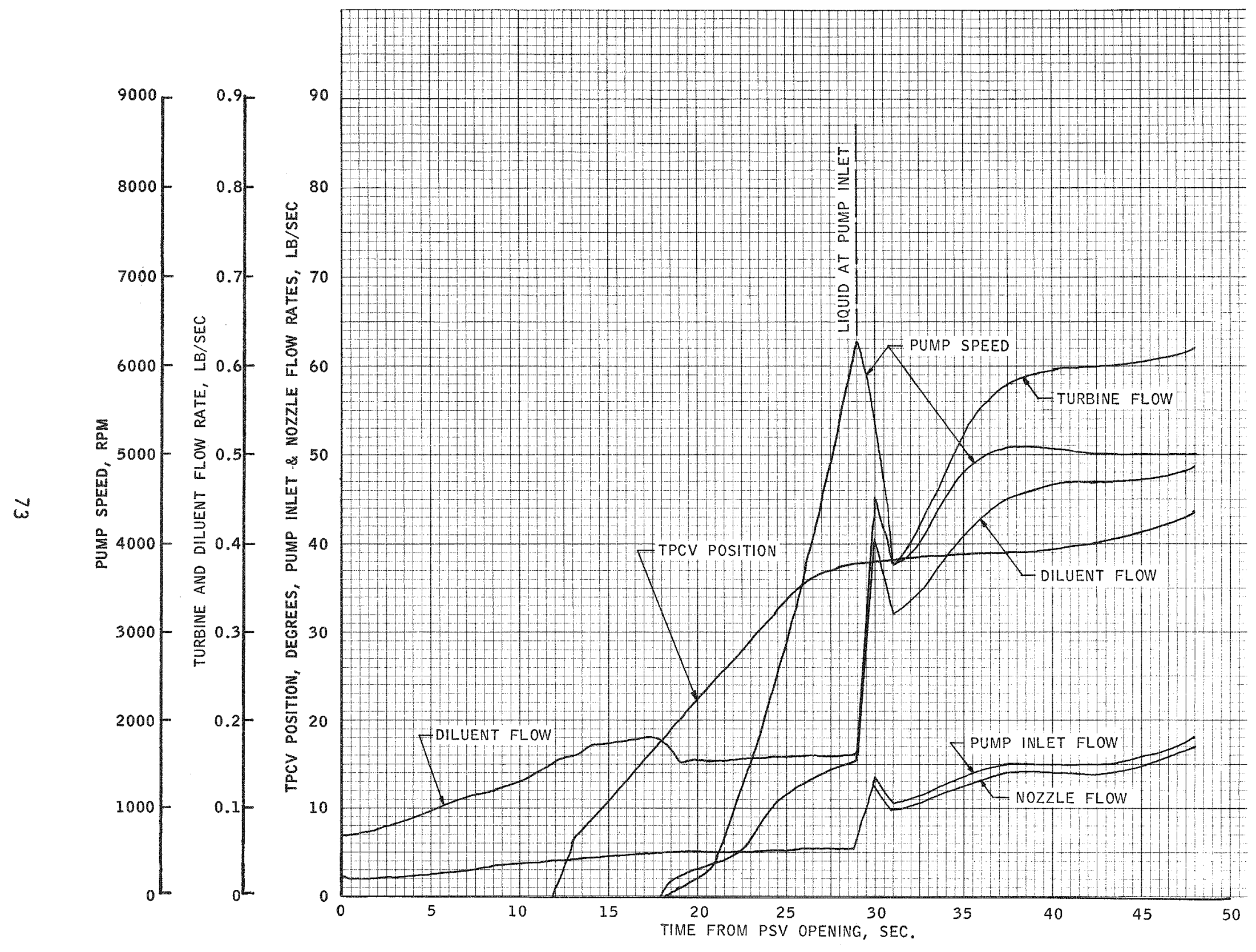

Figure 4-22 - XECF Test Prediction, Phase II, Run 3, Dry Pump, $P_{T}=60$ psia 


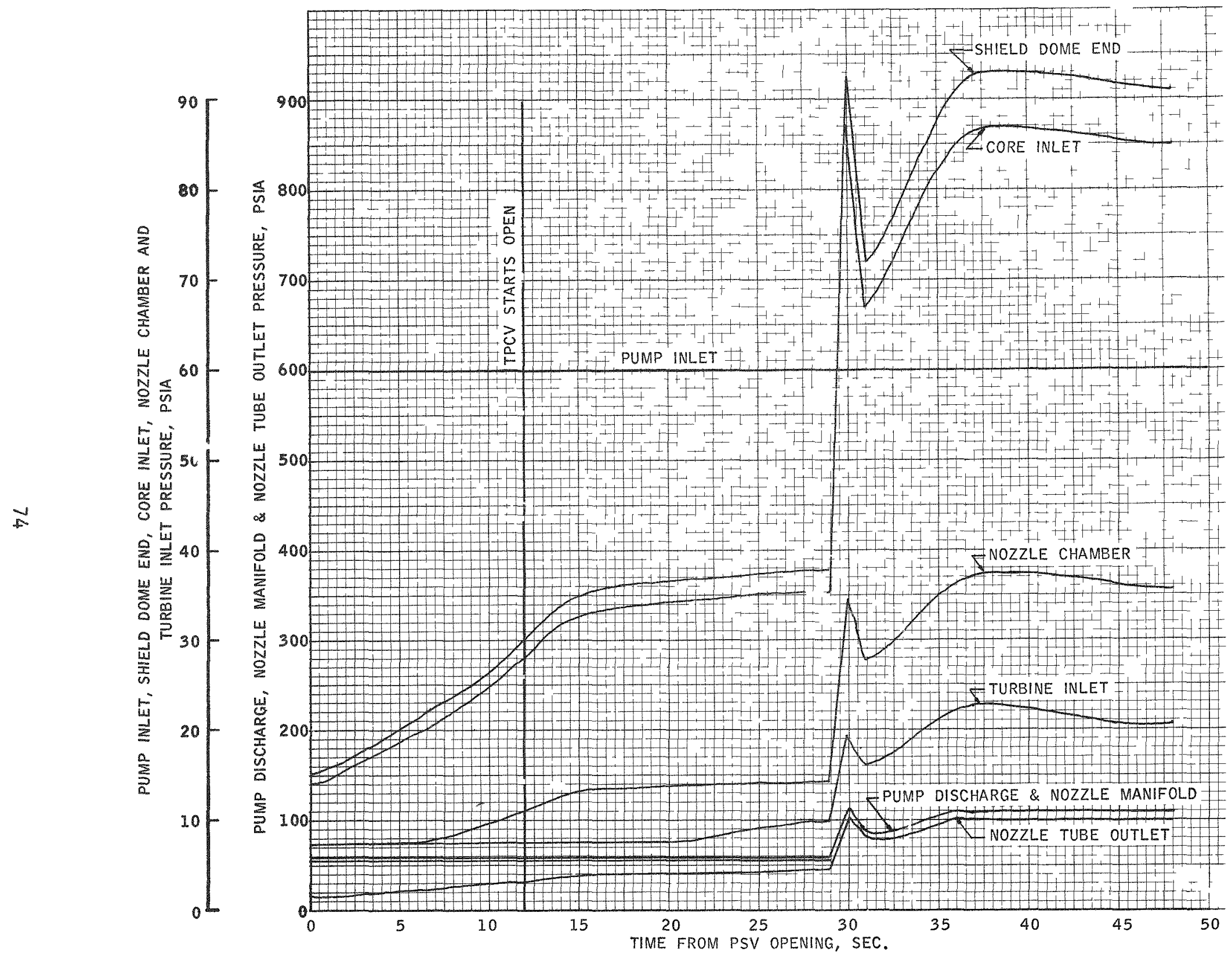

Figure 4-23 - XECF Test Prediction, Phase II, Run 3, Dry Pump, $P_{T}=60$ psia 


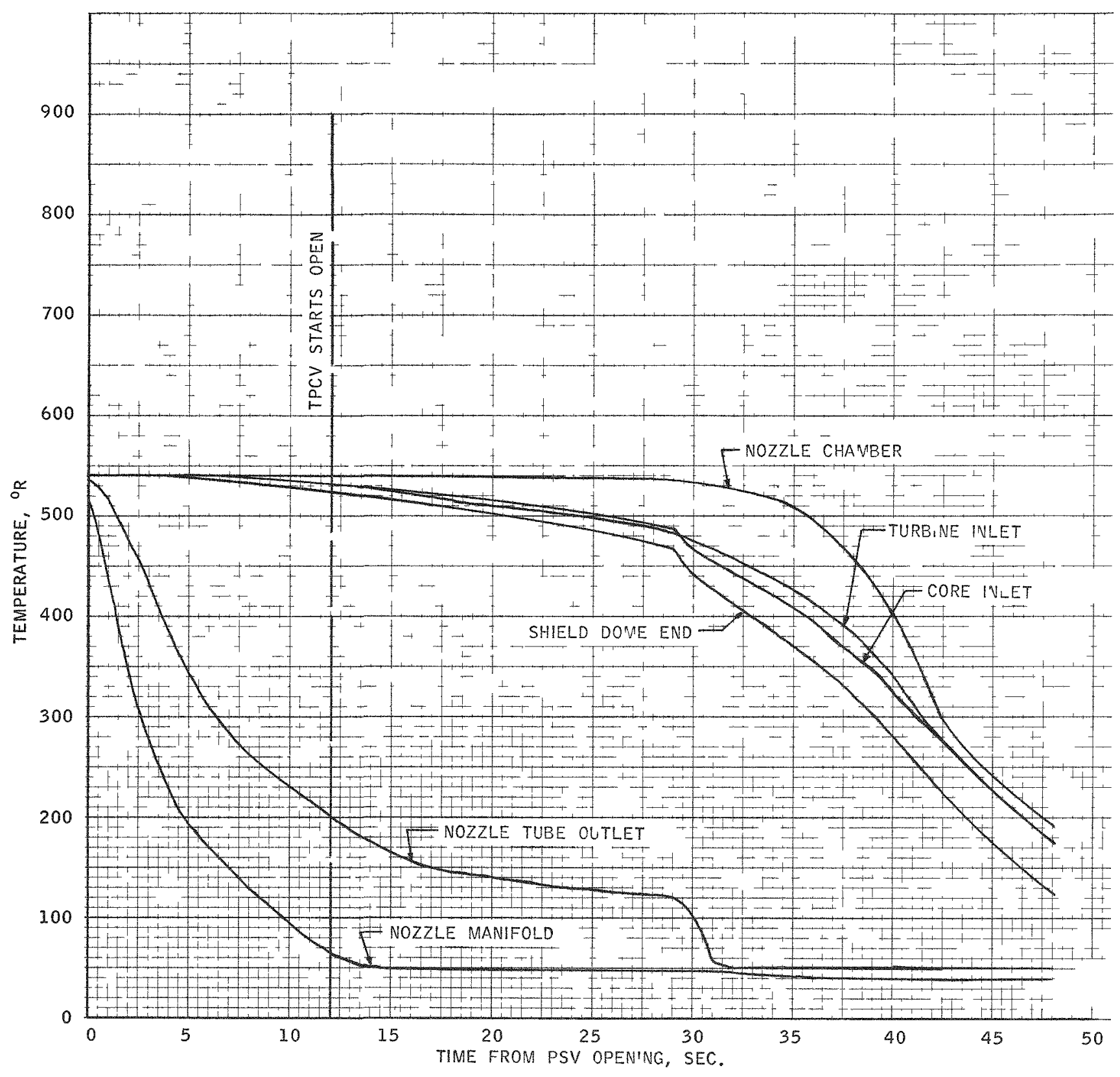

Figure 4-24 - XECF Test Prediction, Phase II, Run 3, Dry Pump, $P_{T}=60$ psia 


\section{BLANK}




\subsection{PHASE III - CONDITIONAL TESTS}

Tests specified in this section are those tests designated to be performed if additional runs are required for operator training.

\section{3 .1 Run 1}

This test will be a repeat of Run 1 of Phase II except that the initial tank pressure will be set at 25 psia, a chamber pressure of 50 psia will be demanded, and the nozzle-tube outlet-fluid temperature upon opening of the TPCV will be based on the temperature at which a smooth pump-speed start transient was obtained during Phase II, Runs 1 and 2.

The problems associated with predicting engine starts at low tank pressure, which were discussed in Section 4.1.2, are equally applicable to this test. The system characteristics for this test can probably be best defined by examining the data from Phase $I$, Run 2, except that a longer time will be required for the nozzle-tube outlet-fluid temperature to reach a prescribed value. The computer model indicated that the nozzle-tube outletfluid temperature would reach $200^{\circ} \mathrm{R}$ approximately $42 \mathrm{sec}$ after initial opening of the PSV.

\section{3 .2 Run 2}

Initial tank pressure will be set at 35 psia. The run-tank line will be chilled until $\mathrm{LH}_{2}$ temperatures exist at the PSV. Before flow is initiated, the reactor temperature, as indicated by reactor core temperature measurements, will be 500 to $560^{\circ} \mathrm{R}$, and the engine-test-compartment pressure will be 7.5 psia. The test will be initiated by opening the PSV. The nozzletube outlet-fluid temperature will decrease to $200^{\circ} \mathrm{R}$ approximately 23 sec after initial opening of the PSV, at which time the TPCV will be stepped from a closed position to a fixed position of $39.5^{\circ}$. Plots of the predicted engine 
characteristics as functions of test time are shown in Figures 4-25, 4-26, and 4-27. The system characteristics during the first $64 \mathrm{sec}$ of this test are quite similar to those of Phase II, Run 1, and the same comments are applicable. At about $64 \mathrm{sec}$, bootstrap of the engine occurs; but, because of the high impedance of the partially opened TPCV in the turbine feed line, a maximum pump speed of $1380 \mathrm{rpm}$ occurs at $66 \mathrm{sec}$, after which pump speed decays very gradually. System pressures will follow the pump speed characteristics, with the pump discharge pressure reaching a maximum value of 39 psia at the time of maximum pump speed. Flow rates will increase through the test because of a reduction in engine flow impedance as the engine is chilled by the liquid hydrogen. The nozzle-chamber fluid temperature should reach $200^{\circ} \mathrm{R}$ about 87 sec after opening of the PDSV, at which time the test will be terminated. 


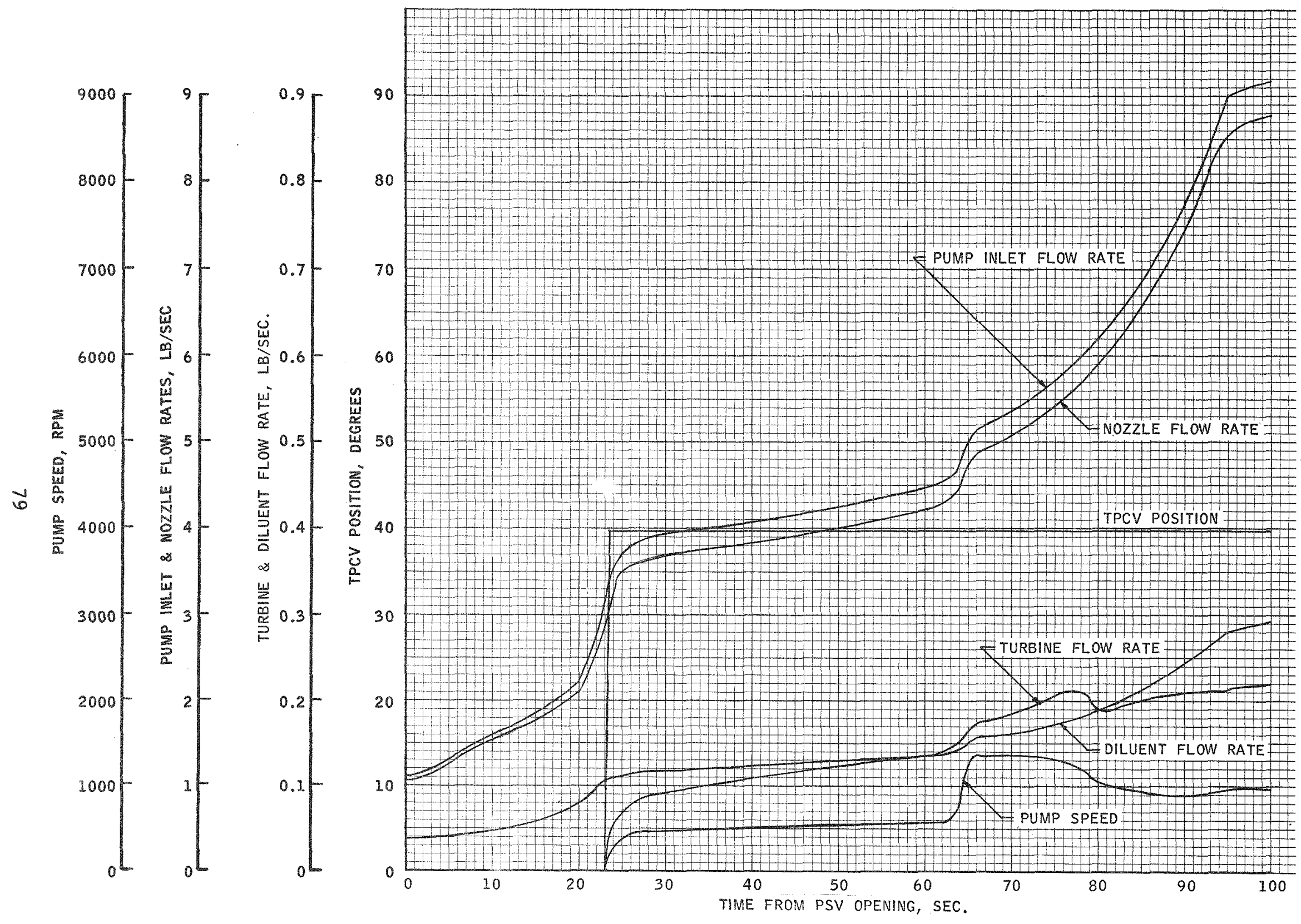

Figure 4-25 - XECF Test Prediction, Phase III, Run 2, Dry Pump, $P_{T}=35$ psia 


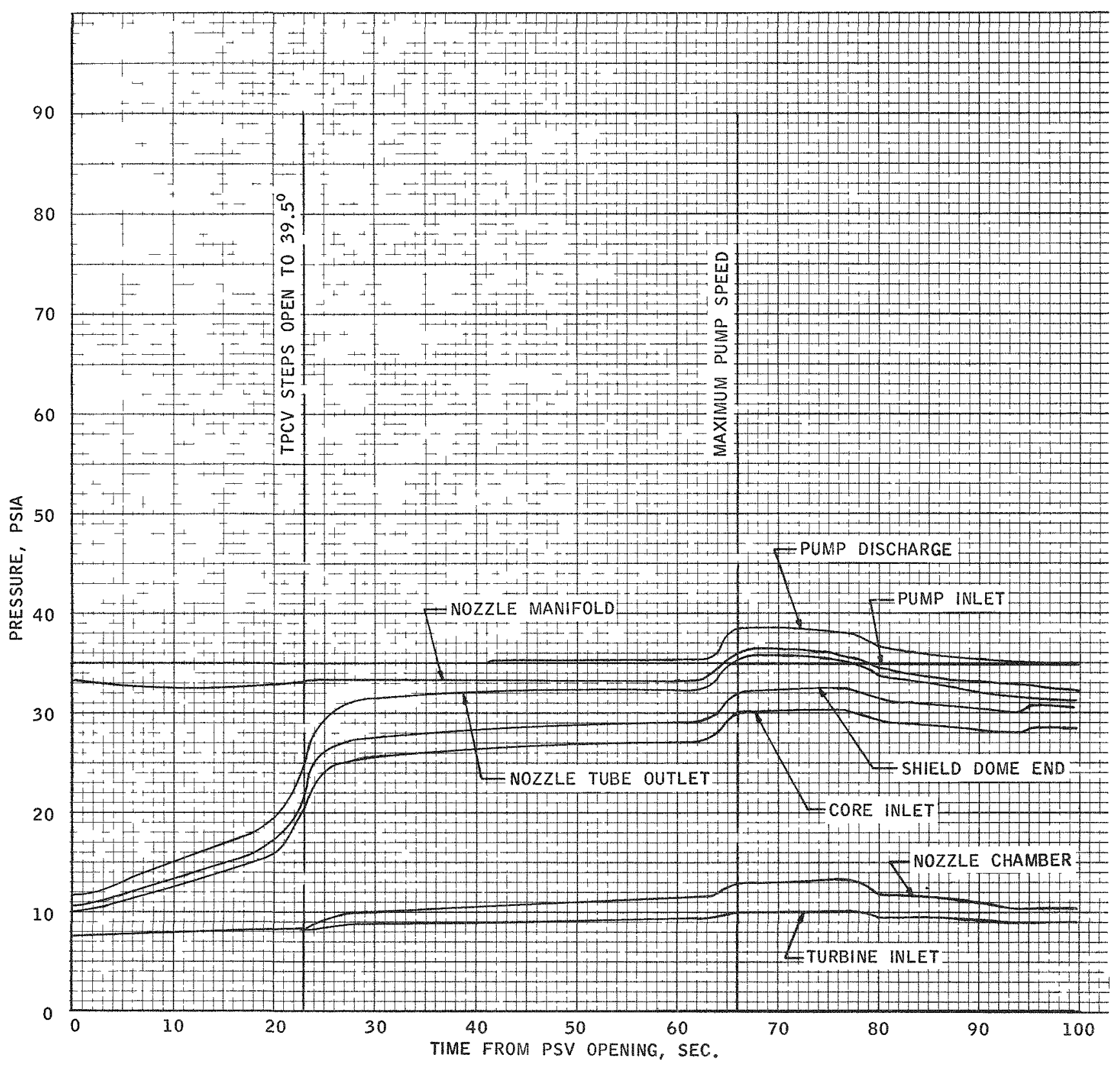

Figure 4-26 - XECF Test Prediction, Phase III, Run 2, Dry Pump, $P_{T}=35$ psia 


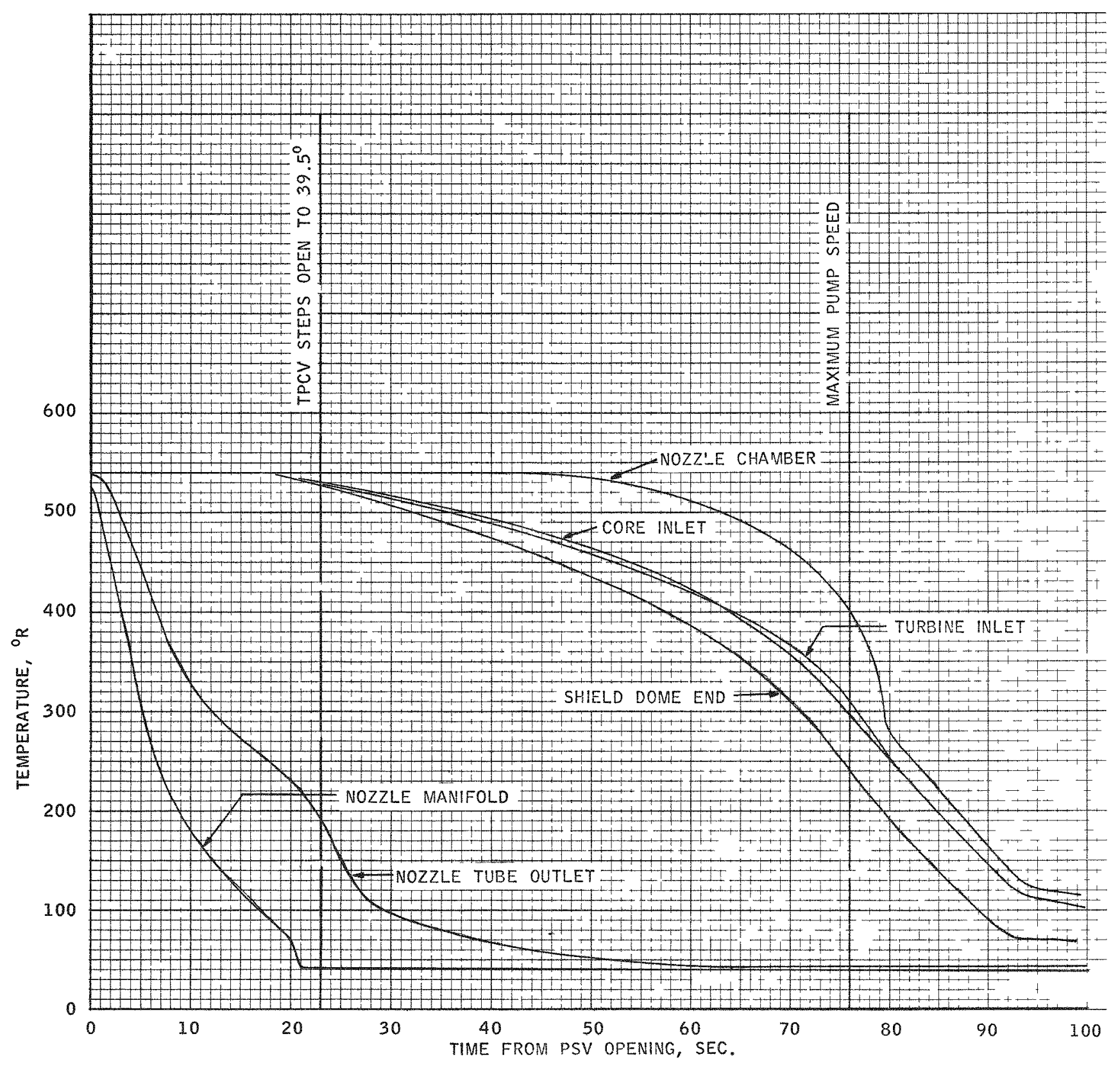

Figure 4-27 - XECF Test Prediction, Phase III, Run 2, Dry Pump, $P_{T}=35$ psia 
BLANK 


\subsection{PHASE IV - VIBRATION TESTS}

The purpose of the XECF vibration tests is to conduct a resonance survey of the XECF test article and the attached ETS-1 structure as a combined system. The results of these tests will determine what resonances, modal deflections, and amplification factors will be generated in the test stand and what response the XE-1 will have to its vibration environment.

A detailed analysis of the results expected from this test is presented in AGC Report RN-TM-0437, XE Engine Dynamic Modal Analysis, May 1966. 
BLANK 


\subsection{INSTRUMENTATION}

\subsection{DISCUSSION}

This section contains a brief description of the DAS and detailed drawings of transducers mounted on the nonnuclear engine components.

\subsubsection{Data-Acquisition System}

The ETS -1 DAS has the function of conditioning and recording engine and facility test information during testing. The DAS accepts an electrical signal from various transducers within the ETS-1 complex, conditions these signals for analog or digital recording, and stores the recorded data on magnetic tape. Data signals in the ETS-1 complex come from three major sources: engine diagnostic transducers, facility control systems, and the TSCS. There are about 1500 data channels from these sources.

The DAS comprises the following subsystems:
a. Diagnostic Signal Conditioning
b. Digital Data System
c. Analog Recording System
d. Events Recording System
e. Patching Systems
f. Digital Data Processer

The equipment is located in three major areas: the test-cell building, the forward control room, and the control-point building. The testcell building contains the diagnostic signal conditioners and the signalcondition output patch. The forward control room contains data patch channels, amplifiers, filters, multiplexers, and analog-to-digital conversion equipment for the digital data system. The recorder room in the control-point building 
contains the data formation and control logic for the digital data system, the analog recording system, and the analog record patch. The recorder room of the control point also contains the digital data system, the master control console, and the digital-tape transports.

A variety of facilities for processing and displaying data will be available on the site for ETS-1 tests. The following is a brief description of these systems and lists the primary end use for each.

\subsubsection{Strip Charts}

On-line strip charts will be used primarily to monitor "red-lined" parameters during test operations. These strip charts will also be used for quick-look evaluation of major test parameters immediately after a test is completed and for determining the time period of events of particular interest in order to establish the requirements for special data requests. Because of the laborious process and the inaccuracy associated with reading data from the strip charts, their further use is limited when processed narrowband data become available.

\section{a. Digital Data System}

The digital data system utilizes computer-compatible magnetic tape to store digitized data obtained from transducers embedded in the hardware. Because of its high accuracy and its capability of handing large volumes of data rapidly and semiautomatically, the system represents the most significant and the principal recording means within the DAS. It is, therefore, the principal source of data for posttest analysis of steady-state and transient engine conditions. The limitations of this data process are: (1) it is not suitable for analyzing oscillating functions of medium or high frequency and (2) because of the time required for processing, the data are not available in readable form immediately after a test. 


\section{b. Analog Magnetic Tape}

The analog magnetic-tape system provides a means for recording and producing wide-band frequency data. The data obtained from this system are used mainly for vibration and transfer-function analysis.

\section{c. Oscillographs}

In addition to magnetic-tape recording, wide-band analog data may be obtained from on-line oscillographs. These oscillographs are available for study shortly after the test; however; they cannot be subjected to the computerized calibration and frequency analysis that is available with analog magnetic-tape recording. Hence, the oscillograms are useful mainly as quick-look data that are superseded by the analog magnetic-tape data when available.

\subsection{ENCLOSURES}

\subsubsection{System Schematic}

A piping and instrumentation schematic diagram, illustrating the fluid flow paths and the relative location of engine diagnostic transducers, is presented in Figure $2-1$.

\subsubsection{Engine Transducer Locations}

The locations of all unclassified transducers are provided by the measurements requirements 1 ist (MRL). The locations of transducers within the reactor are described by the MRL. However, the locations of transducers in the engine-system lines and other components are not well described by the MRL with respect to the component in which they are inserted. Therefore, detailed drawings of the locations of transducers for nonnuclear engine parametex measurements are shown in Figures 5-1 through 5-7. 
For convenience, an alpha-numerical listing of instrument. transducers is provided in Table 5-1, which provides the functional description and the appropriate figure number on which the transducer location appears.

Instrumentation transducers installed on the propellant feed line between the $\mathrm{LH}_{2}$ run tank and the turbopump are shown in Figure 5-1. The turbopump-discharge-1ine transducer locations are shown in Figure 5-2.

Figure 5-3 shows the transducers installed on the nozzle tube assembly, the hot-bleed port, and the bolt-coolant lines.

Locations of the diluent- and turbine-inlet-line transducers are presented in Figure 5-4.

Pressure-vessel instrumentation is shown in Figure 5-5. Transducers installed on the turbine exhaust lines are shown in Figure 5-7. 


\subsubsection{Facility Transducer Locations}

A simplified schematic diagram of the facility, showing the relative locations of temperature and pressure transducers, is presented in Figure 5-8. Table 5-2 provides the locations (the schematic diagram coordinates and transfer-line identification number) of the temperature and pressure transducers shown in Figure 5-8.

More detailed drawings of the location of transducers mounted on 1iquid hydrogen pressure vessels $V-5001, V-5502$, and $V-3801$ are shown in Figures $5-9,5-10$ and $5-11$ respectively.

The location of instrumentation transducers installed on the gaseous helium, gaseous hydrogen, liquid hydrogen fill line, and the liquid hydrogen emergency cooldown line are detailed in the isometric schematics shown in Figures 5-12 through 5-15. 


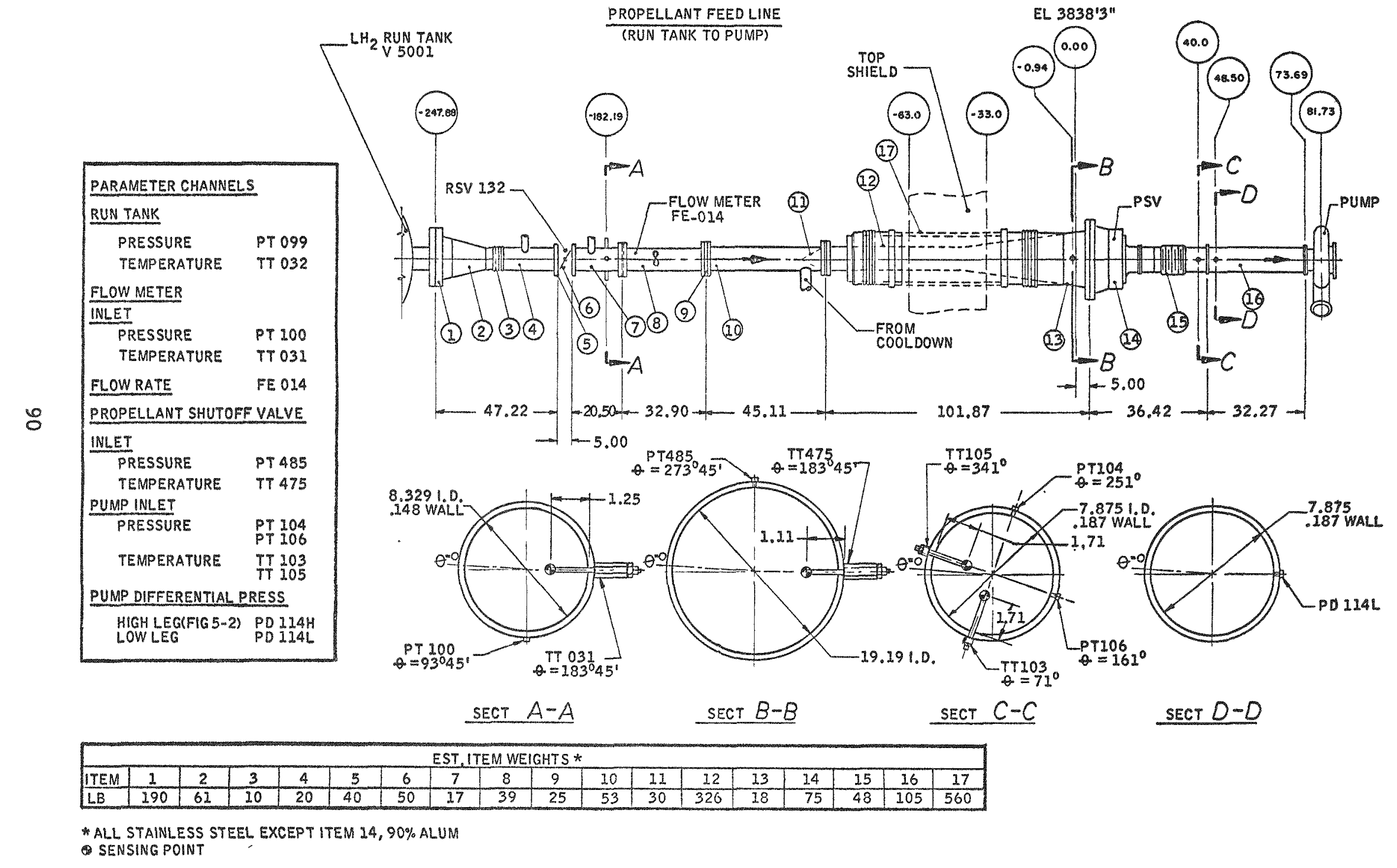

Figure 5-1 - Propellant Feed Line 

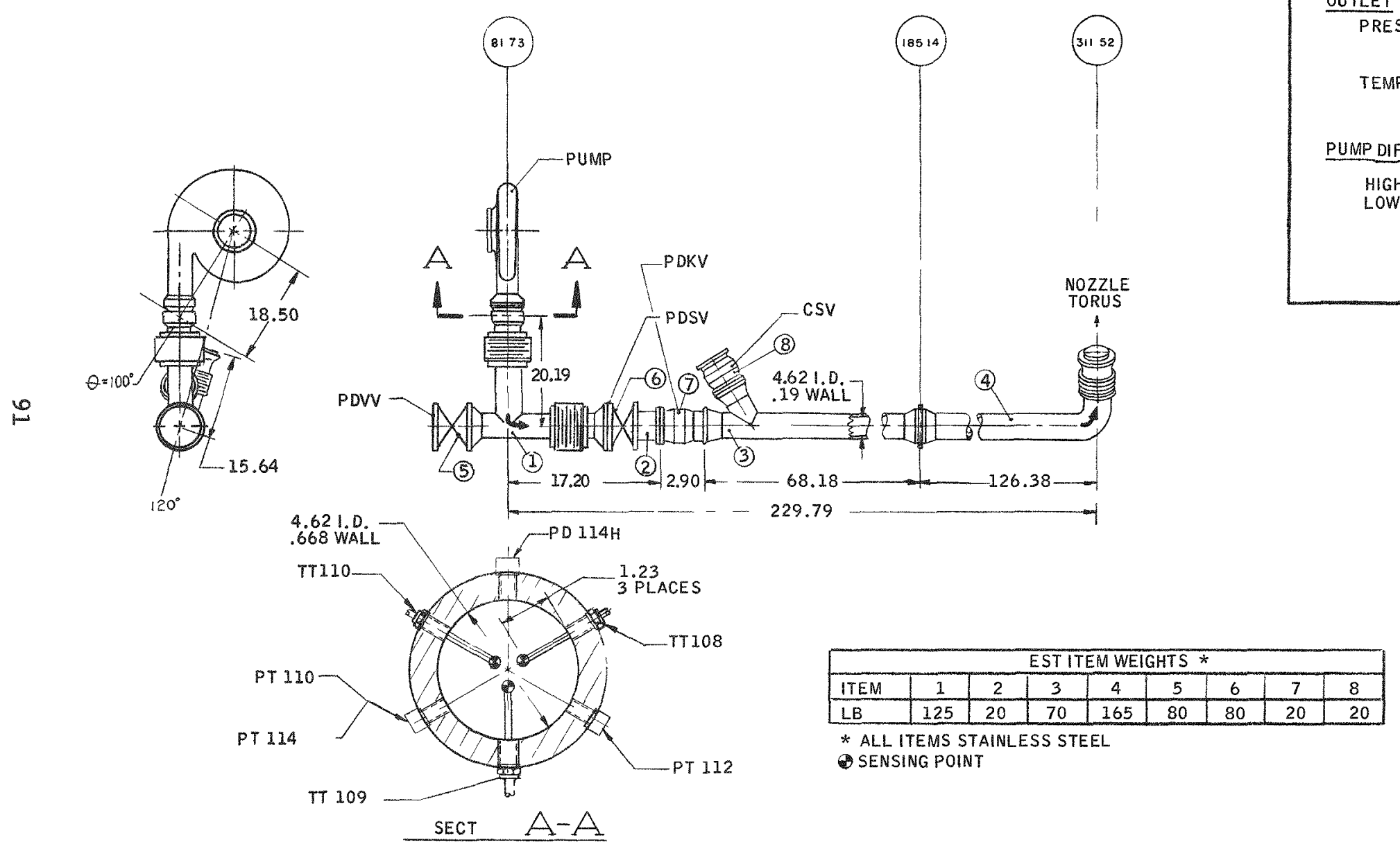

PT 114

- SENSING POINT

Figure 5-2 - Pump Discharge Line 


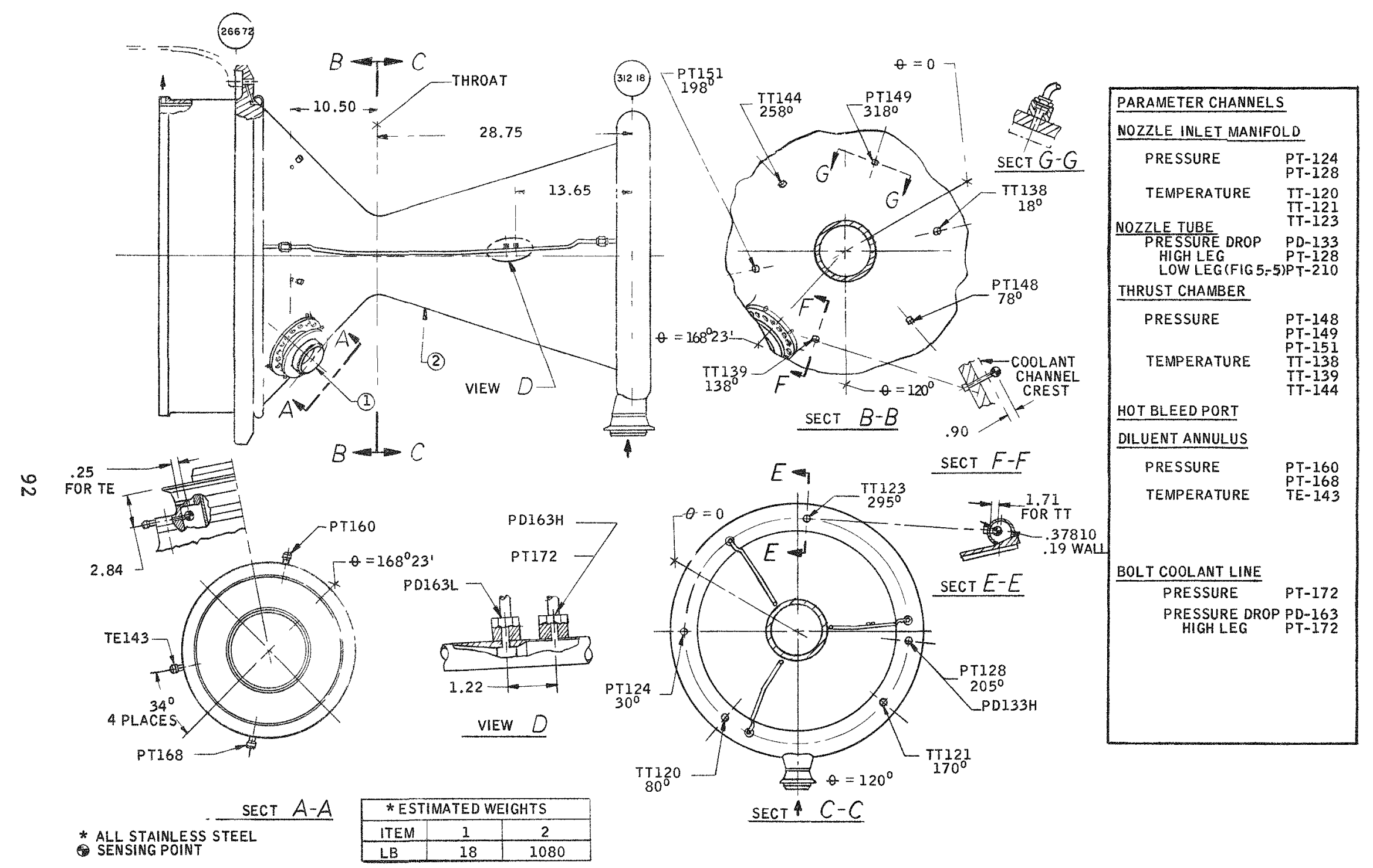

Figure 5-3 - Nozzle Assembly: Hot-Bleed Port and Bolt Coolant Line 


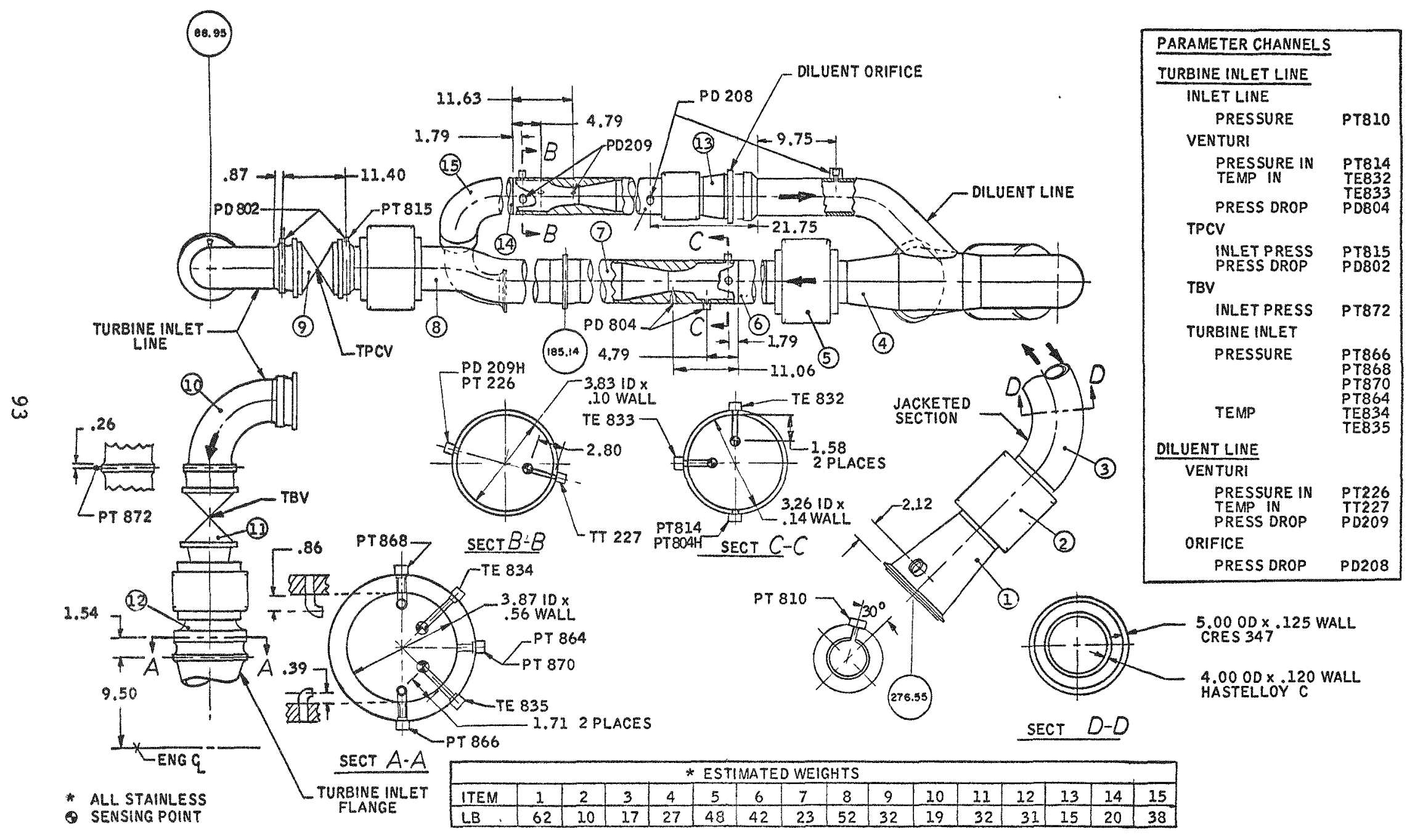

Figure 5-4 - Turbine Inlet Line and Diluent Line 


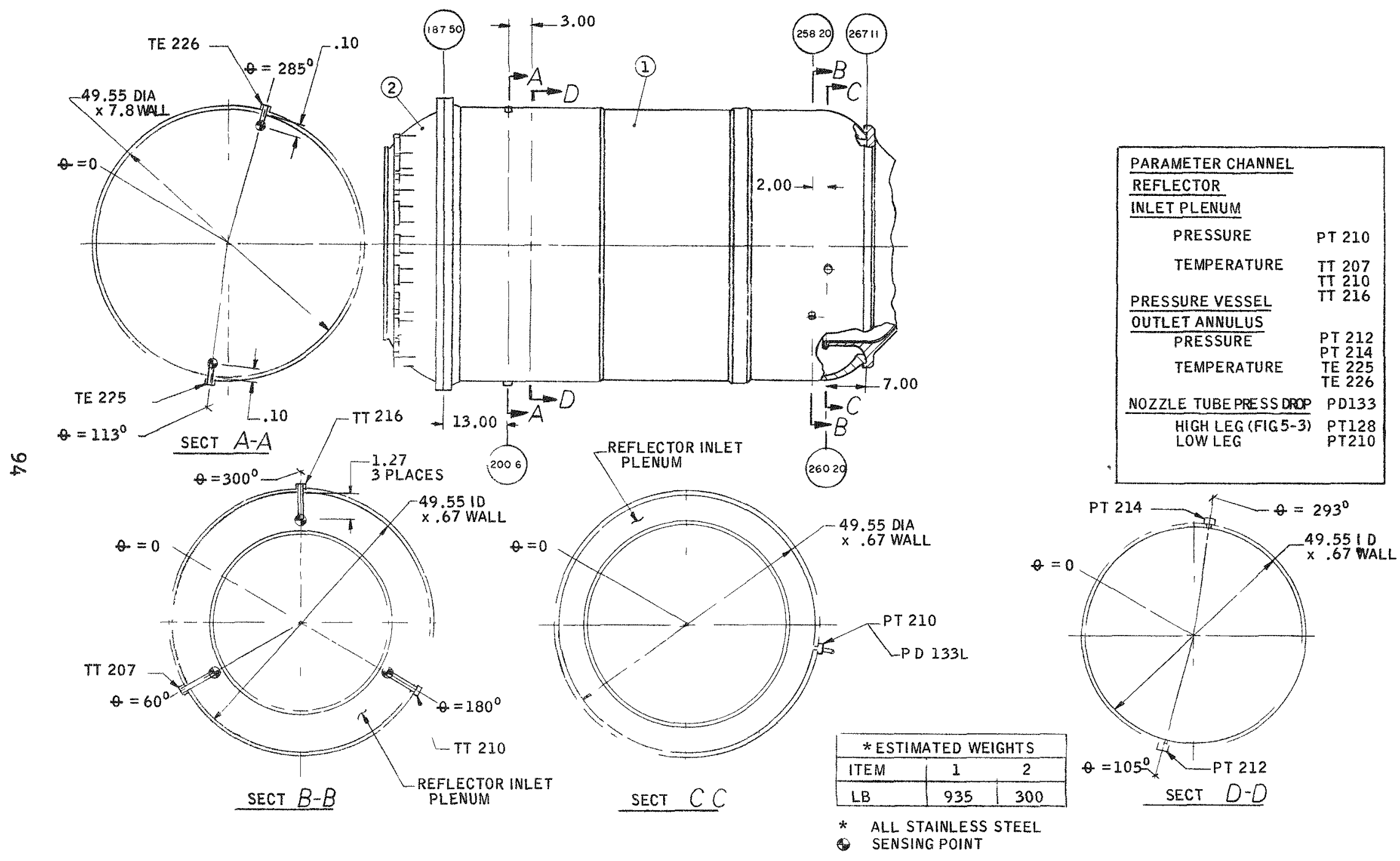

Figure 5-5 - Pressure Vessel 


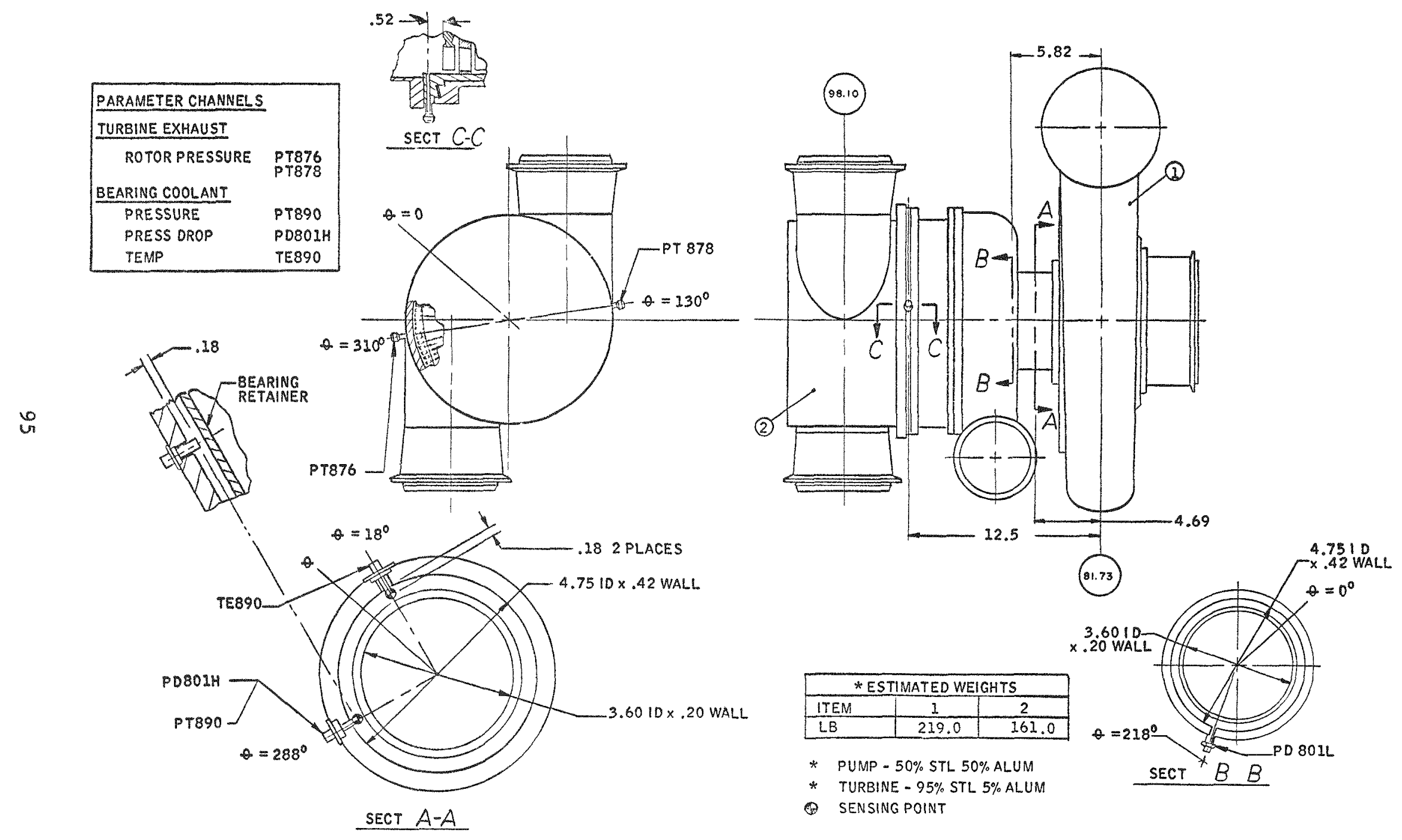

Figure 5-6 - Turbopump Assembly 


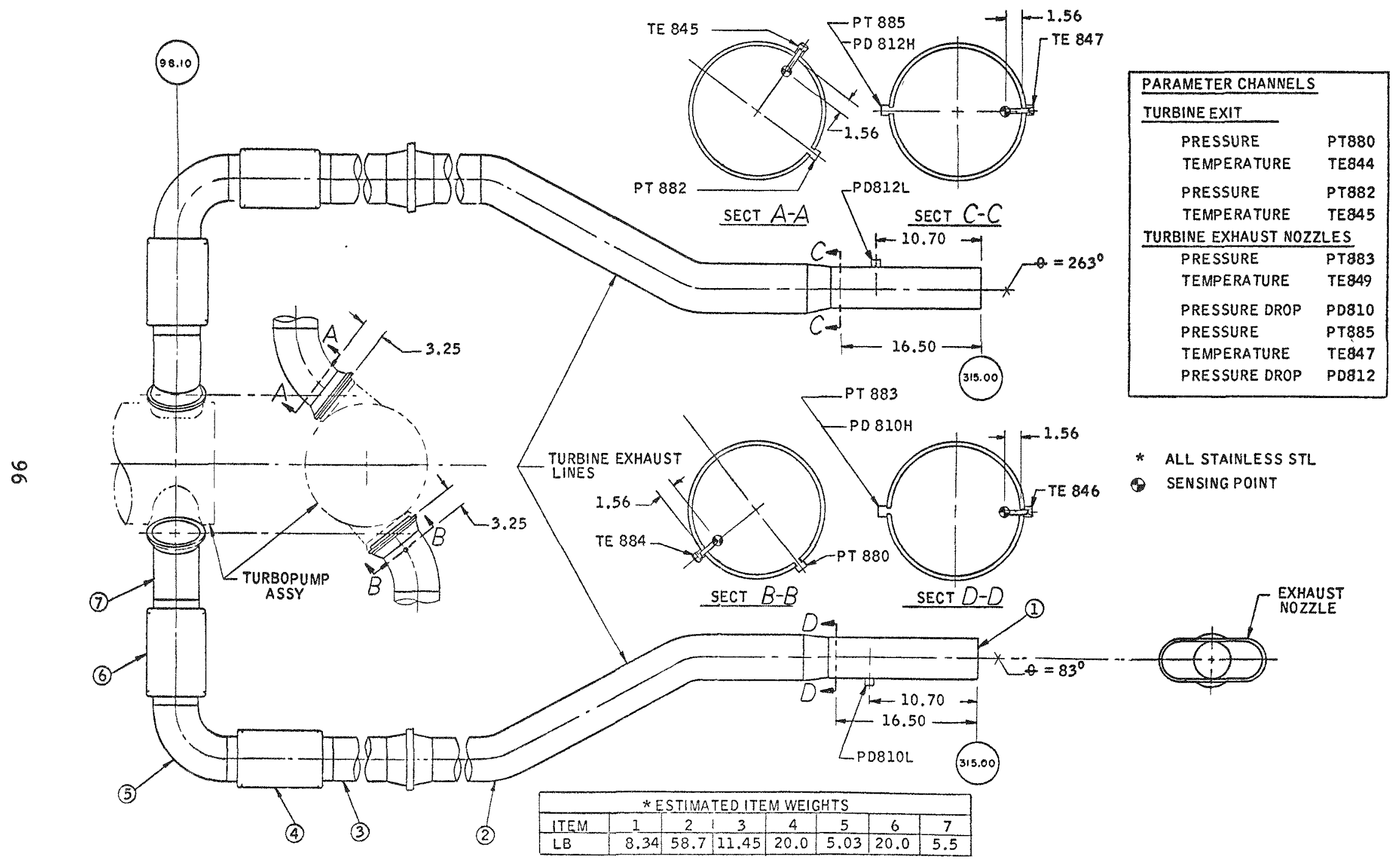

Figure 5-7 - Turbine Exhaust Lines 


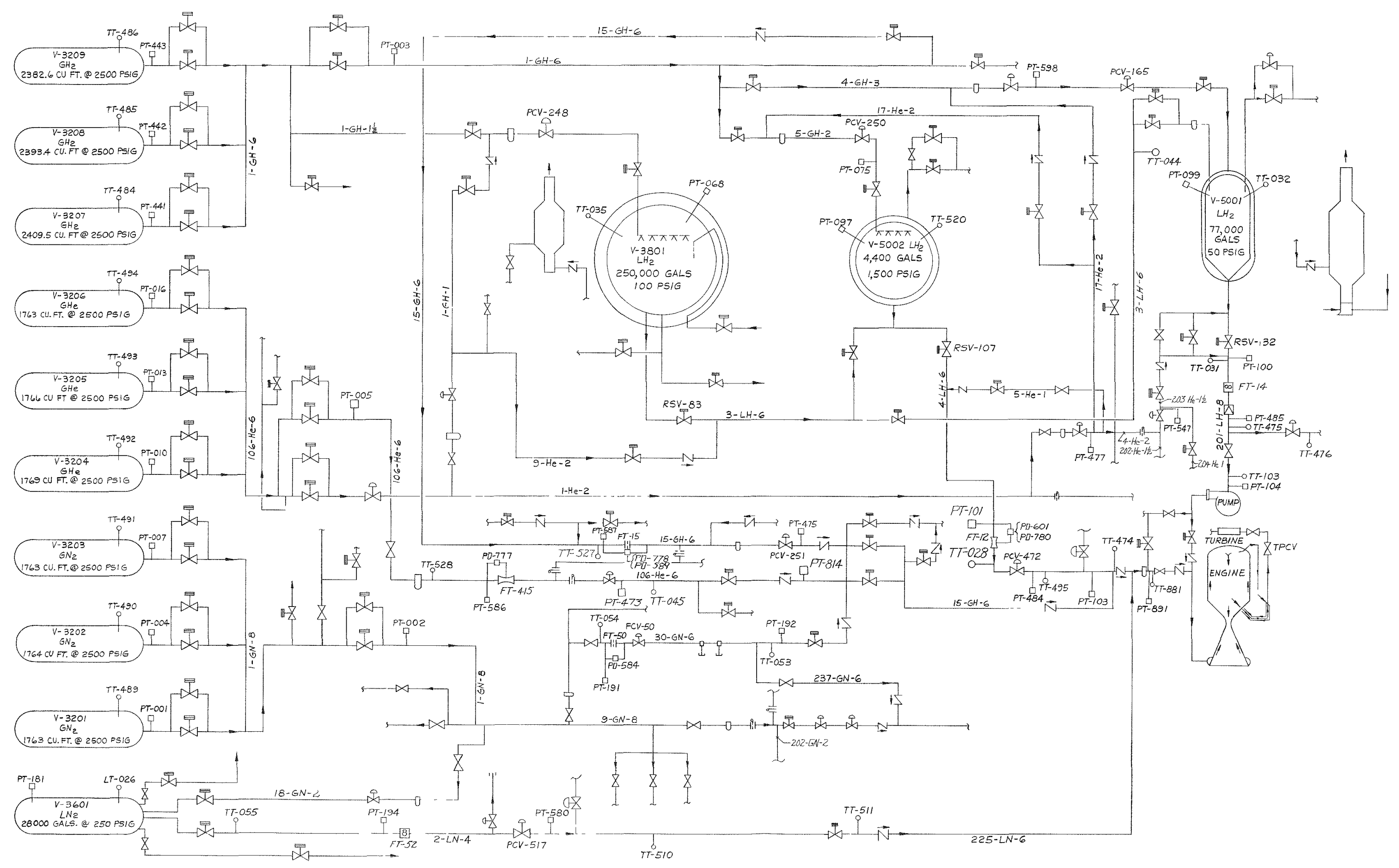

EGEND

TYPICAL PROCESS LINE NUMBER DESCRIPTION LINE NUMBER $\rfloor^{20-G N-8}$ LPROCESS LINE SIZ SYMBOL DESIGNATION GH__ GASEOUS HYDROGEN GAEEOUS NITROGEN HELUM MYRPOGEN ELEMENT FLUID LEVEL TRANSDUCER PRESSURE TRANSDUCER 
12 " VENT I INNER VESSEL VACUUM

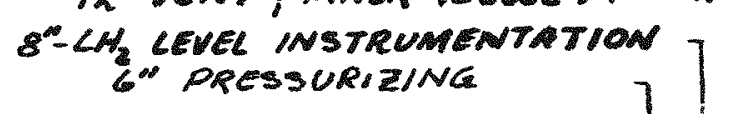

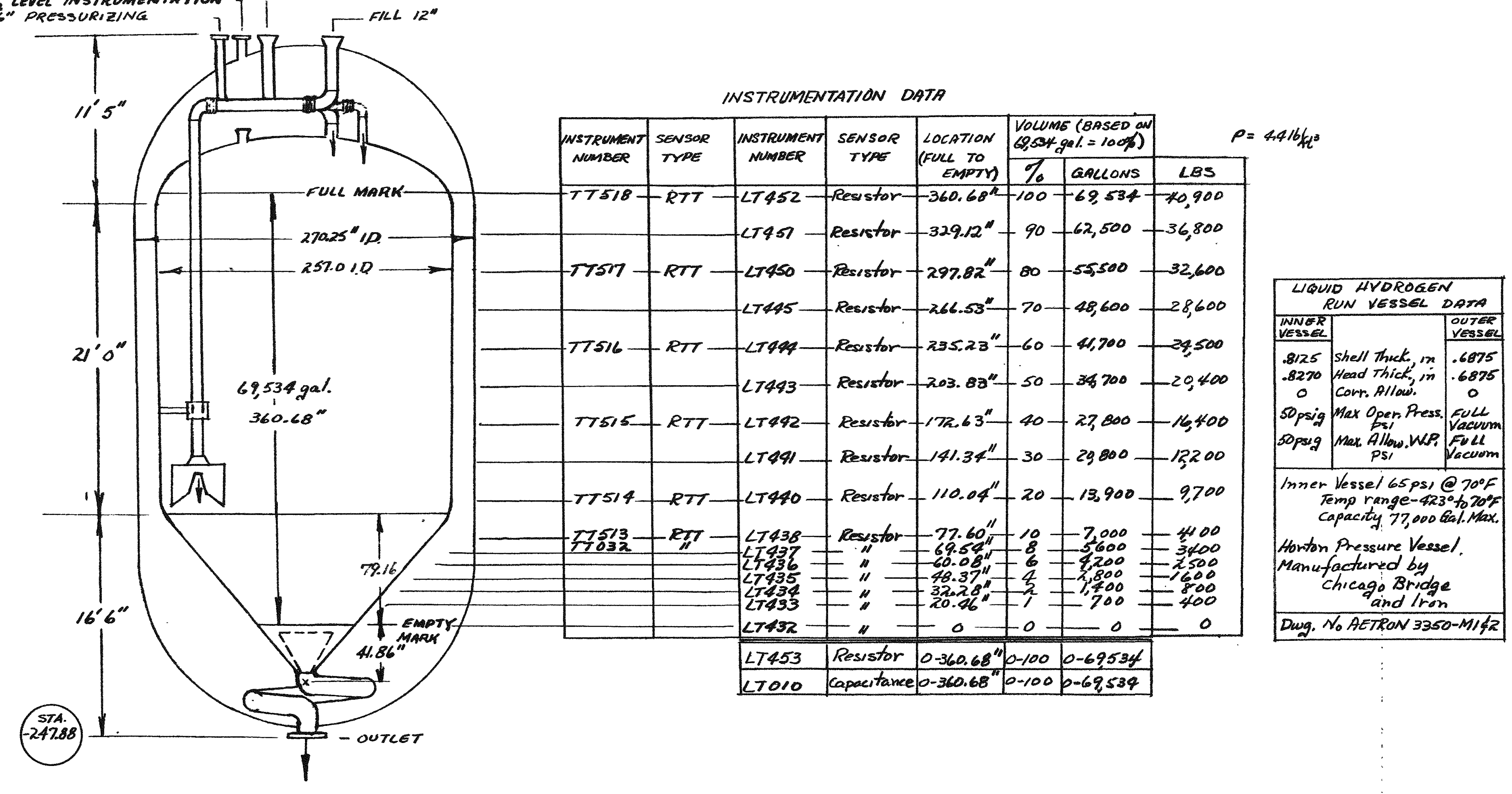

INSTRUMENTATION DATA 


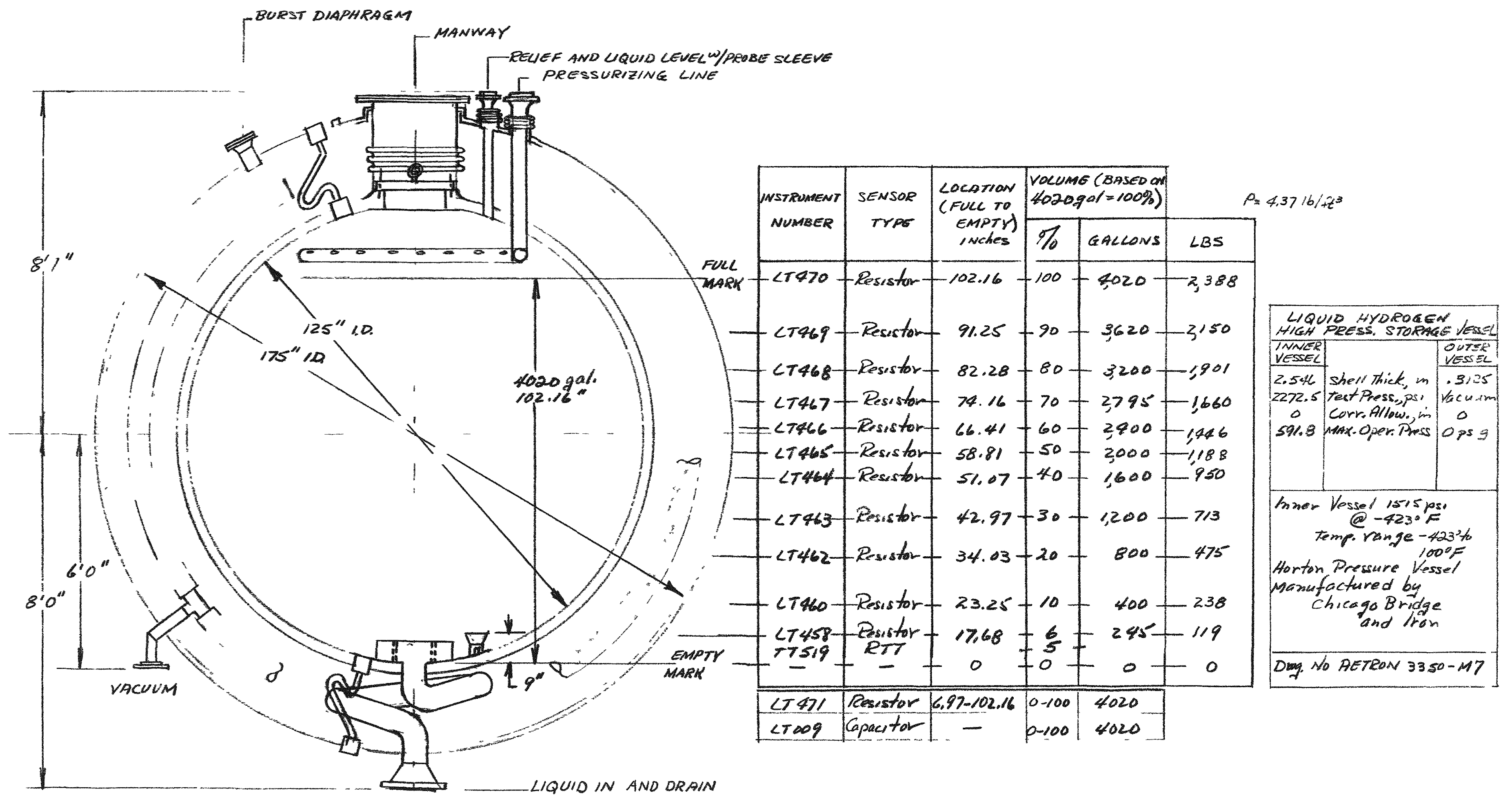

Figure 5-10 - V5002-High Pressure Storage Tank 


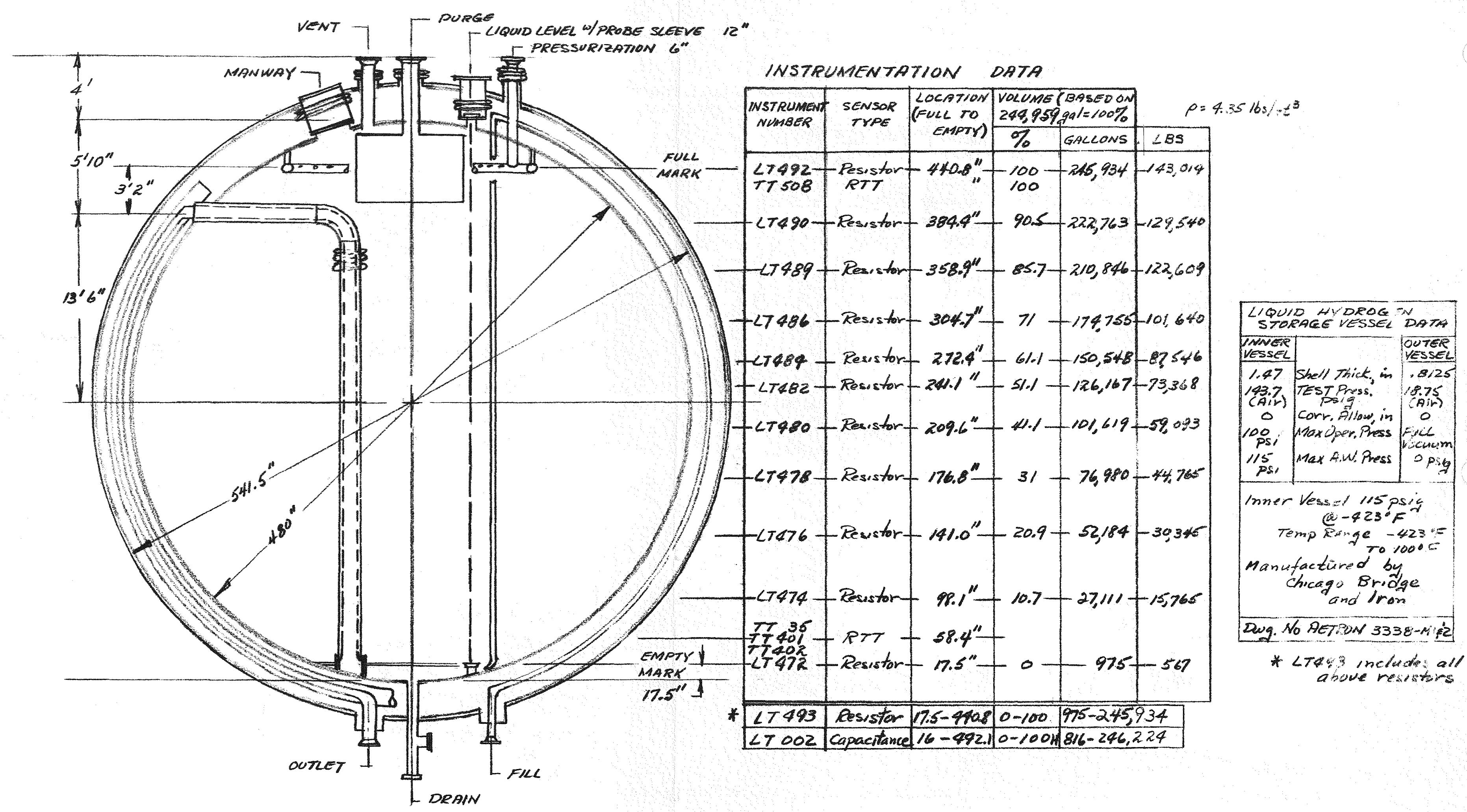

Figure 5-11 - V3801-LH 2 Storage Tank 
NOTE

DOTE DIMENSIONS ARE INCHES
MEASURED IN JULY I 967

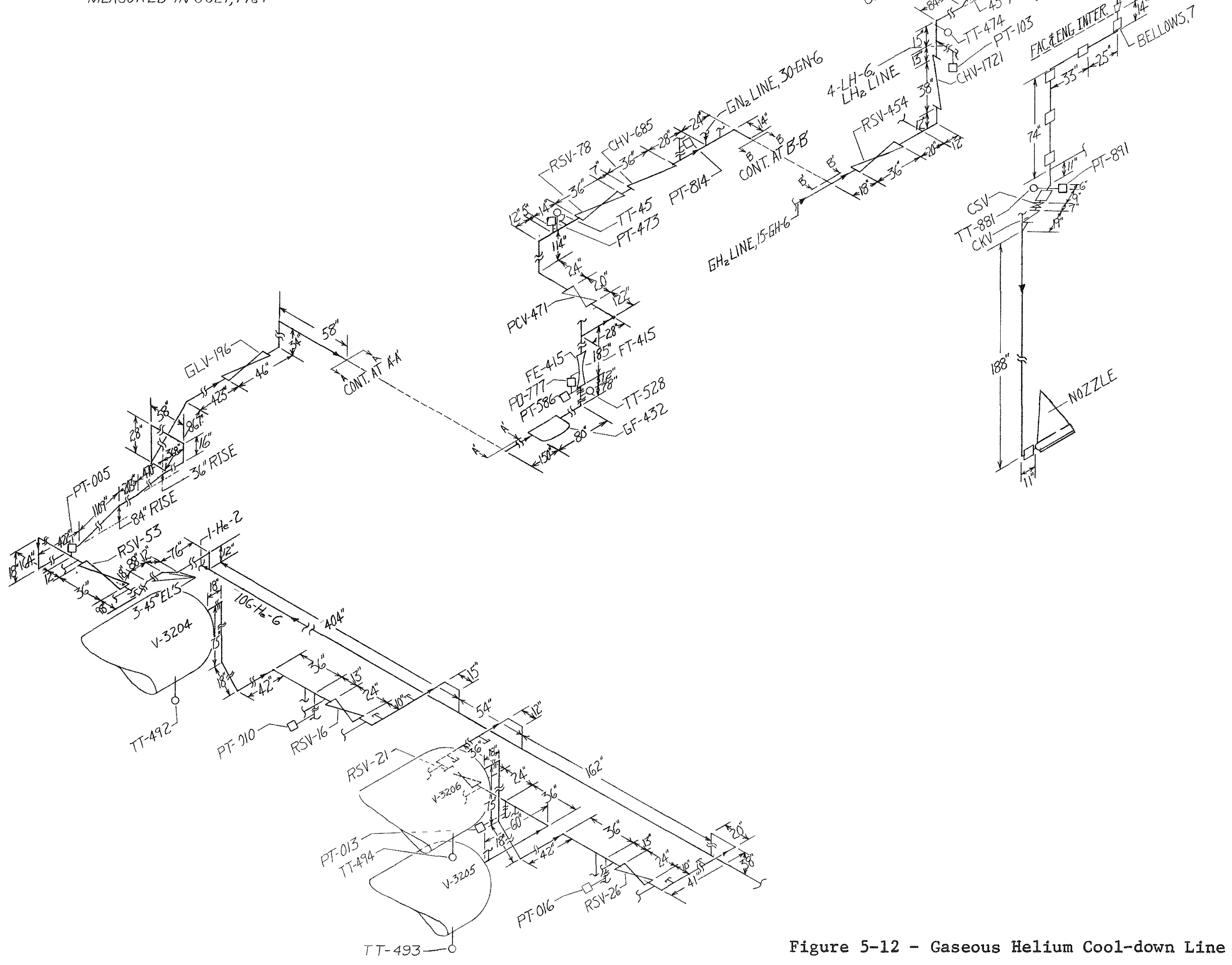




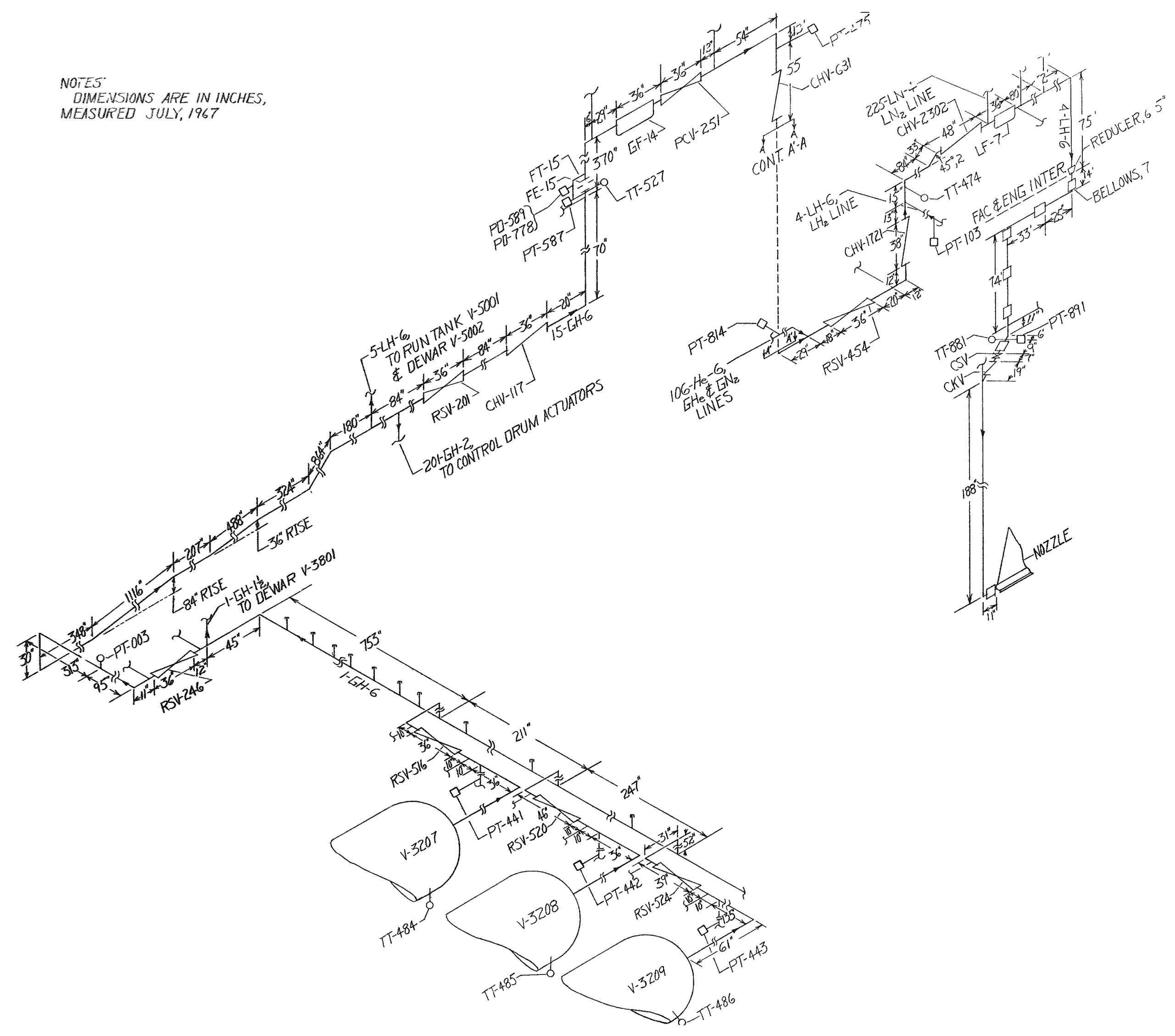

Figure 5-13 - Gaseous Hydrogen Cool-down Line 


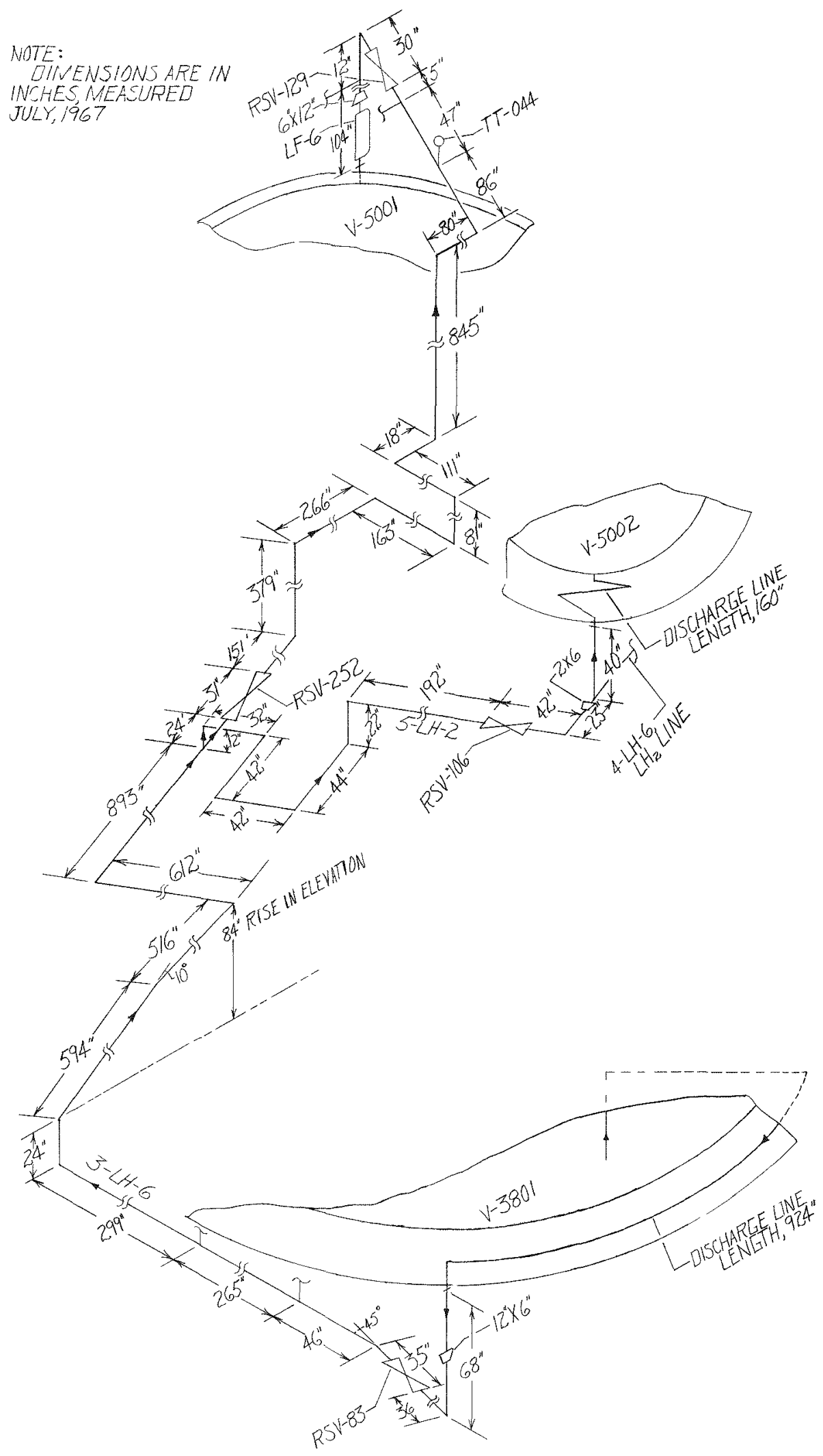

Figure 5-14 - Liquid Hydrogen Fill Line 


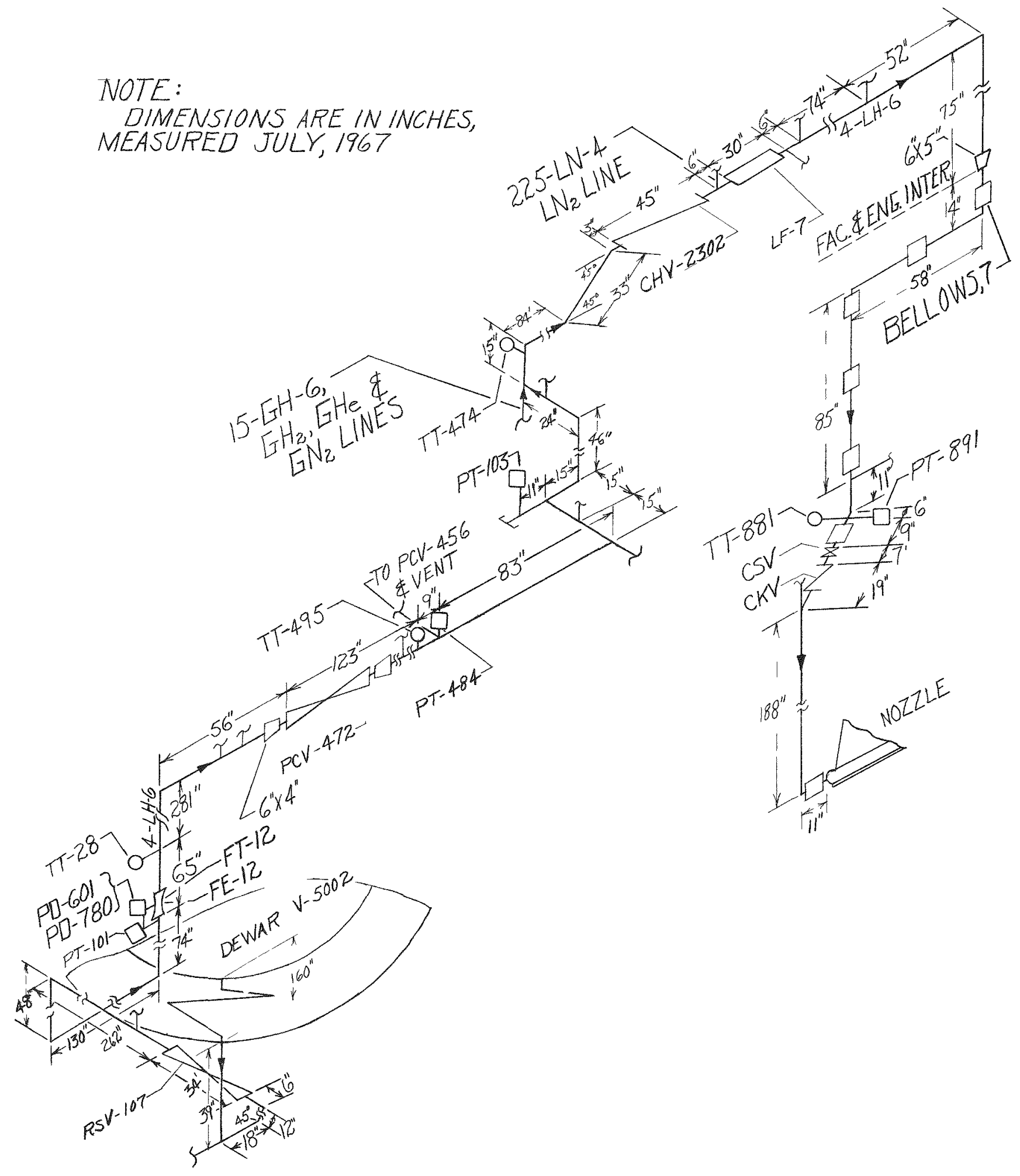

Figure 5-15 - Liquid Hydrogen Cool-down Line 
TABLE $5-1$

ENGINE INSTRUMENTATION TRANSDUCER LIST

Channe1

$\mathrm{FE} \quad 014$

PD 114

PD 133

PD 163

PD 208

PD 209

PD 801

PD 802

PD 804

PD 810

PD 812

PT 099

PT 100

PT 104

PT 106

PT 110

PT 112

PT 114

PT 124

PT 128

PT 148

PT 149

PT 151

PT $\quad 160$

PT 168

PT 172

PT 210

PT $\quad 212$
Description

Propellant-Feed-Line Flow

Pump

Nozzle Tube

Bolt-Coolant Line

Diluent-Line Orifice

Diluent-Line Venturi

Bearing Housing

TPCV

Turbine-Inlet-Line Venturi

Turbine Exhaust Nozzle

Turbine Exhaust Nozzle

V5001 Run Tank

Propellant-Feed-Line Flowmeter Inlet

Pump Inlet

Pump Inlet

Pump Discharge

Pump Discharge

Pump Discharge

Nozzle Manifold

Nozzle Manifold

Nozzle Chamber

Nozzle Chamber

Nozzle Chamber

Hot-Bleed-Port Diluent Annulus

Hot-Bleed-Port Diluent Annulus

Bolt-Coolant Line

Reflector Inlet Plenum

Pressure-Vesse1 Annulus
Figure

$5-1$

$5-1,5-2$

$5-3,5-5$

$5-3$

5-4

$5-4$

5-6

5-4

5-4

5-7

5-7

5-1

5-1

5-1

5-1

5-2

$5-2$

5-2

5-3

5-3

$5-3$

$5-3$

5-3

$5-3$

$5-3$

5-3

5-5

5-5 
TABLE 5-1 (cont.)

\begin{tabular}{|c|c|c|c|}
\hline \multicolumn{2}{|c|}{ Channel } & \multirow{2}{*}{$\begin{array}{l}\text { Description } \\
\text { Pressure-Vessel Annulus }\end{array}$} & \multirow{2}{*}{$\frac{\text { Eigure }}{5-5}$} \\
\hline $\mathrm{PT}$ & 214 & & \\
\hline $\mathrm{PT}$ & 226 & Diluent-Line Venturi & $5-4$ \\
\hline $\mathrm{PT}$ & 485 & Pump-Shutoff-Valve Inlet & $5-1$ \\
\hline $\mathrm{PT}$ & 810 & Turbine-Inlet-Line Entrance & $5-4$ \\
\hline PT & 814 & Turbine-Inlet-Iine Venturi & $5-4$ \\
\hline PT & 815 & TPCV Inlet & $5-4$ \\
\hline $\mathrm{PT}$ & 864 & Turbine Inlet (Narrow Range) & $5-4$ \\
\hline PT & 866 & Turbine Inlet (Total Pressure) & $5-4$ \\
\hline PT & 868 & Turbine Inlet (Total Pressure) & $5-4$ \\
\hline PT & 870 & Turbine Inlet & $5-4$ \\
\hline PT & 872 & TBV Inlet & $5-4$ \\
\hline PT & 876 & Turbine Exhaust Rotor & $5-6$ \\
\hline $\mathrm{PT}$ & 878 & Turbine Exhaust Rotor & $5-6$ \\
\hline PT & 880 & Turbine Exit & $5-7$ \\
\hline $\mathrm{PT}$ & 882 & Turbine Exit & $5-7$ \\
\hline PT & 883 & Turbine Exhaust Nozzle & $5-7$ \\
\hline PI & 885 & Turbine Exhaust Nozzle & $5-7$ \\
\hline PT & 890 & Bearing Coolant & $5-6$ \\
\hline $\mathrm{TE}$ & 143 & Hot-Bleed-Port Annulus & $5-3$ \\
\hline $\mathrm{TE}$ & 225 & Pressure-Vessel Annulus & $5-5$ \\
\hline $\mathrm{TE}$ & 226 & Pressure-Vessel Annulus & $5-5$ \\
\hline $\mathrm{TE}$ & 832 & Turbine-Inlet-Line Venturi & $5-4$ \\
\hline TE & 833 & Turbine-Inlet-Line Venturi & $5-4$ \\
\hline $\mathrm{TE}$ & 834 & Turbine Inlet & $5-4$ \\
\hline$T E$ & 835 & Turbine Inlet & $5-4$ \\
\hline $\mathrm{TE}$ & 844 & Turbine Exit & $5-7$ \\
\hline $\mathrm{TE}$ & 845 & Turbine Exit & $5-7$ \\
\hline $\mathrm{TE}$ & 847 & Turbine Exhaust Nozzle & $5-7$ \\
\hline $\mathrm{TE}$ & 849 & Turbine Exhaust Nozzle & $5-7$ \\
\hline
\end{tabular}


TABLE 5-1 (cont.)

Channe1

TE 890

TT 031

TT 032

TT 103

TT 105

TT 108

TT 109

TT 110

TT 120

TT 121

TT 123

TT 138

TT 139

TT 144

TT 207

TT 210

TT 216

TT 227

TT 475
Description

Bearing Coolant

Flowmeter Inlet

Run Tank

Pump Inlet .

Pump Inlet

Pump Discharge

Pump Discharge

Pump Discharge

Nozzle Manifold

Nozzle Manifold

Nozzle Manifold

Nozzle Chamber

Nozzle Chamber

Nozzle Chamber

Reflector Inlet Plenum

Reflector Inlet Plenum

Reflector Inlet Plenum

Diluent-Iine Venturi

PSV Inlet
Figure

$5-6$

$5-1$

$5-1$

5-1

$5-1$

$5-2$

5-2

$5-2$

$5-3$

$5-3$

$5-3$

$5-3$

$5-3$

$5-3$

$5-5$

$5-5$

$5-5$

$5-4$

5-1 
TABLE 5-2

FACILITY FLOW, PRESSURE AND TEMPERATURE LOCATIONS

\begin{tabular}{|c|c|c|c|}
\hline \multirow{3}{*}{$\begin{array}{l}\text { Component } \\
\text { Identification } \\
\text { Number }\end{array}$} & \multicolumn{2}{|c|}{ Component Locations } & \multirow{2}{*}{$\begin{array}{l}\text { Component } \\
\text { Identification }\end{array}$} \\
\hline & Line & ematic & \\
\hline & Number & rdinates & Number \\
\hline $\mathrm{FT}-12$ & $4-\mathrm{LH}-6$ & D5 & PT-101 \\
\hline $\mathrm{FT}-14$ & $201-\mathrm{LH}-8$ & E4 & $\mathrm{PT}-103$ \\
\hline $\mathrm{FT}-15$ & $15-\mathrm{GH}-6$ & D7 & $P T-104$ \\
\hline $\mathrm{FT}-50$ & $30-G N-6$ & $\mathrm{C7}$ & $\mathrm{PT}-181$ \\
\hline $\mathrm{FT}-52$ & $2-L N-4$ & B9 & $\mathrm{PT}-191$ \\
\hline $\mathrm{FT}-415$ & 106-He- 6 & D8 & $\begin{array}{l}\mathrm{PT}-192 \\
\mathrm{PT}-194\end{array}$ \\
\hline$P D-584$ & $30-G N-6$ & C7 & $\mathrm{PT}-441$ \\
\hline$P D-589$ & $15-\mathrm{GH}-6$ & D7 & $P T-442$ \\
\hline$P D-601$ & $4-\mathrm{LH}-6$ & D5 & $\mathrm{PT}-443$ \\
\hline $\mathrm{PD}-777$ & 106-He-6 & D8 & $\mathrm{PT}-473$ \\
\hline $\mathrm{PD}-778$ & $15-\mathrm{GH}-6$ & D7 & $\mathrm{PT}-475$ \\
\hline$P D-780$ & $4-L H-6$ & D 5 & $\mathrm{PT}-477$ \\
\hline & & & $\mathrm{PT}-484$ \\
\hline $\mathrm{PT}-001$ & $104-G N-3 / 4$ & $\mathrm{~B} 10$ & $\mathrm{PT}-485$ \\
\hline $\mathrm{PT}-002$ & $1-G N-8$ & $\mathrm{Cg}$ & $\mathrm{PT}-547$ \\
\hline $\mathrm{PT}-003$ & $1-\mathrm{GH}-6$ & G9 & $\mathrm{PT}-580$ \\
\hline PT-004 & $110-\mathrm{GH}-3 / 4$ & $\mathrm{C} 10$ & $\mathrm{PT}-586$ \\
\hline $\mathrm{PT}-005$ & $1-\mathrm{He}-6$ & E9 & $P T-587$ \\
\hline $\mathrm{PT}-007$ & $107-\mathrm{GN}-3 / 4$ & D10 & PT-598 \\
\hline $\mathrm{PT}-010$ & $113-G N-3 / 4$ & D10 & $\mathrm{PT}-814$ \\
\hline $\mathrm{PT}-013$ & $105-\mathrm{He}-3 / 4$ & E10 & PT-891 \\
\hline $\mathrm{PT}-016$ & $116-\mathrm{GH}-3 / 4$ & F10 & \\
\hline PT-068 & Dewar, V-3801 & F7 & TT-028 \\
\hline $\mathrm{PT}-075$ & $5-\mathrm{GH}-2$ & G6 & TT-031 \\
\hline $\mathrm{PT}-097$ & Dewar, V-5002 & F6 & $\mathrm{TT}-032$ \\
\hline $\mathrm{PT}-099$ & Run Tank, V-5001 & G4 & $\mathrm{TT}-035$ \\
\hline $\mathrm{PT}-100$ & 201-LH-8 & E4 & $\mathrm{TT}-044$ \\
\hline
\end{tabular}

\begin{tabular}{ll}
\multicolumn{2}{c}{ Component Locations } \\
\hline Line & *Schematic \\
Number & Coordinates
\end{tabular}

4-LH-6

4-LH-6

201-LH-8

E5

Vessel, V-3601

$30-G N-6$

$30-\mathrm{GN}-6$

$2-\mathrm{LN}-4$

$125-\mathrm{GH}-3 / 4$

$122-\mathrm{GH}-3 / 4$

$119-\mathrm{GH}-3 / 4$

$106-\mathrm{He}-6$

$15-\mathrm{GH}-6$

$5-\mathrm{He}-1$

30-GN-6

201-LH-8

204-He-1

$2-\mathrm{LN}-4$

106-He-6

15-GH-6

4- $\mathrm{GH}-3$

106-He-6

4-LH-6

D4

BII

C7

$\mathrm{C} 6$

B9

F10

G10

G10

D7

D6

E4

C5

E4

E4

B8

D8

D7

G5

D6

4-LH-6

D4

201-LH-8

E5

Run Tank, V-500I

Dewar, V-3801

3-LH-6

* See Figure 5-8 
TABLE 5-2 (cont.)

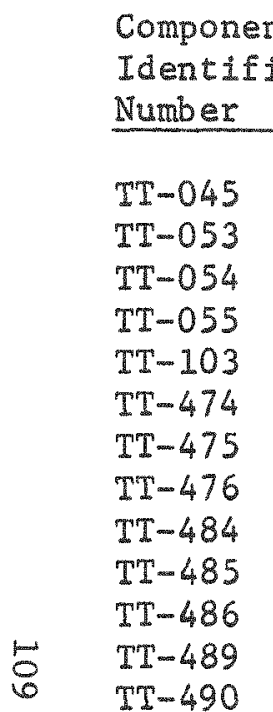

Component

ication

$T-045$

TI -055

$T-103$

$T T-476$

$T-484$

$1 T-486$

$T T-490$

\begin{tabular}{lc}
$\frac{2}{2}$ Component Locations \\
\hline Line & Schematic \\
Number & Coordinates \\
\hline
\end{tabular}

$106-\mathrm{He}-6$
$30-\mathrm{GN}-6$
$30-\mathrm{GN}-6$
$2-\mathrm{LN}-4$
$201-\mathrm{LH}-8$
$4-\mathrm{LH}-6$
$201-\mathrm{LH}-8$

Vesse1, $V-3207$

Vesse1, V-3208

Vesse1, V-3209

Vesse1, V-3201

Vesse1, $V-3202$
Component

Identification

Number

$T T-491$

TT -492

TT -493

TT -494

$T T-495$

$\mathrm{TT}-510$

TT -511

$\mathrm{TT}-520$

TT -527

$\mathrm{TT}-528$

$\mathrm{TT}-881$

$\mathrm{LT}-026$

\begin{tabular}{|c|c|}
\hline compon & Locations \\
\hline Line & *Schematic \\
\hline Number & Coordinates \\
\hline
\end{tabular}

Vesse1, V-3203

D10

Vesse1, V-3205 E10

Vesse1, V-3206 F10

4-LH-6 D5

$2-\mathrm{LN}-4 \quad \mathrm{~B} 7$

225-LN-6 B6

Dewar, $\mathrm{V}-5002$ F5

15-GH-6 D7

106-He-6 D8

4- $\mathrm{LH}-6$ D4

Vesse1, V-3601 B10 


\section{BLANK}




\section{REFERENCES}

1. AGC Report RN-S-0314, XECF Test Specification, November 1966 (U)

2. AGC Report RN-S-0289, XE-Engine Systems Analysis Design Data Book, 1967 (CRD)

3. Report NTO-R-0086, ETS-1 Facility Data Book, August 1966 (U)

4. AGC Report RN-TM-0437, XE Engine Dynamic Modal Analysis, May 1967 (U) 


\section{BLANK}




\section{ABBREVIATIONS}

$\begin{array}{ll}\text { CFDTS } & - \text { Cold-Flow Development Test System } \\ \text { CKV } & - \text { Cooldown Check Valve } \\ \text { CSV } & - \text { Cooldown Shutoff Valve } \\ \text { DAS } & - \text { Data-Acquisition System } \\ \text { E-MAD } & - \text { Engine Maintenance, Assembly, and Disassembly } \\ \text { ESS } & - \text { Engine Safety System } \\ \text { ETC } & - \text { Engine Test Compartment } \\ \text { ETS-1 } & - \text { Engine Test Stand No. } 1 \\ \text { FCS } & - \text { Facilities Control System } \\ \text { NES } & - \text { Nuclear Exhaust System } \\ \text { PCV } & - \text { Propellant Control Valve } \\ \text { PDSV } & - \text { Pump Discharge Shutoff Valve } \\ \text { PSV } & - \text { Propellant Shutoff Valve } \\ \text { TPCV } & - \text { Turbine Power-Control Valve } \\ \text { TSCS } & - \text { Test-Stand Control System } \\ \text { XECF } & - \text { Experimental Engine Cold Flow }\end{array}$

